VIETNAMESE EDUCATIONAL LEADERS AS BORDER CROSSERS:

VIETNAM AND ACADEMIC AND CAREER GUIDANCE AND COUNSELING

ACTIVITIES

A Dissertation Presented to

the Faculty of the Graduate School at the University of Missouri-Columbia

In Fulfillment

of the Requirements for the Degree

Doctor of Philosophy

by

THI KIEU VAN NGUYEN

Dr. Emily Crawford-Rossi, Dissertation Supervisor

MAY 2019 
The undersigned, appointed by the dean of the Graduate School, have examined the dissertation entitled

\section{VIETNAMESE EDUCATIONAL LEADERS AS BORDER CROSSERS: VIETNAM AND ACADEMIC AND CAREER GUIDANCE AND COUNSELING}

Presented by Thi Kieu Van Nguyen,

A candidate for the degree of doctor of philosophy

And hereby certify that, in their opinion, it is worthy of acceptance.

Professor Emily Crawford-Rossi

Professor Lisa Dorner

Professor James Sebastian

Professor Jerry Nelson 


\section{ACKNOWLEDGMENTS}

My dissertation, part of my Ph.D. program, was a long but unforgettable journey. As I complete this journey, I would like to express my appreciation and gratitude to a great many people who contributed to this study and are deserving of this acknowledgments.

First of all, I would like to thank my participants who were open to share their experiences in Academic and Career Guidance and Counseling (ACGC) activities with me. I highly appreciate your trust, time, and honesty.

A sincere appreciation to Dr. Emily Crawford-Rossi, my wonderful advisor and committee chair, for your support so far in my Ph.D. journey and your superb feedback on this dissertation. I have been grateful for everything I learned from you. I also thank my other committee members, Dr. Lisa Dorner, Dr. Sebastian, and Dr. Jerry Nelson, for your feedback and support in my Ph.D. journey. I have been so happy to hear from you, Dr. Nelson, that I have been growing professionally in the past few years, which is much different from the first time we met. You all have helped me make such growth!

Many thanks to the ELPA Student Scholarship and Awards committee, Dr. Lisa Dorner, Dr. Amalia Dache-Gerbino, and Dr. Ty-Ron Douglas, at the Department of Educational Leadership and Policy Analysis (ELPA), for providing me with a research grant which assisted with my travel expenses to Vietnam to collect data for this study. I also want to take this opportunity to thank ELPA professors for the opportunities to attend my Masters and Ph.D. programs so that I could enhance my professional growth. 
Accompanying with me on this journey is my family-my husband, Giang Bui, my son, Bao Bui, and my daughter, Hue-Lam Bui. To my life partner, I never forgot the day I told you that I wanted to pursue my Masters' degree in the States since we had been married a month. I also never forgot how difficult it was for you to let me go and six months later you left everything behind to follow me and make your own Ph.D. journey. Thank YOU for being by my side in the past eight years with many difficulties and great experiences in this beautiful country. A big thanks to Bao and Hue-Lam, my babies, for your love and your understanding. Mommy has felt guilty every day for not spending time enough for you in the past years, but I have been thankful for opportunities to more grow every day since being a mom. You have taught me a lot about responsibility, love, friendship, parenting tactics, myself, and so on. This has been my important life lessons.

I can never say thank you enough to my parents, Hue Nguyen and Tien Nguyen, and my sister, Thuy Nguyen, for your unconditional love and endless support for me not only during my Ph.D. journey, but also every single step in my life. I have learnt a lot from you. You are the greatest teachers of my life. You have inspired and encouraged me all the way through this journey. I made it through because of YOU! I also want to say thank you to my former and current supervisors, Dr. Jennifer Fellabaum-Toston, Dr. Joe Hobbs, and Dr. Marcelle Siegel for your support. Thank you all for offering me the opportunities to gain many experiences and skills while working with you and for the financial support during my program. I really appreciate it!

Finally, during my journey, I have felt so lucky to have wonderful professors and friends who have supported and encouraged me when I needed them. Thank you, Dr. Noelle Arnold, Hoa Hoang, Maggie Dittmer, Trung Tran, Hang Tran, Catherine 
Heimsoth, Michelle Bollinger, Sara Cochran, Laura Page, Laura Browning, Colleen Cleary, Thu Nguyen, Hien Huynh, Ta Boonseng, Needra Jackson, Betty Kissane, Jude Sommerjones, Yang Ye, Dr. Hagen Huang, Andrew Bennet, Pawasha Khan, Ohm Maitreephun, Jason McKinney, Linh Ly, Dena Lane-Bonds, Ngoc Le, Enyn Zhou, JeongMi Moon, Kim Starks Berglund, and others. Without you, my doctoral journey could not have been so unforgettable and beautiful! 


\section{TABLE OF CONTENTS}

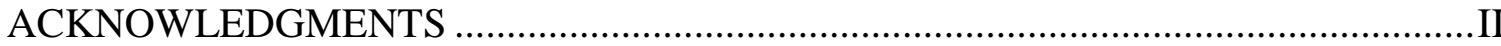

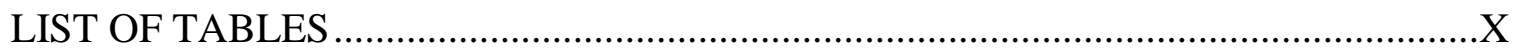

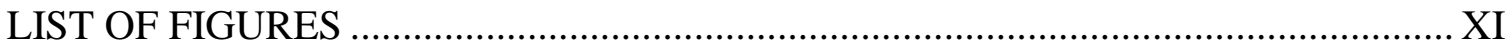

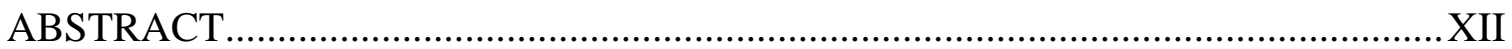

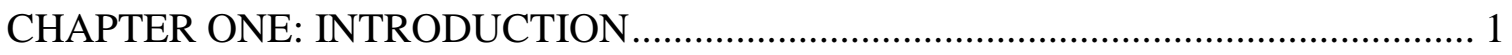

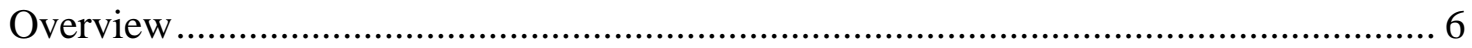

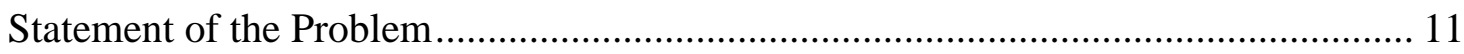

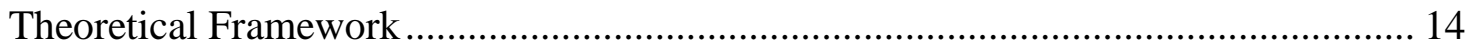

Research Design................................................................................................. 18

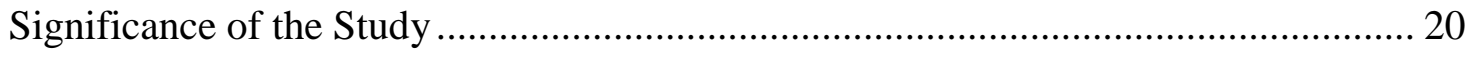

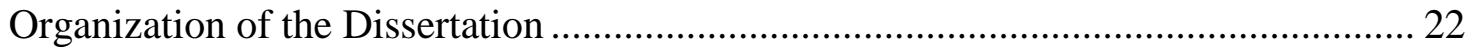

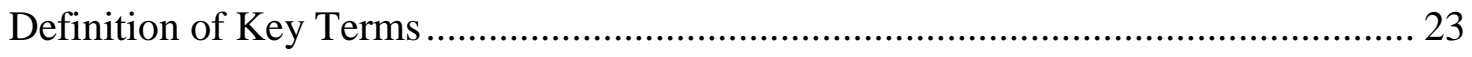

CHAPTER TWO: LITERATURE REVIEW ......................................................... 26

Workforce Trends and Possible Responses from the Vietnamese Education System.. 27

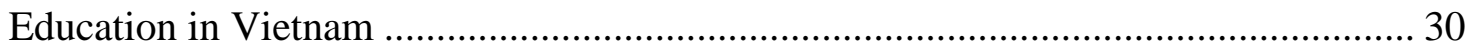

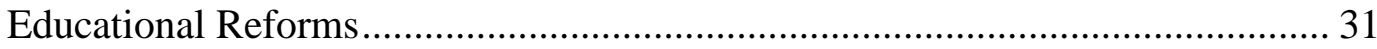

Current Educational and Career Tracks ......................................................... 35

The Context of Existing ACGC Activities for Vietnamese High Schoolers ................ 44

Issues and Problems Regarding Vietnamese Students' Academic and Career Choices50

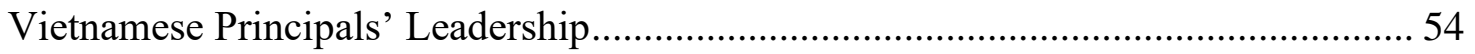

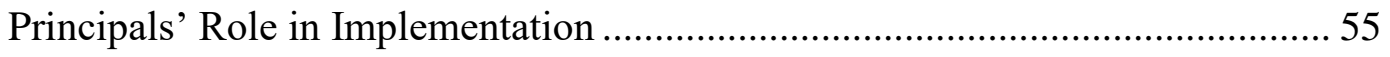


The Vietnamese Principalship with Political Factors ...................................... 57

Principal Leadership Practices with Cultural Factors ....................................... 58

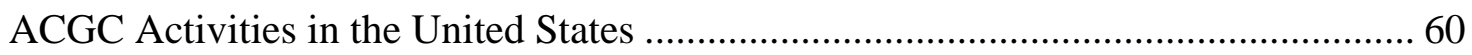

A Brief Overview of the Development of ACGC Activities ............................... 61

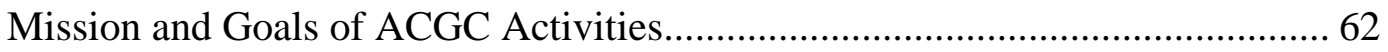

Research on U.S. High School Students' Outcomes in ACGC Activities............ 63

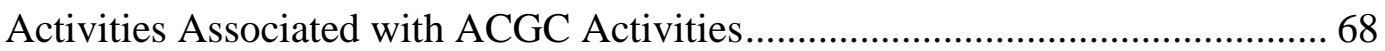

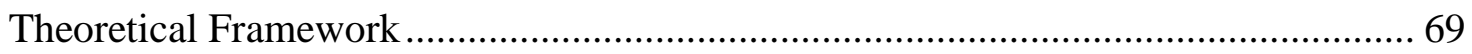

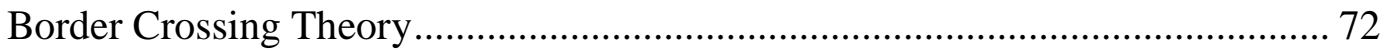

A New Application of Border Crossing Theory …...................................... 76

CHAPTER 3: RESEARCH DESIGN AND METHODOLOGY ................................... 79

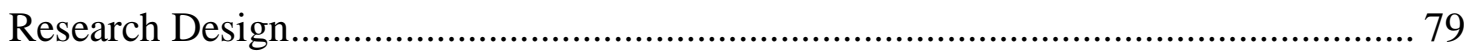

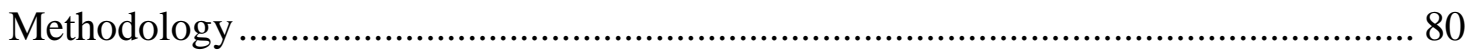

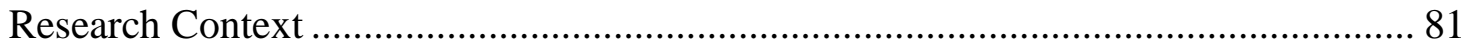

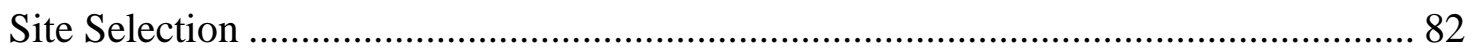

Participants and Sampling Technique............................................................... 83

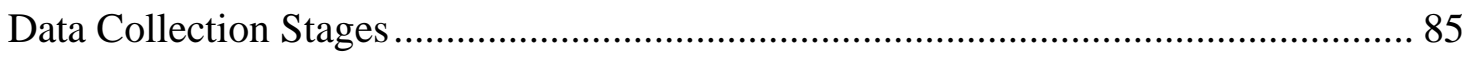

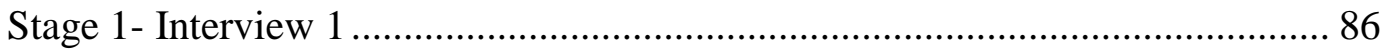

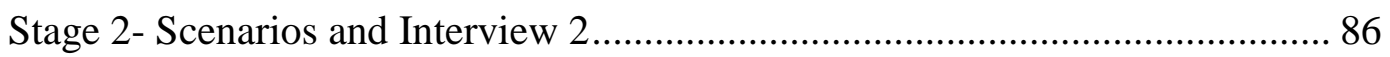

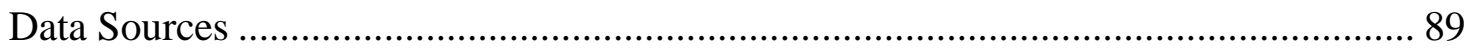

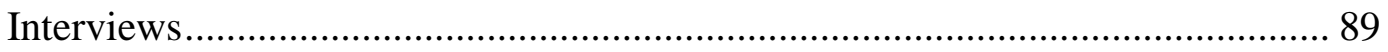

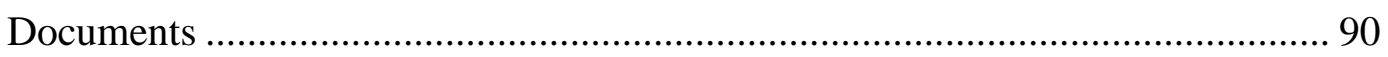

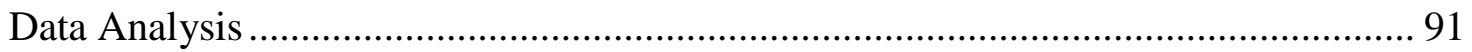




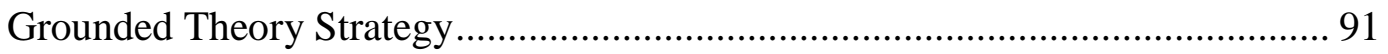

Use of Theoretical Framework to Guide Data Analysis ....................................... 92

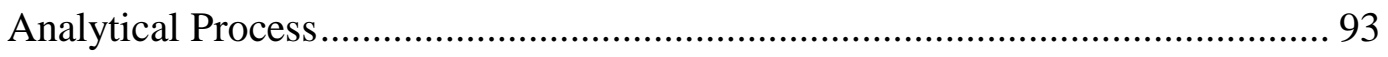

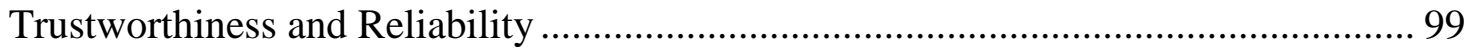

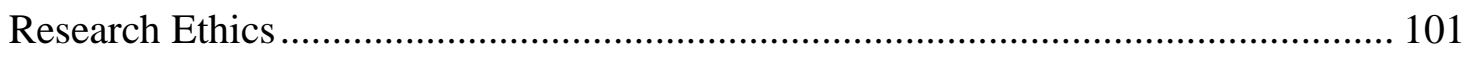

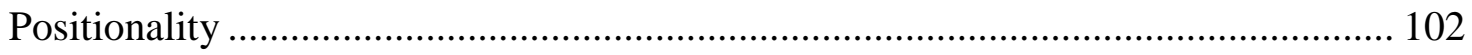

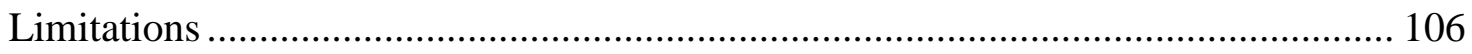

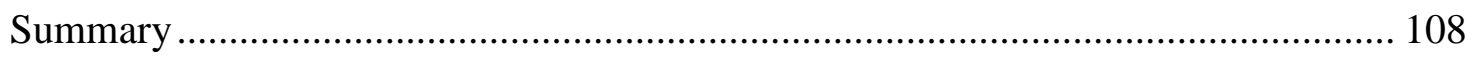

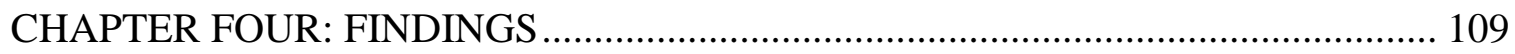

Finding 1: Principals Viewing ACGC as Either Integrated into the Curriculum or as

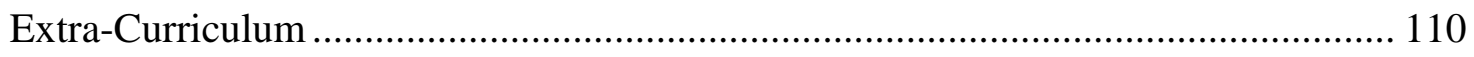

Non-BC Principals Viewing ACGC as Extra-Curricular .................................... 111

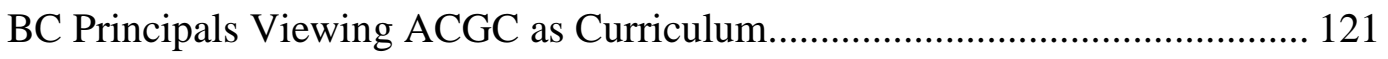

Finding 2: Non-BC Principals Viewed Their Challenges as Barriers Preventing Them from Designing and Implementing ACGC activities; BC Principals Knew There Were Challenges but Proactively Found Ways to Overcome Them ..................................... 131 Non-BC Principals' Views of Their Challenges to Designing and Implementing

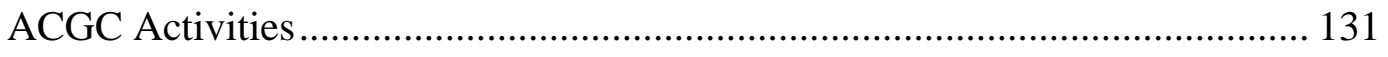

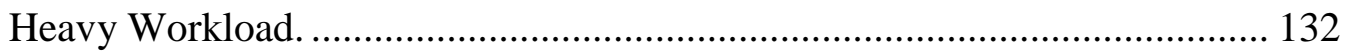

A Lack of Guidance and Counseling Staff. ................................................... 134

A Lack of Support from Community Agencies..............................................137

Family's Influence on Students' Choices. .................................................... 140

BC Principals' Challenges in Designing and Implementing ACGC Activities.. 142 
Deep-Rooted Traditional Vietnamese Educational Ideology.

Lack of Collaboration/Support from Parents.

Lack of Best Practices in ACGC.

Finding 3: BC Principals as Instructional Leaders in ACGC

Getting Professional Development Opportunities for Teachers and Other Staff 151

Directly Getting Involved in Designing and Implementing ACGC 155

Ensuring Self-Learning about ACGC Activities and Implementing Them 158

Using Instructional Leadership to Align ACGC and Teaching Methods to School

Goals, Mission, and Vision 160

Finding 4: BC Principals as Active Social and Educational Change Agents 164

Viewing Parents as Educational Partners 164

Viewing Individuals and Local Community Organizations in the Community as

Educational Partners and Supporters 167

Finding 5: Non-BC Principals' Relying on Limited Internal and External Resources and Parents' Interest to Implement ACGC Activities. 170

Relying on Head Teachers to Organizing a Few of ACGC Activities Outlined by MOET 170

Relying on External Resources to Reach Out ACGC Opportunities. 171

Relying on Students' and Parents' Interest 172

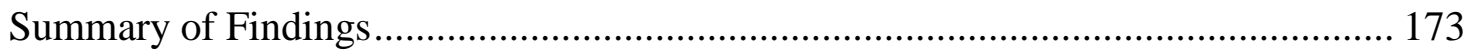

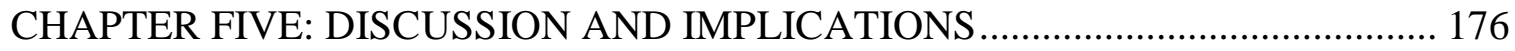

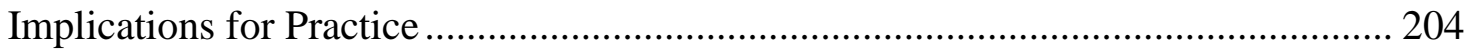

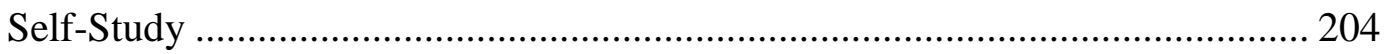


Build a Shared Organizational Vision, Mission, and Goals 207

Create Own School Improvement Plans ........................................................... 208

Implications for Future Research.................................................................. 212

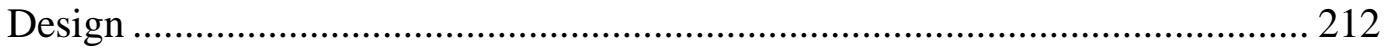

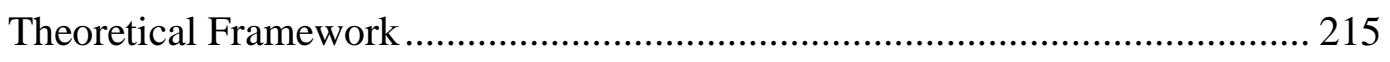

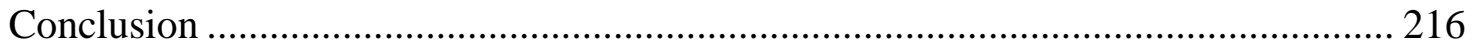

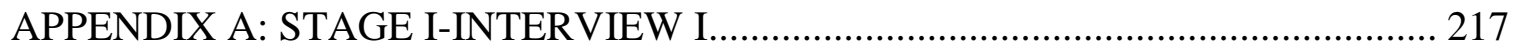

APPENDIX B: STAGE 2-SCENARIOS AND INTERVIEW 2.................................. 219

APPENDIX C: THE LIST OF THE ACGC ACTIVITIES BC PRINCIPALS ............. 226

AND NON-BC PRINCIPALS HAD OFFERED AND BEEN AWARE OF ................. 226

APPENDIX E: TYPES OF ACGC ACTIVITIES, IMPLEMENTATION STRATEGIES,

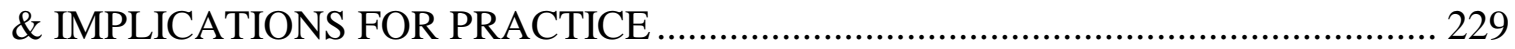

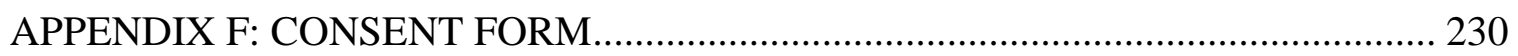

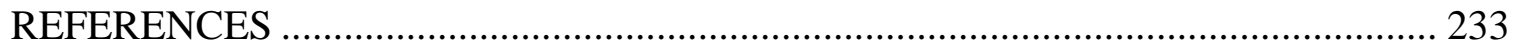

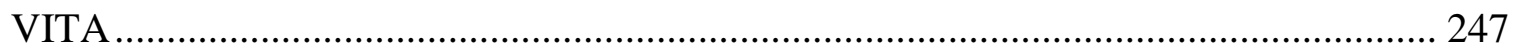




\section{LIST OF TABLES}

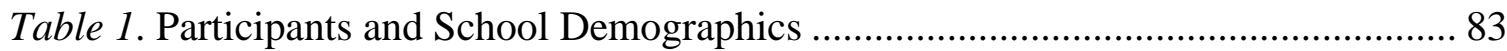

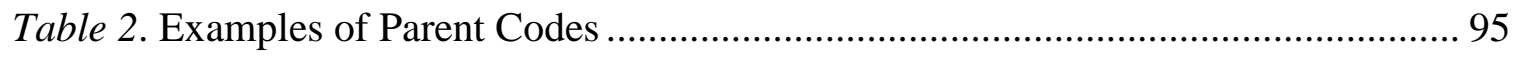

Table 3. Examples of a Parent Code and Relevant Excerpts ....................................... 96

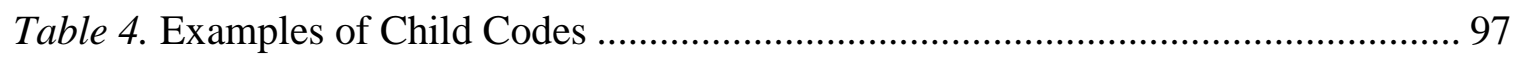




\section{LIST OF FIGURES}

Figure 1: Structure of the National Educational System of Vietnam (According to

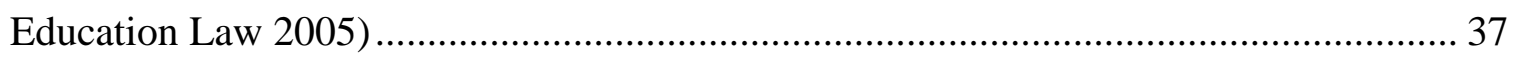

Figure 2: The Virtualization of the Borders in This Study........................................ 72

Figure 3: Data Collection Stages............................................ 88 


\begin{abstract}
The purpose of this qualitative case study was to seek a deeper understanding of Vietnamese high school principals' perceptions of academic and career guidance and counseling (ACGC) activities in terms of preparing students for their future academic and career paths. Moreover, this study also sought to understand difficulties they perceived and faced in the design and implementation of ACGC activities, then explored strategies which the principals used to sustain their abilities to implement these activities. The primary data for this research mainly came from individual semi-structured interviews with 11 Vietnamese high school principals from eight urban and three suburban areas of Hanoi, Vietnam. Findings from this study showed that there were differences in the ways the principal participants in this study thought about ACGC activities, viewed challenges, and spent resources, which affected the success or the failure of ACGC activities. As a theoretical contribution, this study emphasized the significance of becoming "border crossers" or border crossing principals who are able to improve education by adopting a new educational opportunity like ACGC activities to better facilitate the academic and career development of all students. In the last chapter, the discussion of the key findings and their implications drawn from the study have the potential to benefit a variety of audiences, including Vietnamese high school principals who want to better prepare before designing and implementing the activities and Vietnamese policymakers, teachers, school staff, college leaders and faculty, parents, and interested individuals and community organizations who would like to provide support for high school students' career and academic development and to boost related educational reforms.
\end{abstract}




\section{CHAPTER ONE: INTRODUCTION}

I was born in 1986, at the time my country, Vietnam, started to transition from an agricultural-based economy to a market-based economy. Many small children, including many relatives, peers and myself, were told that the purpose of going to school and being able to go to college guaranteed a better job as well as a brighter future than their parents, who were poor farmers who lived on agriculture with success determined weather conditions. Thus, after graduating high school, many of our elders, including parents, teachers, and school leaders, often expected us to pursue post-secondary education, specifically going to college. The suggestion of attending vocational institutions or other routes were only given to low-performing students or those who had little capability of going to college.

In high school, my friends and I did not seek out any school personnel for guidance and counseling, because my high school did not have specific school personnel who offered academic and career guidance and counseling ${ }^{1}$ (ACGC) for students. Going to college or university was our highest priority, but we did not know how to achieve it. In the final year of my high school, I had an opportunity to take a career-oriented typing course at a vocational center outside the school on the weekend. I took that class because I could get a vocational certificate and get a few bonus points for the graduation exam. In spite of receiving ACGC from my high school, I also looked for necessary support from my well-educated family.

\footnotetext{
${ }^{1}$ Academic and Career guidance and counseling (ACGC) activities defined as a set of multiple processes, techniques, interventions, and services designed "to help students make more informed and better educational and career choices". Please read more explanation about this term in the section of Key Terms on page 14.
} 
In particular, I grew up in an extended family who had gone through higher education and had a strong tradition of working in education. Thus, I likely received more support in my studies than my friends did. However, after high school graduation, most of my classmates and I felt vague about what educational and career options were available to us, how to access and identify those options, and which of our interests and abilities we should consider in making better educational or career choices. Eventually, I decided to go to the college my sister attended to become a teacher of English and to follow my family's tradition. My parents were my career counselors in a sense, or at least, they gave me suggestions while my teachers could not. Some of my classmates dropped out of school early or left during secondary school (grade 6-9) or high school (grade 10-12) and ended up working to earn additional money for their families. Luckily, going to college was the right choice for me; however, not all of my classmates had the same experience or support.

Realizing the difficulties many Vietnamese high school students encounter, specifically students like my friends and myself, when choosing future academic and career paths, I wanted to make changes in order to help students see opportunities available to them. Thus, I became self-employed as an academic and career advisor after getting a bachelor's degree. In 2009-2010, I successfully persuaded some high school principals in the area of Hanoi, where I was living at the time, to organize some of the first career and academic advising sessions for about 365 students at three high schools there. At that time, the only career-oriented activity, known as career fairs, that high school students were able to participate in, had been held outside their schools one or two times a year by vocational or higher education institutions which are located in a couple 
of the biggest cities in Vietnam such as Hanoi and Ho Chi Minh City (Ho Chi Minh City's Department of Education and Training, 2014). Much like my high school, they also did not offer academic and career counseling for their students. Instead, these schools collaborated with an outside vocational center to provide their students with one opportunity to take a career-related course, which was similar to my previous experience.

As a speaker at these career and academic advising sessions, I provided students with information about vocational institutions in their areas including a list of programs they provided, the deadline to apply, and additional help with the application processes. Since then, I have maintained my educational and career guidance and counseling practices through developing a non-profit website, entitled EduPortal. With the website, I can easily reach out to more students and even school leaders in need. In just one school year, I helped nine high school students choose good vocational or higher education institutions where they could start pursuing their dream jobs. However, the number of students I helped, as well as the number of students I organized advising sessions for at that time, was too small in comparison to the numbers of students across the country who might struggle with their future paths after high school.

Over the past three decades, from the mid-1970s to the early 2000s, problems relating to the lack of ACGC, including how to help Vietnamese high school students make the right decisions for their future paths after graduation, have continued to exist. Particularly, in 1981, the Vietnamese Central Committee and the Politburo stated that since the mid-1970s to the early 1980s, thousands of graduates among the half million secondary and high school Vietnamese students did not pursue higher educational levels 
or vocational training, but instead went to the labor market due to the lack of career guidance $^{2}$ at all levels of schooling (The Central Committee and the Politburo, 1981, p1).

In the last three decades, there have been minimal improvements in helping high school graduates across Vietnam pursue vocational and higher education after their graduation. Indeed, according to the Ministry of Education and Training (MOET), the highest governmental department responsible for managing every aspect in Vietnamese education, although the numbers of Vietnamese high school graduates attending vocational and higher education institutions have increased, there was discrepancy in the enrollment rates of Vietnamese high schoolers between vocational schools and universities across the country. Between 2000-2001, while more than two million high school students across the country attended colleges and universities, only 254,535 students attended vocational institutions (MOET, 2011a). By 2010-2011, the number of college students had increased over 34\%, while the number of vocational students increased nearly 13\%. The enrollment of Vietnamese high school students into higher education institutions was three times more than the enrollment for vocational institutions across the country in 2010-2011 in particular.

In short, the discrepancy is problematic, because the number of skilled workers needs to increase dramatically to meet the national economic development strategy by 2020 (The Prime Minister of Vietnam, Nguyen Tan Dzung, 2012). Furthermore, despite the increasing numbers of students attending college and vocational institutions over the past decades, there are a certain number of students who graduated from colleges/universities with professional qualifications face unemployment, because the

\footnotetext{
${ }^{2}$ Career guidance refers to assistance is targeted to the whole student population through career-oriented activities. Read the full explanation of career guidance in Key Terms section on page 13.
} 
market often requires more workers with technical skills than professional skills (Bodewig, et al., 2014; GSO, 2009).

As an individual who has crossed physical and psychological borders, I realize how important the establishment and development of ACGC activities can be at the high school level in Vietnam. It could potentially be a way to help students develop academically or career-wise to help grow the country's economy. Indeed, from the 2000s to the present, many schools in the United States, Germany, Canada, as well as other countries in Asia have offered school counseling programs including ACGC activities. These activities have become an integral part of the total school program during the general education $^{3}$ in other countries (Cobia \& Henderson, 2003; Gallant \& Zhao, 2011; Gysber \& Henderson, 1988), because research (Bradby \& Teitelbaum, 2000; Frone, 2001; Hughes \& Karp, 2004; Kaufman, Frome \& Dunham, 2002; Lapan, Gysber, Hughey, \& Arni,1993; Lapan, Gystes, \& Sun, 1997; Levesque el al., 2008; Parsad et al., 2003; Pope, 2000) shows that participating in ACGC activities provides students with necessary skills and knowledge to choose paths for their future.

In Vietnam, high school principals have the responsibility for organizing careeroriented activities, which are some kinds of ACGC activities, to help students gain necessary skills and knowledge to explore their academic and career options after high school graduation (MOET, 2003; 2014; 2018b). However, little is known about what these principals know about ACGC activities, what they are doing to prepare students for further education and careers or what challenges and opportunities leaders perceive in

3 General education in Vietnam refers 12 years of formal education including three levels: primary school (grade 1-5) secondary school or lower secondary school (grade 6-9), and high school or upper secondary school (grade 10-12). 
implementing such activities. This is a gap in the literature this study seeks to fill. In order to better provide the background of issues in this study, in the next section, I give an overview of Vietnam's socioeconomic state and the growth of Vietnamese education over time to understand how ACGC activities can become a strategy to help Vietnamese high school students make better future academic and career choices.

\section{Overview}

Vietnam is undergoing many socioeconomic changes, including reforming education in order to turn its economy into a modern, industrialized country by 2020 . In Vietnam's socioeconomic development strategy for the period of 2011-2020 (The Prime Minister of Vietnam, 2012), the Prime Minister of Vietnam, Mr. Nguyen Tan Dzung in 2012, emphasized education as the main focus of these changes. Education is expected to play a significant role in developing a highly skilled workforce to meet the given national goal to modernize and globalize the Vietnamese economy. However, it is a big challenge for education and educators who are responsible for helping students gain necessary skills and knowledge to make informed choices for their future academic and career paths, especially when the current development of Vietnamese education lags behind the demands needed to increase economic growth.

Over the last few decades, Vietnam has tried to successfully integrate into the global economy through national policy efforts (Bodewig, Badiani-Magnusson, Macdonald, Newhouse, \& Rutkowski, 2014). These national policy efforts include forming free trade agreements in 1997 with nine other member states of the Association of Southeast Asian Nations (ASEAN), including Indonesia, Malaysia, the Philippines, Singapore, Thailand, Brunei, Myanmar, Cambodia, and Laos. Vietnam also joined the 
World Trade Organization (WTO) in 2007 in an effort to globalize the economy. Since 2007, Vietnam has gained many advantages, such as a higher degree of economic freedom, more competition among national and international businesses, higher quality of goods and products for consumers and more foreign investment (Thi, 2004). As a result of multiple efforts over time, Vietnam has obtained many socioeconomic achievements. According to the World Bank, Vietnam's Gross Domestic Product (GDP) growth rate in the period of 2012-2016 kept stable from 5-7\% (World Bank, 2017). Specifically, as of 2016, the GDP growth rate was over 6\% and placed behind Thailand and the Philippines. The high economic growth rate led to a sharp increase in the per capita income from $\$ 239$ in 1985 to $\$ 2,107$ in 2015 (World Bank, 2017) and a poverty reduction from nearly 60\% to $20 \%$ in the past two decades (World Bank, 2013). These efforts have transformed Vietnam from one of the poorest countries in the world to a lower middle-income country.

However, while Vietnam's developing economy needs a skilled workforce in order to continue to further modernize and globalize, the majority of its workforce has low levels of education and technical/professional training with a disparity between the rural and urban areas. The young population in both rural and urban areas have not had opportunities to receive good vocational training or guidance while in school. Indeed, according to the 2009 Vietnam Population and Housing Census by GSO (2009), Vietnam's labor force ages 15 or greater was 49.2 million, and accounted for nearly $58 \%$ of the total population. However, about $74 \%$ of the labor force across Vietnam is concentrated in rural areas where the sectors of agriculture, forestry, and fishing are 
dominant and require mainly unskilled occupations with manual and routine tasks (GSO, 2009).

In terms of educational attainment, the proportion of the labor force completing high school and higher was only nearly $26 \%$; particularly $18 \%$ in rural and $47 \%$ in urban areas (GSO, 2009). In terms of technical or professional qualifications, over $85 \%$ of the Vietnamese population ages 15 years and up have not received any technical or professional training from vocational education or higher education (GSO, 2009). Similar to the educational attainment above, the nearly $15 \%$ share of the workforce with technical or professional training is different across regions and genders in Vietnam. For example, while only $18 \%$ of people living at rural areas had university and higher training, the percent of people living in urban areas with the same qualifications was nearly three times higher. Moreover, the share of the male labor force with university qualifications or higher was only over $5 \%$, which was higher than the percentage of females in the labor force with the same training at over $4 \%$. Overall, there are low educational qualifications for current Vietnamese workforce across regions and an imbalance of the share of the workforce between genders.

In response to goals to achieve greater economic development and to ensure more job opportunities for more Vietnamese, Vietnam has undergone a number of educational reforms with a focus on vocational education and higher education. From 1957 to the present, Vietnam has made many efforts to enhance and develop its national education system, including the establishment and expansion of vocational institutions, academic colleges, and universities, both public and non-public, and fields of training across the country. In particular, in terms of vocational education, Vietnam increased from 50 
vocational institutions across the country with about 7 training fields, such as post office and telecommunication, electric industry, transportation, mine engineering, chemicals and culture/arts in 1994 to 136 vocational colleges, 290 secondary vocational schools, 849 vocational centers across the country (MOET, 2011a) with about 18 main training fields in the school year of 2010-2011.

The number of vocational students increased from 887,300 people in 2001 to $1,860,000$ people in 2011 (MOET, 2014). In terms of changes in higher education, there were 193 colleges (30 non-public) with 726,219 students, 163 universities (50 nonpublic) with $1,435,887$ students across the country in 2010-2011, compared to 84 colleges, 69 universities and 893,754 students in 1999-2000. Moreover, in order to improve the professional quality of leaders, professors, and lecturers at this postsecondary level, these educators have opportunities to have academic exchanges at international institutions (Nguyen \& Nguyen, 2008). However, there are no such training and retraining opportunities for educational leaders, particularly at the high school level.

Despite educational achievements in establishing and expanding vocational education and higher education in Vietnam over the past 30 years to offer more opportunities for technical and professional training for more Vietnamese students, both domestic and foreign employers have complained about the inadequate skills of job applicants (a skills gap) and a scarcity of workers in some occupations (skills shortage) (Bodewig, et al., 2014). In particular, less than a quarter of better-educated professionals and technicians perform well with more analytical, interactive, non-routine and nonmanual tasks (Bodewig, et al., 2014). Approximately 14\% of international employers, particularly in Vietnam, are not satisfied with applicants' job-specific technical skills 
such as analytical skills, argument foundation skills, and IT skills. Nearly $40 \%$ of these international employers see their applicants' skill gap and skill shortage as the result of a weak, general education including the high school level (Bodewig, et al., 2014). For local businesses, they require better leadership skills, communication skills, and teamwork from employees. Moreover, due to new modern jobs which require new skills such as technical, cognitive, social, and behavioral skills, there is a shortage of applicants for jobs to become managers, professionals, and technicians (Bodewig, et al., 2014).

Overall, due to the difficulties current workers and students face, Vietnamese education needs to implement specific strategies. This is especially true in the early training orientation of youth to help increase the enrollment rates in vocational institutions in particular, which may help prepare future workers to better contribute to the country's goals for socioeconomic development (GSO, 2009; Bodewig, et al., 2014). One specific way that can be done in high schools may be through introducing school counseling activities like ACGC.

For continued development, Vietnamese education needs further reforms at the high school level (Bodewig, 2012; Bodewig, et al., 2014). For nearly a century, many countries over the world-including the United States, Germany, and Canada, and others in Asia such as such as China, Thailand, and Singapore-have successfully developed ACGC activities as a linkage between general education and vocational and higher education to help high schoolers explore their personal interests and abilities, then make informed academic and career choices after graduation (Hohenshil, Amundson \& Niles, 2015). In contrast, the design and implementation of ACGC activities are quite new to Vietnamese schools. MOET places the responsibility for designing and organizing 
ACGC activities for high school students on high school principals (MOET, 2018b), but there is no or little research in Vietnam about what Vietnamese high school principals know about ACGC activities, whether they believe ACGC activities are valuable, what do they perceive challenges in the design and implementation of these activities, and what strategies they use in order to overcome challenges to implement those activities for their students.

\section{Statement of the Problem}

More than two decades ago, when Vietnam was an agricultural-based country, some career-oriented activities in Vietnam were designed by MOET to aid high school graduates explore careers available in their community. The aims of these activities were to help high school students find jobs society needed at that time based on the student's

own interests and physical strength. Simultaneously, organizations in the community had opportunities to further train and employ these students after graduation. Indeed, according to Decision No. 126 made in 1981 by the Central Committee and the Politburo of the Communist Party of Vietnam (CPV), MOET was supposed to propose and create career-oriented activities for secondary and high schools while organizations such as vocational institutions, colleges, universities, factories, and business in the community were expected to help those schools in training, such as offering training places as well as professional staff, and in employing and continuing further training for students after graduation.

At the school level, MOET expects high school principals, the highest administrative school personnel, to play an active and pivotal role in the process of helping high school students become more aware of educational and career choices and 
their personal interests and abilities (MOET, 1981; MOET, 2018b). In particular, in terms of career-oriented education, MOET has clearly defined Vietnamese high school principal's responsibilities and obligations which include organizing, operating, and assessing the four main ACGC activities including monthly academic and career-related discussion sessions, career-related activities integrated into courses, especially through technology course, and career-related courses. (MOET, 2003; MOET, 2014).

However, nearly four decades after the policy was issued, Vietnam is no longer an agricultural-based economy, but has been trying to turn from a market-based to an industrialized one. Therefore, it seems that the four ACGC activities above have not been suitable for the academic and career development of the students as well as to meet the new economic demands. One possible solution for high school principals may be to start designing and implementing new ACGC activities as some countries in the region have done (Hohenshil, Amundson \& Niles, 2015).

While Vietnamese high school principals are expected to help their students be well prepared for their academic and career paths after graduation by designing and implementing new ACGC activities (MOET, 2018b), the problem is that Vietnamese high school principals have not been trained in knowledge and skills of ACGC, because universities or colleges did not offer professional ACGC training for them when they attended at university level (Bui, 2014; Do, 2009; Nguyen, 2011). As a result of the lack of school leaders' training in ACGC activities and what makes ACGC effective, Vietnamese high school principals may not know what effective ACGC activities can do and how to implement these activities. Research has not yet shown what Vietnamese high school principals know about these ACGC activities and how they think about the need 
of the design and implementation of such activities for their students' academic and career development, and their roles in helping student explore their future academic and career interests and abilities. This is a gap in Vietnamese and international research on this topic of leadership and specific roles toward students' transition from high school to post-secondary education or career.

\section{Statement of Purpose and Research Questions}

The purpose of the study was to explore how Vietnamese high school principals perceive ACGC activities in terms of preparing students for their further education and career and what principals think is necessary or to prepare students for their future academic and career paths. This study sought to explore what obstacles principals need to overcome in order to start designing and implementing these activities as well as in what ways they can implement these activities for their students. Specifically, the study sought to answer the following research questions:

1) What are urban and suburban Vietnamese high school principals' perceptions of ACGC activities they currently have in their schools and how they perceive new ACGC activities?

2) What do these principals challenges they perceive or face in the design and implementation of ACGC activities?

3) How do the principals sustain their ability to implement ACGC activities?

In particular, while Vietnamese high school principals do not have training in ACGC, this study aims to understand what these high school principals currently know about ACGC activities and how they think about the design and implementation of such activities for their students. All of these concerns are significant, because as the primary 
school personnel responsible for getting students prepared for career exploration and choices after high school, Vietnamese high school principals' perceptions of ACGC activities and their openness to such activities may greatly contribute to the potential success of their students' future academic and career development and the achievement of the country's economic goals in the future. Also, because Vietnamese high school principals have not been well trained in ACGC activities, the ways principals view obstacles to implementing ACGC may be different. Thus, this study sought to address what principals perceive as difficulties in the design and implementation of ACGC activities. Furthermore, the study aims to understand how border crossing principals overcome the managerial principalship style, where Vietnamese principals make sure to appropriately operate given learning and teaching activities (Doan, 2005; C. Nguyen, 2010; Nguyen \& Wu, 2012), in order to design and implement ACGC activities (Wilson \& Douglas, 2013).

The implications drawn from the research may benefit not only principal participants in this study but other Vietnamese high school principals who want to better prepare before implementing these activities. Additionally, policy-makers, national educational leaders, other educators, community members, and family may view implications from this study to better provide necessary support to students and their high schools in the process of organizing ACGC activities in the near future.

\section{Theoretical Framework}

This study utilized border crossing theory as the main theoretical framework to explore Vietnamese high school principals' perceptions of ACGC activities, seeking to understand their experiences implementing ACGC activities by exploring what 
challenges they face in the design and implementation of ACGC activities as well as how they sustain their ability to implement these activities. In this study, borders or boundaries in this study refer to barriers and obstacles involving Vietnamese traditional managerial principalship style, including political and cultural factors, power dynamics in Vietnamese education system and others which prevent Vietnamese principals increasing their critical consciousness and also students' critical consciousness. Additionally, this traditional managerial style prevents many Vietnamese school leaders pushing beyond their responsibilities and expectations in order to make differentials in students' learning outcomes. The borderland in this study refers to sites of exploration and transformation where school principals as border crossers who are engaged as pivotal agent to create new learning practices including ACGC activities and in order to increase their students' outcome.

Aligned with the concepts of borders and borderlands, the concept of border crossing in this study is a metaphor which refers to extraordinary efforts educators make to go over the existing borders/obstacles mentioned above in the educational Vietnamese context to create and implement new learning activities at school for the future educational and career development and achievement of their students. Particularly, in this study, the metaphor suggests that by questioning existing career-oriented activities, challenging the Vietnamese traditional managerial principalship, and changing the power imbalance in Vietnamese educational hierarchy, Vietnamese principals are critical educators who are able to navigate and use strategies to create new ACGC activities for students; they identify with a leadership style where they see themselves as key agents, or street-level bureaucrats (Lipsky, 1980), who are able to utilize their autonomy and 
discretion to influence student' learning experiences, and in this way balance the power dynamics and increase the critical consciousness of stakeholders, including parents, teachers, students, individuals and community organization.

The concept of borderlands was first used by Gloria Anzaldúa in her book Borderlands/La Frontera: The New Mestiza in 1987. Anzaldúa focused on analyzing the everyday experiences of people, specifically immigrant and first-generation immigrant students and students of color who, like herself, cross borders of race, ethnicity, language, gender, sexuality, and geography in order to affirm their identities which can be marginalized by others. In Anzaldúa's study, the borderlands refer to immigrant students' mental boundaries that are produced by feelings of margination, discomfort, and unwelcomeness due to a dominant group's power, and the differences between the dominant culture and the homeland culture of these immigrant students (Anzaldúa, 2007). Additionally, Anzaldúa shared her experiences of crossing her own borderlands successfully. By critically writing about her lived experiences regarding biological and sociological differences, Anzaldúa successfully challenges readers, including those with dominant identities, privilege, and power from historically dominant groups, to push against the limits of what they know about specific contexts and situations, particularly the lived experience of other marginalized persons including herself in borderlands (Lockhart, 2006).

Many other scholars like Douglas (2013), Douglas and Peck (2013), Giroux (1992), Lopez, et al. (2006), Luz Reyes and Garza (2005), and Wilson and Douglas (2013) have also utilized the concept of borderlands in their research as an important contribution to the establishment and expansion of an educational theory, called border 
crossing theory. According to research by the scholars above, the borderlands are not only "the physical and/or conceptual landscapes" (Wilson \& Douglas, 2013, p.1) where immigrant youth confront and resist inequality in their education, but are also "sites of risk and transformation" (Wilson \& Douglas, 2013, p.1), where youths' school leaders act as active agents to improve their students' education by using border leadership (Douglas \& Peck, 2013; Douglas, 2013; Garza, 2007; Goldstein, 2016; Lopez, et al., 2006, Wilson \& Douglas, 2013) and border pedagogy (Douglas, 2013; Douglas \& Peck, 2013; Garza 2007; Goldstein, 2016; Giroux, 1992; Wilson \& Douglas, 2013).

According to these scholars, border leadership refers to the ability and process where an educational leader is able to prepare his/herself with necessary skills and knowledge to work across the national context. Then, he/she is able to take action and give guidance in order to offer new practices, activities, or programs to help raise stakeholders' critical consciousness about power, privilege, inclusion, exclusion, etc., and their related issues. By doing this, students who have been minoritized and other students from historically dominant groups may get quality educational opportunities. However, to do that, the leader needs to possess the kind of leadership where the leader pushes beyond her/his daily responsibilities and expectations in order to support new activities as good educational opportunities for students' development. Further, these leaders inspire, encourage, and assist other educators and students in the process of implementing the new activities. This new leadership, known as border leadership, is different from the traditional principalship approaches where educators act as educational managers to merely fulfill assigned tasks and responsibilities according to Hallinger and Truong (2014) and Walker et al. (2012). Border pedagogy emphasizes transformative learning 
opportunities as new educational methods and practices, as mentioned above, that educators create in order to better support the development of students, especially students who are marginalized (Douglas, 2013; Douglas and Peck, 2013; Garza, 2007; Giroux,1992; Goldstein, 2016; Wilson \& Douglas, 2013).

Drawn from the application of border crossing theory by Wilson and Douglas (2013) and my constructivist approach, evolving efforts to explore how people construct their own understanding and knowledge of the world through personal experiences, the concept of border crossing in this study emphasizes efforts and achievements that critical educators as border crosser or active agents have made and obtained in order to best assist their students' success while in school and later in their future, as well as the betterment of the society by using their border leadership and border pedagogy strategies. As a result, these principals are able to become aware of ACGC activities, be creative, seek out more resources, push above and beyond their assigned responsibilities for just implementing the required career-oriented activities in order to implement ACGC activities for their students.

\section{Research Design}

This qualitative study was designed to seek a thorough understanding of how Vietnamese high school principals consider what they can do to prepare students for their future academic and career paths after high school, and whether or not they think ACGC activities are valuable (Creswell, 2003; Merriam, 1998). Specifically, building on the theoretical framework of border crossing, the study explored how these high school principals become aware of ACGC activities and how willing they are to implement these activities while considering impediments and advantages in implementing such activities 
for their students. Using qualitative methodology for my study is appropriate, because this method allows me to not only better understand the given research problem by exploring the perspectives/experience of the local population it involves, but this approach also helps me understand how those perspectives/experience influence their behavior (Creswell, 2003; Stake 2006; Yin, 2013).

This study used a case study design (Yin, 2013) where the case of this study is identified by two boundaries; the first boundary is the high school level and the second is Hanoi, a particular city in Vietnam. Both are settings for the research context in which my participants work. Choosing an exploratory case study design in particular allows me to not only explore the experiences of Vietnamese high school principals in preparing students for their future academic and career paths at urban and suburban schools in Hanoi. This creates a bounded system (Merriam, 1998; Stake 2006; Yin, 2013). This design allows me to conduct a new area of research on principal leadership in Vietnam with a new application of border crossing theory. Particularly, the exploratory case study design offers description and explanation (Merrian, 1998) of Vietnamese high school principals' efforts, applying border crossing theory (Wilson \& Douglas, 2013) to understand if these principals are willing to become border crossers who implement ACGC for their students.

The data sources in this study included two-round semi-structured interviews with 11 Vietnamese high school principals and some related documents such as individual school career guidance plans, MOET's circulars and instructions, and government's guidance on career guidance for high school students (Merriam, 1998; Stake 2006; Yin, 2013). I applied a new vision of border crossing theory (Wilson \& Douglas, 2013) and 
Grounded theory methods as my analytical strategy in order to guide every step of the data collection and analysis in this study. Indeed, with a new application of border crossing theory (Wilson \& Douglas, 2013), this study tries to explore if these principals with border leadership and border pedagogy strategies are border crossers or potential border crossers willing to design and implement ACGC activities for their students. In the process of data analysis, I used member-checks, asked my peers to take coding-blind tests within Dedoose for inter-rater reliability, and deeply analyzed related documents (Charmaz, 2006; Strauss \& Corbin, 1990) to minimize possible bias from my positionality.

\section{Significance of the Study}

The study is important for the following reasons. First, while today's growing public debate among Vietnamese students, parents, employers, educators, and policymakers is underway on how each of the stakeholders can participate in improving the skills of the workforce (Bodewig et al, 2014), this study focuses on Vietnamese high school principals in particular as key stakeholders. This study considers particularly their perspectives of ACGC and their view of difficulties and opportunities in developing and implementing ACGC as a potential answer to the research questions. Indeed, the specific reasons for emphasizing what these school leaders think and do is because they have the highest administrative roles in organizing and developing career guidance activities for their high school students (MOET, 2003 \& 2014). Bodewig (2012) suggested Vietnamese educational reforms should focus on general education, not just vocational education and higher education. This direction may bring a significant contribution in order to strengthen the Vietnamese youth workforce for the national goals of integrating the 
global market and turning into a modern industrialized country by 2020. My study has the potential to offer specific strategies for the direction of Bodewig (2012)suggests; that is, focusing on the high school level by building and developing ACGC activities for which principals are mainly responsible.

Second, a number of studies, such as those by Do (2009), Nguyen (2011), and Bui (2014), have been conducted on Vietnamese high school students' experience on careeroriented activities. By recruiting high school student participants, these studies aimed to give explanations for the ineffectiveness of guidance activities at the high school level and why there is a need to develop ACGC activities in Vietnam. However, there are no studies with Vietnamese high school principals' voices, particularly their perceptions of ACGC activities and what challenges and opportunities they perceive in the design and implementation of such activities for their students. This study hopes to fill this gap in the literature in Vietnam in this area, because as the highest administrative positions for the academic and career development of students, what Vietnamese high school principals think and do can affect the success or the failure of ACGC activities.

Moreover, as a theoretical contribution, this study hopes to expand border crossing theory to the Vietnamese context and with Vietnamese educators and to study border crossing as the principal transition from traditional managerial roles to transformational roles. In particular, this study emphasizes the significance and meaning of Vietnamese high school principals' perceptions and efforts to push above and beyond their managerial leadership style in order to gain an awareness of ACGC activities and to create these activities. In addition, like critical educators in the U.S context in the study by Wilson and Douglas (2013), Vietnamese principals may be able to become "border 
crossers" to improve education by adopting a new educational opportunity like ACGC activities to better facilitate the academic and career development of all students and ultimately improve education and society.

Next, based on the findings in this study, there are implications that may be beneficial to Vietnamese policymakers, high school principals, and future school counselors who want to push to start the design and the implementation of ACGC activities. Additionally, the findings and its implications may be useful for other audiences including teachers, school staff, college leaders and faculty, parents, and interested individuals and groups in the community who would like to provide support for high school students' career and academic development and to boost related educational reforms.

\section{Organization of the Dissertation}

This dissertation is organized into five chapters. Following the Introduction, Chapter Two presents a review of the relevant literature including two main sections. The first section is Vietnam-focused that includes an overview of workforce trend that indicates the need for skilled workers and the growth of professional and technical occupations in the future. Additionally, the first section also focuses on the Vietnamese educational structure and students' educational and career tracks; the context of career guidance activities for high school students; current issues and trends regarding Vietnamese students' academic and career choices. The second section provides an overview of ACGC and its outcomes in the United States. The reason I look at ACGC and its outcomes in the U.S. is because, first, the U.S is one of the first countries to successfully implement ACGC activities, and several research studies have shown the effectiveness of these activities for their student 
participants, both academically and vocationally. There is potential for developing these ACGC activities in Vietnam. Chapter Three provides a detailed explanation of the research design, conceptual framework, and the methods used to collect and analyze the study's data. Chapter Four includes the study's findings, and finally, Chapter Five presents discussions of the key findings and their implications on the design and implementation of ACGC activities for urban and suburban area high schools in Vietnam and overall conclusions.

\section{Definition of Key Terms}

The following terms appear frequently in this study. The definitions provided here may reflect differences between the Vietnamese education system and others.

Academic and Career Guidance and Counseling (ACGC) Activities are defined as a set of multiple processes, techniques, interventions, and services designed to "help [individual] students make more informed and better educational and career choices. Among other things, activities offer information on high school course offerings, career options, the type of academic and occupational training needed to succeed in the workplace, and postsecondary opportunities that are associated with their field of interest. Activities also often provide teachers, administrators, and parents with the information they can use to support students' career exploration and post-secondary educational opportunities." (The U. S Office of Career, Technical, and Adult Education, 2017, para $1)$.

Decision made by the government refers a mandate or by-law document that gives directions and guidelines about leadership strategies, collaborative tasks for the 
government's members, ministries, Commune People's Committee at all levels in order to implement the government's given principles, tasks, vision, or strategies.

Career is defined as the totality of work-paid and unpaid-someone does in his/her lifetime (National Career Development Association, 2003).

Career guidance in Vietnam refers to collaborative efforts between high schools and other sectors to assist high school students make career decisions which are appropriate with the demands of social development and are associated with the students' attitudes and physical strength (MOET, 1981). In the process, given assistance is targeted to the whole student population, not only individual students, through four main careeroriented activities. Activities include monthly academic and career-related discussion sessions, career-related activities integrated into other subjects, and career-related activities through the subject of technology, and career-related courses (MOET, 2003).

Future academic and career paths/plans/goals refers to choices or decisions students make to pursue post-secondary education (vocational institutions, 3-year colleges, 4-year universities in the country or overseas) or other routes (immediate employment after leaving high school or others). These terms are used interchangeably in this study.

General education in Vietnam refers to 12 years of formal education including three levels: primary school (grade 1-5), middle school/lower secondary school (grade 69), and high school/upper secondary school (grade 10-12).

Principal refers to the highest administrative position at an individual school. In Vietnam, there are no school districts and superintendents like in the United States. 
Vocational education, also known as Career and Technical Education (CTE)

refers to vocational training at vocational institutions with elementary, intermediate, and college levels. Vocational education and CTE are used interchangeably in this study. 


\section{CHAPTER TWO: LITERATURE REVIEW}

This chapter is composed of two sections, one focusing on the Vietnamese context of how workforce trends and the national system are performing to meet the country's economic goal and one focusing on the international context regarding the development and research on the effectiveness of ACGC. Being aware of the development and research on ACGC activities in Vietnam and the U.S. is important to help school leaders understand the significance and potential of ACGC activities. Specifically, in the first section, I provide information regarding workforce trends in Vietnam during its transition from a market-based economy to an industrialized one. This information is necessary to show how Vietnamese education is being viewed as a path to help strengthen the Vietnamese workforce to meet the country's economic goals and the reasons why there is a focus on career-oriented strategies for high school students in particular. I also provide an overview of Vietnam's educational system and how it affects students' options for choosing among available educational and career tracks.

Next, I focus on the historical background and elements of existing careeroriented activities that Vietnamese high schools have implemented, which should show how out-of-date these activities are in helping students gain necessary skills and knowledge in order to be well prepared for various paths after high school. Moreover specifically, I provide an overview of Vietnamese principal's leadership in order to better show how Vietnamese principals' principalship and practices influence their students' teaching and learning.

Finally, this chapter provides an overview of U.S. ACGC activities and research on high school student participants' outcomes from participiating in these activities to 
show the characteristics and components of such activities. The successes, as well as shortcomings of these activities in the U.S., may provide Vietnamese educational leaders with helpful strategies to build and develop effective ACGC activities.

\section{Workforce Trends and Possible Responses from the Vietnamese Education System}

Vietnam has a large and young population. With nearly $70 \%$ of the population between the ages of 15 and 64, and over 25\% from 0 to 14 (GSO, 2016), Vietnam needs to absorb a massive influx of young people into the workforce over the next few years. According to a report by the General Statistics Office of Vietnam (GSO) (2016), Vietnam had 92.7 million people in 2016, which was 987 thousand (1.08\%) more than it had in 2015. The labor workforce of people from the ages of 15 and older in 2016 was approximately 53.3 million, including the male workforce of 28.1 million (52\%), and female at 26.3 million (49\%). Of the total labor workforce, nearly $68 \%$ of the labor workforce is located in rural areas (GSO, 2016).

Over the past few decades, although Vietnam has experienced a shift in employment from less- productive agricultural jobs to more productive non-agricultural wage jobs (Bodewig, et al., 2014), Vietnam is still a predominantly rural country with agriculture as its most important economic sector. Particularly, the share of the labor force employed in agricultural, forestry, and fishing industries declined from $98 \%$ in 1986 to $45 \%$ in 2010, while non-agriculture work sectors increased from $2 \%$ in 1986 to 24\% in 2010 (Bodewig, et al., 2014). Most non-agricultural jobs in Vietnam in 2010 were in blue-collar occupations, service, and sales (Bodewig, et al., 2014). Service and sales workers accounted for $30 \%$ of non-agricultural jobs. Jobs as craftsmen, machine operators, and elementary workers jointly made up $40 \%$ of non-agricultural employment 
- much more than technicians with 9 percent. Professionals positions were $16 \%$ of the non-agricultural workforce, managers $2 \%$, and clerical workers $4 \%$.

However, despite the transition toward non-agricultural jobs, the percent of the Vietnamese labor workforce from ages 15 and up in 2016 in agriculture sectors, which do not require highly qualified skills and qualifications, still remains the largest participating proportion of the economy. As a result, the overall productivity of the Vietnamese labor workforce is low (GSO, 2016). Specifically, the percent of the labor workforce of the ages of 15 and greater in 2016 working in agriculture, forestry, and fishing sectors accounted for about $42 \%$ of the workforce while that in the industry was over $24 \%$, and in the service sector, over 33\% (GSO, 2016). GSO (2016) also found that only nearly $21 \%$ of Vietnamese labor workforce was trained professionally, either from vocational or higher education institutions.

The low percentage of professionally trained workers reflects the findings by Bodewig et al. (2014) and other researchers regarding skill gaps, the lack of skills required by employers, occupational skill shortages, and no or few applicants in certain occupations. For example, up to $80 \%$ of employers who were hiring professionals and technicians reported their applicants lacked the required job skills. Not limited to certain professional and technical occupations, employeeds lacked required skills including cognitive, social and behavioral skills, problem-solving, critical thinking and technical skills for people in these positions that follow as managers, clerical workers, service and sales worker, and craftsmen (Bodewig, et al., 2014). Also, according to Bodewig, et al., (2014), both domestic and international employers complained that the demand for workers with certain occupation-specific technical and professional skills exceeds the 
supply. As a result, Vietnamese workforce productivity, the value of goods and services that a Vietnamese worker produces in a given amount of time, is lower than other countries in the region. For example, according to GSO (2016), workforce productivity was $\$ 3.660$ per person, which was only over $4 \%$ of Singapore workforce productivity, about $17 \%$ of Malaysia, $35 \%$ of Thailand, $48 \%$ of the Philippines, and slightly over $48 \%$ of Indonesia. One potential reason for skill gaps and skill shortages, which both international and domestic firms and the workforce claim, was due to the shortcomings of the Vietnamese education system; that is "equipping school leavers neither with the appropriate skills acquired through the school and university system nor with the appropriate vocational skills" (Bodewig, et al., 2014, p.5).

In response to the transition to the global market, Vietnam and Vietnamese education in particular may benefit from effective orientation strategies to encourage students to make more career choices in industrial sectors rather than the agricultural sectors, which is in line with the country's given goals (Bodewig, et al., 2014; Giesecke, Tran, Meagher, \& Pang, 2011). This shift would not only reflect the demand of the current and future labor market, but would also reinforce how important career guidance activities can be for students to help them make better academic and vocational choices. In order for Vietnam's education system help students get the necessary skills for future jobs, educators need to work on developing and implementing ACGC activities for high school students. I give a brief overview of Education in Vietnam, The Context of Existing Career-Related Activities, Issues and Problems Regarding Vietnamese Students' Academic and Career Choices, and Vietnamese Principals' Leadership to show how the 
educational system and school leaders are getting their students prepared for their future paths.

\section{Education in Vietnam}

Since 1990, the Vietnamese the Ministry of Education and Training (MOET) has been responsible for nearly all aspects of public and non-public general education and higher education, including the creation of textbooks and curricula, issuing certificates and diplomas, and managing the evaluation of educators' professional performance (The Education Law 2005). Vocational education and some specialist colleges, however, have been under the control of the Ministry of Labour, Invalids and Social Affairs (MOLISA) since early 2017 according to the Resolution No 76/NQ-CP by Vietnamese Government in 2016.

In parallel with the country's economic development, the Vietnamese education system has made significant achievements compared to countries with similar economic development. Indeed, according to Nguyen and Nguyen (2008), the literacy rate in Vietnam is over $90 \%$, and it keeps increasing. The rate of primary school-aged children attending schools is more than $98 \%$, and there is not a big difference in the enrollment rate for boys and girls. By 2016, all 63 provinces and cities in Vietnam had successfully

implemented compulsory primary education (GSO, 2016). Moreover, Vietnam is making significant efforts to implement compulsory middle school education by 2020 as one strategy to further strengthen the quality of human resources for the country's industrialization and modernization by the same year. Despite these educational achievements and key objectives, however, Vietnam's education system still faces many challenges in keeping up with international standards. Its main problems include, but are 
not limited to, the low quality of teaching and learning and management, teacher-centered learning, outdated curriculum, lack of equipment and infrastructure, a shortage of the linkage between general educational and vocational education, a lack of autonomy and accountability at all levels, and so on (Nguyen \& Nguyen, 2008).

Below, I provide the larger picture of the progress of Vietnamese education over the past decades. First, this section provides information on the four educational reforms that were implemented in response to the demands of Vietnam's socio-economic changes. I outline the current structure of Vietnam's educational system to show the different options available for Vietnamese students' educational and career tracks prior to their entry to the labor market. Finally, I present current Vietnamese educational achievements, challenges, and Vietnam's national strategies for improving its educational system and strengthening its labor force.

\section{Educational Reforms}

After the 1945 Revolution, Vietnam started developing an education system but encountered many difficulties because of two patriotic wars: the anti-French (1946-1954) and the anti-American wars (1965-1975). However, after the post-war renovation period, particularly since 1986, Vietnam's education has made significant changes in response to the country's transition from a centrally-planned economy to a market-based economy and globalization.

Indeed, over the past half-century, the Vietnamese education system has undergone four educational reforms. The first educational reform in 1950 focused on transforming the structure of general education in North Vietnam, which consisted of a total of ten years of schooling, including 4 years of primary school, 3 years of secondary, 
and 3 years of high school. Primary education included Vietnamese language reading and writing, while secondary and high school levels provided students with subjects such as foreign language, music, drawing, housework, current affairs, policy, and citizenship. The reform's objectives were to educate and foster the younger generation to "become future citizens, loyal to the people's democratic regime, and competent to serve people and the resistance war" (Nguyen \& Nguyen, 2008, p. 4). From 1950 to 1956, four medical/pharmacy and science (mainly literature and mathematics) universities continued to operate.

The second reform in 1956 focused on the establishment of 10-years of schooling (4 years of elementary school, 3 years of secondary school, and 3 years of high school) in the North, which was similar to the French educational model. At this time, schools became bomb targets in the Vietnam war, so the goals of education were for "ensure[ing] safety of students and strengthen[ing] links between school and real life, production and fighting activities" (Nguyen \& Nguyen, 2008, p. 6). At the same period, the 12-year education plan (5 years of elementary school, 4 years of middle school, and 3 years of high school) in the South was influenced by North American education. The aims of educational activities in the South were "to meet peoples' learning demands and to fulfill the responsibility of human resource training" (Nguyen \& Nguyen, 2008, p. 6). Also, in this period, professional secondary and vocational schools were established with vocational classes attached to business.

The third educational reform in the school year 1981-1982 was considered the most strategic one, where a new 12-year general education plan (5 years of elementary school, 4 years of secondary school and 3 years of high school) was created and 
implemented across the entire country and continues until the present. Two objectives of this reform were to improve the quality of comprehensive education and to train workers with educational qualifications which were suitable for demands of the workforce distribution in the country's socialist-oriented economy (Central Committee of the Vietnamese Communist Party, 1979). The educational principles were to strengthen the linkage between learning and practice, education and work, and school and society. For general education, the most important task in the third reform was the replacement of textbooks at all schooling levels, which was completed in 1996. Some of the other achievements were the abandonment of the elementary graduation exam in 2005 and the establishment and development of some career-oriented activities at the secondary and high schools levels to aid students to find jobs aligned with the needs of society.

The third educational reform marked the establishment and expansion of vocational education, also known as career and technical education (CTE) as part of the Vietnamese educational system. Several short training courses, vocational secondary programs, and a pilot program of training highly skilled technicians were conducted in the field of post office and telecommunication, transportation, mine engineering, chemicals and culture/arts. By 1993-1994, the structure of the national educational system, including preschool, general education, vocational education and higher education was dramatically expanded and made quite similar to those of Western countries, particularly the United States. The standard for student performance, however, was affected by the Confucian ideology and the USSR's educational model, which Vietnam perceived as focusing too much on educational theories and academic 
knowledge and not enough on opportunities for students to gain skills such as problemsolving and critical thinking (Bodewig, et al., 2014; Hallinger, et al., 2017).

In order to improve the quality of public education and the links between education and employment, the next reform was passed in 2006-2007. Particularly, MOET implemented three tracking programs, including a natural sciences track, social sciences and humanities track, and a basic education track for high school students, also known as the "streamed high school curriculum". However, this streamed curriculum was abolished in 2014 due to improper fit with the high school graduation exam and university entrance exam (Lao Dong, 2014). One significant achievement of this fourth reform was the abandonment of the middle school graduation exam in 2006 (MOET, 2006a). It was an achievement, because evaluating students' performance and outcomes by exams, which have been affected by Confucian ideology for many centuries (Hallinger et al., 2017), were decreased since that year. The abandonment of the middle school graduation exam in 2006 was necessary to avoid pressures coming from testing as well as related issues like heavy private tutoring for students (Baobariavungtau, 2005; Tuoitre, 2005).

The next educational reform on the horizon, also known as the new radical and comprehensive educational reform, which was stated in the Decision No. 29 in 2013 by the Party Central Committee at the 6th plenum, was planned to take place after 2017. The primary aim of this reform was to strengthen the country's human resources to meet the requirements of industrialization and modernization under the conditions of the socialistoriented market economy and international integration by 2020 . The reform focuses on identifying and nurturing the ability and potential of each student, and developing ACGC 
activities for students to get them well prepared for their transition to post-secondary education or career (Party Secretary, Nguyen Phu Trong, 2013). The main educational objectives of the reform were to integrate some subjects, mainly at the elementary school level, reducing the duration of school time at the secondary school level, and offering selective course options for high school students to enhance the effectiveness of teaching and learning, place more focus was on the individual students' ability, and help students prepare for their transition after the high school level. However, until the present of 2019, according to MOET's report on the reform's progress, reforms regarding the new curriculum for the general education (grade one to 12) will merely able to take place since 2020 and may complete by 2025 (MOET, 2018a).

\section{Current Educational and Career Tracks}

While Vietnamese education was influenced by some cultures such as the Chinese and French during the feudal and colonial periods, since the third educational reform in 1981-1982 until the present, the structure of the Vietnamese educational system has been similar to many other Asian countries and Western countries including the United States (Hallinger, \& Truong, 2014; Nguyen \& Nguyen, 2008; World Education News \& Reviews, 2014). That is, it is composed of 12 years of schooling followed by bachelor, Master's, and doctoral studies. Particularly, according to Education Law 2005, the national educational system of Vietnam is divided into the following stages: 1) Early childhood education, 2) General education, 3) Vocational education, and 4) Higher education (see Figure 1 below). All levels of schooling are either state-run or private; however, except for a limited number of international institutions, all schools in general 
education follow the national curriculum, with some adjustments based on socioeconomic factors in different local areas (The Education Law 2005).

The following chart provides information regarding the different stages of education in Vietnam, which shows available educational and career tracks for Vietnamese students prior to their entry to the labor market. Although the aim of Vietnam and Vietnamese education is enhancing its quality to be as high as others in the region and the world (The Prime Minister, Nguyen Tan Dzung, 2012), based on the aims of each educational level and their lists of courses/subjects offered, it becomes evident that career education, in particular, has not been paid attention to as a compulsory requirement. As a result, Vietnam, as well as Vietnamese education, will need to make necessary changes in order to get their students, including those at the high school level in particular, well prepared in terms of ACGC as an attempt to strengthen future human resources to meet the national economic goals.

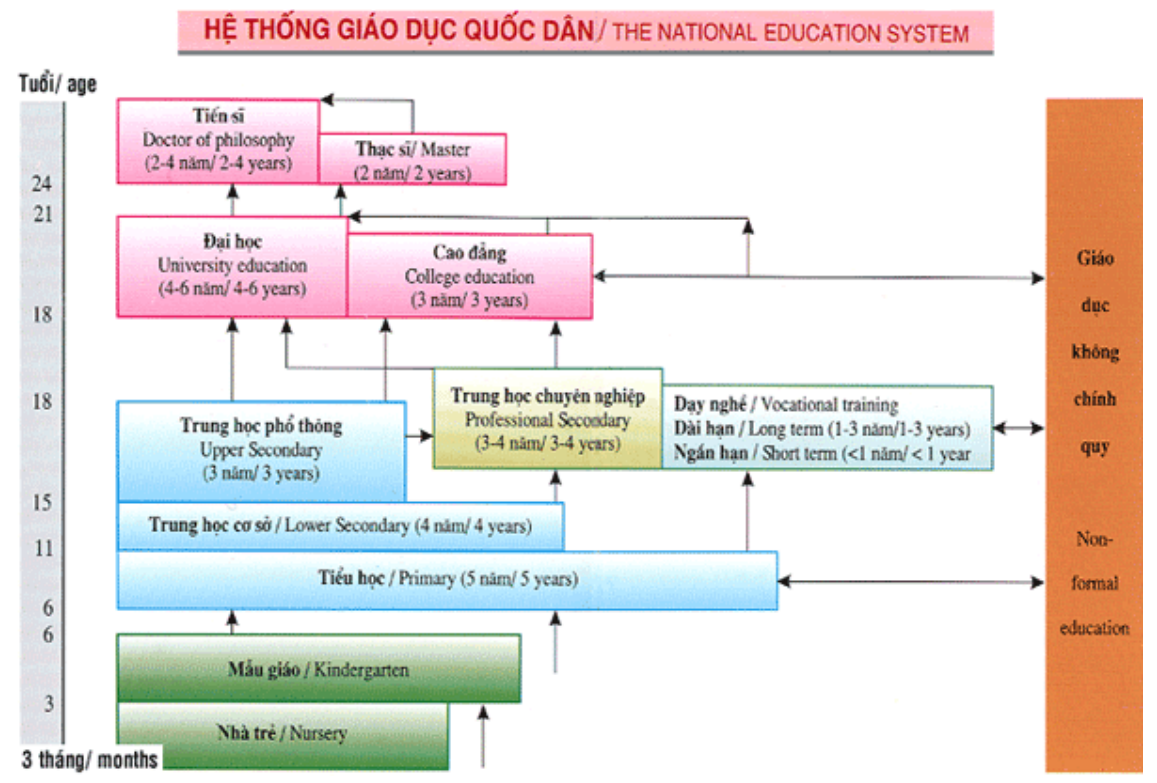


Figure 1: Structure of the National Educational System of Vietnam (According to Education Law 2005)

Early Childhood Education. Early childhood education consists of three types of institutions. 1) Nurseries (childcare for infants aged three months to three years), 2) Kindergarten (childcare for infants from the age of three years up to six years), and 3) Pre-primary schools (incorporating the functions of both the nursery and the kindergarten, childcare for infants from the age of three months up to the age of six years). The aims of early childhood education are "to help children develop physically, emotionally, intellectually and aesthetically, in order to shape the initial elements of personality as well as to prepare children for the first grade" (The Education Law 2005, Term 22). As a result, the Ministry of Education and Training (MOET) encourages all Vietnamese children to attend kindergarten to ensure school readiness. During the 20162017 school year, Vietnam had 4.9 million students at this level (GSO, 2016).

General Education. General education in Vietnam is 12 years of formal education including three levels: elementary school (grade 1-5), middle school (grade 69), and high school (10-12), which follow a national curriculum across the country for all public and private schools. The school week has six days, beginning on Monday and ending on Saturday. Over 55\% of elementary school students were able to attend the whole day since the school year of 2012-2013, while most of the middle and high school students attend school for half day from 7:30 a.m to 12 p.m (MOET, 2014). Public school is free, and there is a nominal fee for high school. According to the American Education Group (2015), though private schools and partially privatized schools are increasing, they accounted for nearly $2 \%$ of all schools in the school year 2010-2011 (GSO, 2016), and they exist almost exclusively in the two biggest cities, Hanoi and Ho Chi Minh City. 
Students at these schools make up a small percentage of applicants to colleges and universities abroad. Tuition and fees at such private and international schools vary, and some are extremely expensive compared with public school tuition and fees.

Elementary school. Elementary school lasts five years between first and fifth grade, the ages of $6-11$. It is the only compulsory years for Vietnamese children (Education Law 2005). Less than 5\% of the Vietnamese population has never been to school (Nguyen \& Nguyen, 2008). Data on school and enrollment (GSO, 2016) showed there were 7.7 million students and 15,242 institutions. The subjects studied at this level are Vietnamese, mathematics, morality, nature and society, arts, English, and physical education for grades 1 - 3 and Vietnamese, mathematics, morality, science, history, geography, basic techniques, music, arts, English, and physical education for grades 4 and 5. After elementary school, most students continue their study at middle school. Some go to preliminary vocational school for 6 months for jobs with low-level skills.

Middle school (Lower secondary school). Middle school lasts four years from grades 6 to 9 with students typically aged $11-15$. According to GS0, in 2016, there were 10,462 schools with 4,968,302 students at this level. The subjects studied were (are?)Vietnamese, mathematics, biology, physics, chemistry, history, geography, civics, foreign language (mainly English), physical education, technology, art, and music. Optional subjects included class activities, school activities, vocational-oriented activities (three periods per month in grade nine) and extracurricular activities (four periods per month in all grades). For $9^{\text {th }}$ graders, they can take an optional career-based course if offered by their school or local vocational centers. After completing grade 9 , students can choose to attend a high school for 3 years to get a high school diploma, or a professional 
secondary school for 1-2 years to get a vocational certificate. Some choose to attend a secondary vocational college for 2-3 years while studying some subjects such as Literature, Maths, Chemistry, Biology, and Physics to get both a high school diploma and a vocational certificate.

High school (Upper secondary school). This level includes grade 10 to 12, are students are between the ages of 15-18. Compulsory subjects include mathematics, Vietnamese literature, physics, chemistry, biology, history, geography, civics (generally consists of economics, philosophy, politics, law and ethics), foreign language (mainly English, and Mandarin, French and Russian at a few specialized schools), technology, information technology, physical education, career-oriented activities and military and security education. However, only a few career-oriented activities are available for grade 11 only and these activities are optional. As of 2016, there were 14,851,820 students attending 2,288 institutions. After high school, students can go to university (4-6 years), college (3 years), a vocational college ( 2 years), work, military service or study abroad.

In short, there is no research evidence that ACGC activities are taught as part of the general education. Although many Vietnamese high schools offer a few careeroriented activities for students, these activities lack the counseling component which focuses on helping individual students to explore their own academic and career interest and ability as well as gain required knowledge and job skills.

Vocational Education. In Vietnam, vocational education is part of the national educational system, but it is separate and is not integrated into general education. While vocation education has been under the management of the Ministry of Labour, Invalids and Social Affairs (MOLISA) since 2017, MOET has been responsible for other levels of 
education including early childhood education, general education, and higher education. According to the first vocational training law, called Vocational Training Law 2006, passed by the National Assembly of Vietnam in 2006 in response to the increased demand for skilled workers for the national goal of economic development, vocational training means "training a technical workforce in direct production and service provision, who have practical capabilities compatible to their qualifications, have a work ethic and conscience, have professional working style, are disciplined and healthy so that after graduation they can find a job or be self-employed, or acquire further education, meeting the national requirements for industrialization and modernization" (2006 Vocational Training Law, p.1). In Vietnam, learners with middle school diplomas can choose to attend one or some of the three tracks of vocational education including elementary-level, intermediate-level, and college-level vocational training (Vocational Education Law, 2014, Article 3) which informs the difference in the level of training duration as well vocational knowledge and the skills learners are expected to obtain upon completion of their training.

The elementary level. At the elementary level, students attend an elementary vocational training program which often lasts 3 months to 1 year at vocational training centers, vocational secondary schools, colleges and enterprises, professional secondary schools, colleges, and others who have registered to provide vocational training at the elementary level. The objectives of this level are to "equip students for abilities to perform simple tasks of a particular job" (Vocational Education Law, 2014, Article 4, No page). However, this law does not give an idea of what jobs graduates may apply after graduation with an elementary certificate. 
The intermediate level. The intermediate level of vocational education is designed to "equip students for abilities to perform elementary-level tasks and some complicated and special tasks; apply technology to jobs, work independently or work in teams" (Vocational Education Law, 2014, Article 4, No page). Yet, the law did not give any ideas of what jobs graduates may apply for after completing their programs. After about 2-3 years of training at a secondary vocational school, vocational college, professional secondary schools, college or university that is registered to provide vocational training at this level. Trainees at this level get a secondary degree.

The college level. The college level is the highest one students are able to get in vocational education in Vietnam. The college level aims to "equip students for abilities to perform intermediate-level tasks and some complicated and special tasks; create and apply modern technology to jobs, instruct and observe other members in their teams in performing the tasks" (Vocational Education Law, 2014, Article 4, No page). Like the two other levels, the law did not mention what kinds of jobs graduates may find after completing their programs. This lack of clarity may lead to a disparity between job requirements and applicants' skills and knowledge. After 2 to 3 years of study for those who have graduated from high school or 1 to 2 years for those with a secondary level certificate, graduates get a vocational diploma from vocational colleges, colleges or universities, who have registered to provide vocational training at the diploma can find a job, where those students attended. Then they may go into the labor market or pursue a higher educational level.

Since the establishment of vocational education in the 1980s, vocational education has obtained many achievements including its expansion in terms of school 
size and student enrollment. Until 2011, Vietnam had 136 vocational colleges, 308 secondary vocational schools, and 849 vocational centers across the country (MOET, 2014). The student population increased from 887,300 in 2001 to $1,860,000$ in 2011 (MOET, 2014). However, enrollment rate has been a big issue for vocational institutions across the country (Bodewig, et al., 2014), because the number of students enrolled in vocational education, in 2014 for example, was only $1 \%$ of that is enrolled higher education.

Higher Education. Higher education is composed of colleges, universities, or research institutes that offer bachelor, masters and doctoral programs (Nguyen and Nguyen, 2008). Over the last decade, Vietnam's higher education has experienced a significant expansion in enrollment. According to MOET (2011a), as of the academic year 2010- 2011, there are 223 colleges (30 non-public) with 726,219 students, 163 universities (50 non-public) with 1,435,887 students. Concurrently, students at college and university levels increased from 1,540,201 to 2,162,106 between 1999-2000 and 2010-2011 (MOET, 2011a). Overall, the majority of those students have gone through the national university system, while an increasing number of students attend private foreign universities with a local campus or study abroad in the U.S. (Ashwill, 2016), Canada, Australia, or Europe (Bain, 2015).

Access to higher education remains limited. For example, in 2007, while Vietnamese universities had places for only 300,000 students, up to 1.8 million candidates took university entrance exams (cited from Ho \& Berg, 2010). However, Vietnam's higher education has been complained about for its lack of linkages between knowledge and reality; poor training quality and efficiency, out-of-date teaching and 
learning methods, lack of resources, lack of institutional autonomy and accountability, and so on (Nguyen \&Nguyen, 2008)

In short, through the four educational reforms since 1950 until the present, Vietnamese education has obtained many achievements, mainly including the improvement and expansion of early childhood through higher education across the country. Although the model of Vietnamese school system follows many Western countries, the content is still influenced by the USSR's model and Confucian ideologies which pay much attention to gaining much knowledge, transferring as much knowledge as possible from teachers to students without encouragement of creativeness and critical thinking, problem-solving, and focusing on student's learning outcomes based on exams (Schenck, 2015; Tran, 2009; Truong, 2013; Truong et al., 2017). As a result, more work is needed to help students prepare to become skilled workers to meet the national demands for industrialization, modernization, and international economic integration. While Vietnamese education seems to mainly focus on improving post-secondary education, including vocational education and higher education as an effort to strengthen the quality of human resources, little has been done in general education at the high school level, in particular, to link general education and post-secondary education. Career-oriented activities are proposed as one way to better prepare students and show them different options after high school in Vietnam; however, Bodewig, et al., (2014), Do (2009), La (2007), and Nguyen (2011) showed the ineffectiveness of these activities in terms of students' academic and career development. 


\section{The Context of Existing ACGC Activities for Vietnamese High Schoolers}

In 1981, the Central Committee and the Politburo of the Communist Party of Vietnam (CPV) made its first policy decision, namely Decision No. 126, to provide guidance on career guidance for middle and high school students, to address the negative consequences of the lack of adequate career guidance at the middle and high school levels. It states:

Annually Vietnam has more than a half of a million of middle school graduates and nearly 20,000 high school graduates. This would be the big future workforces as well as great numbers of candidates for universities, colleges, professional secondary schools and vocational institutions across the country; however, due to the lack of career guidance for middle and high school students, thousands of those middle and high school graduates did not pursue higher educational levels but went to the labor market without good preparation (The Central Committee and the Politburo, 1981, p. 1)

In Decision No. 126, career guidance was defined as career-oriented activities designed to help students to have a good work ethic, learn about career options, and help students explore their ability/interest in order to choose appropriate careers based on the society's needs at that time (The Central Committee and the Politburo, 1981). In order to establish these career-oriented activities, the Central Committee and the Politburo, who are the most senior ministers of the State, directed MOET to create the curriculum, textbooks, and train teachers, while businesses and vocational institutions began to offer career- 
related courses as well as training places and teaching staff for the students. As a result, these businesses could employ students who complete the training.

Since Decision No. 126 in 1981 to the present, the Central Committee and the Politburo of CPV and MOET established basic guidelines and instructions (visit the link ${ }^{4}$ for the list) regarding career guidance for middle and high school students across the country. Part of the purpose of these documents was to help school leaders organize and implement the four main ACGC activities including 1) monthly academic and careerrelated discussion sessions, 2) career-related activities integrated into other subjects, and 3) particularly through the subject of technology, and 4) career-related courses (MOET, 2003). Although in 2018, MOET provided school leaders and teachers with a new guidance on the design and implementation of ACGC activities, the design and implementation of these activities will not required to implement in a systematic way by 2025 (MOET, 2018b). Thus, until 2025, at the high school level, school leaders will still need to organize the four ACGC activities above.

While the previous guidance and instructions from MOET helped provide how the four ACGC activities at the high school level should look, there is limited research on these activities' effectiveness. Thus, in order to understand part of the impact of these activities on high school students' academic and career development, it is necessary to look closer at the four existing ACGC activities that have been implemented at this high school level across Vietnam.

\footnotetext{
$4 \quad$ http://hcm.edu.vn/huong-nghiep-day-nghe-pt/van-ban-chi-dao-ve-giao-duc-huong-nghiep-c4139553472.aspx

Specially, they are the circular No. 48-BT in 1982, the circular No. 332003CT-BGDĐT in 2003, the instruction No. 1126_CV8608 in 2007, the instruction No. 8608BGDĐT-GDTrH in 2007, the instruction No.10945/BGDĐT-GDTrH in 2008the instruction No. 7475BGDĐT-GDTrH in 2008, the instruction No. 3119/BGDĐT-GDCN in 2014.
} 


\section{Monthly Academic and Career-Related Discussion Sessions}

Monthly academic and career-related discussion sessions are a type of schoolbased, career-related activities where Vietnamese 10th-12th graders and their head teachers have nine periods ${ }^{5}$ per school year for discussion about careers in society. In particular, head teachers lecture students on themes that rotate monthly. Examples of these may include "Youth and the Nation's Industrialization and Modernization" in September, "Youth and the National Construction and Defense" in December, and "Youth and Establishing Business" in March (MOET, 2006). However, these activities mainly focus on 12th graders (MOET, 2006; MOET, 2007).

Two studies by Do (2009) and Nguyen (2011) showed the ineffectiveness of these activities for high school students. Particularly, a study by Nguyen (2011) on the status of vocational consultancy for 223 students in three high schools in Ho Chi Minh City, Vietnam, found over 57\% of the student participants did not know what careers their community and society need. More than $60 \%$ of the student participants indicated they could not find anyone to ask for occupational advice, and up to $26 \%$ of the student participants contended that their head teachers did not do anything to help them get knowledge or experience to explore careers. Nguyen (2011) explained that head teachers and subject teachers who are responsible for helping their students get this knowledge about careers and vocational institutions do not have professional training in terms of ACGC.

Do (2009) showed similar findings to Nguyen (2011) in his study with many groups of participants, including 240 10th, 11th, and 12th-grade student participants at

\footnotetext{
${ }^{5}$ A period is 45 minutes
} 
six high schools in Hanoi, Ho Chi Minh, and Da Nang city, the three biggest cities in Vietnam. Do (2009) added that teachers may have likely experienced a lot of difficulties while helping students with career-oriented activities, because they do not have opportunities to attend necessary training courses about career guidance. In addition, many of the teachers in Do's study were not even adequately aware of the goals and purposes of ACGC, which led to many of them not facilitating the mandated sessions for their students (Do, 2009). Nguyen (2011) identified one of the reasons; that is, the teachers have used teaching time to help student practice strategies of taking the graduation exam or university entrance exam (Nguyen, 2011). As a result, the teachers as well as school leaders, who are responsible for helping the students make better academic and career decisions for their future, could not make these ACGC activities effective as expected.

\section{Career-Related Activities Integrated into Different Courses}

While students are supposed to participate in monthly sessions during class time, career guidance also requires that subject teachers integrate career-related activities into their courses (MOET, 2014). According to Ho Chi Minh City's Department of Education and Training (2014), despite the requirement of spending two periods per month integrating career-related activities into courses, high schools can organize for students to participate in extra-curriculum activities outside of school. For example, in some big cities like Hanoi and Ho Chi Minh City, students can participate in annual career fairs organized by some vocational institutions, universities, business, and organizations such as the Vietnamese Youth Association. These fairs offer students and employers or vocational institutes opportunities to meet one another. 
The effectiveness of career-related activities in high school courses is low. In the previously noted study by Nguyen (2011), which was conducted with 223 students in three high schools in Ho Chi Minh City, the researcher found over $48 \%$ of student participants felt that their course teachers did not use this time to explore different careers, but rather to prepare students for nationally mandated exams. Approximate $26 \%$ of the student participants had the same experiences with their head teachers, and greater than $28 \%$ for a particular teacher or school leaders who are assigned to responsible for career guidance at their school (Nguyen, 2011). Overall, the forms of these ACGC activities integrated into other courses as well as career fairs seem to be ineffective because of the lack of standard guidelines for implementation.

\section{Career-Related Activities Integrated into the Course of Technology}

Unlike other courses mentioned previously, which are intended to connect course materials with career-related activities for students, technology teachers use a specific textbook that has guidelines designed to help the teachers and their students develop career-related activities at class. Once developed, such activities have taken place in 35 periods per school year for $9^{\text {th }}$ graders, 52.5 periods for 10th and 11th graders, and 35 periods for $12^{\text {th }}$ graders (MOET, 2007). However, there have been no studies on the efficacy of these activities.

\section{Career-Related Courses}

All Vietnamese high schools in big cities offer students one opportunity to participate in a career-specific course. Some examples include planting, typing, embroidering, forging, basic tailoring, cooking, repairing motorcycles, electrical circuits in the house and some (MOET, 2007; MOET, 2013; Ho Chi Minh city, Department of 
Education and Training, 2008). This course is limited to three periods per week, which is equivalent to 105 periods per school year for high school students (MOET, 2008). The aims of these courses are to help students begin to establish the basic skills of a particular vocation. After completing the course, student participants are able to receive one or two bonus points toward their graduation exams (MOET, 2006). However, due to the limitation of infrastructure at high schools in Vietnam, these courses are often organized on weekends at vocational centers in local areas or far from schools. In rural and mountainous areas, the availability of such activities depends on school contexts as well as the availability of vocational centers in the area. Like the previously noted careeroriented activities at schools above, courses at vocational centers have also proven ineffective at providing sufficient academic and career advising for high school students. For example, Nguyen (2011) stated that more than half of the participants perceived no help at all in terms of career information resource from career guidance staff at vocational centers or counseling centers in the community.

In short, the four existing ACGC activities, which are outlined by MOET, at Vietnamese high schools offer high school students opportunities to know more about certain jobs like one of the objectives the Government required in the first decision No.126 on implementing career guidance for high school students. However, nearly three decades have passed with the new demands for the national socio-economic development, it seems that these activities are likely not effective enough to help students explore their own attitudes and gain good knowledge and skills to make decisions for their future academic and career paths. Moreover, the existing ACGC activities have a lack of the components of counseling. This is because these activities have not been 
performed or coordinated by individuals/experts who have the professional credentials to work with or counsel others such as individual student or groups of students about experience related to educational and career choices. The next section will explain some of these issues in detail.

\section{Issues and Problems Regarding Vietnamese Students' Academic and Career}

\section{Choices}

While Vietnam needs more highly qualified human resources to meet the national goals of industrialization, modernization, and globalization (Bodewig, et al., 2014), limited research on Vietnamese high school students' educational and career choices has been conducted. Overall, research by Bodewig, et al., (2014), Do (2009), La (2007), and Nguyen (2011), has found that Vietnamese high school students have encountered difficulties in their academic and career choices due to the lack of secondary education information, lack of activities to explore their interests and capabilities, and a lack of support from professional guidance and counseling school staff. First, Vietnamese youth, including high school students, have suffered from a lack of information regarding their potential future employment and school choices after graduation (Bodewig, et al., 2014;

Do, 2009; La, 2007; Nguyen, 2011). Particularly, Nguyen's (2011) findings showed that 123 students (about 55\%) out of 223 students in three high schools in Ho Chi Minh City indicated they had a lack of post-secondary education information. Over $48 \%$ indicated they needed more information regarding different majors that higher education institutions offered and jobs and skills employers were seeking (Nguyen, 2011).

Similarly, Do's (2009) research showed many limitations in providing students with information about post-secondary education options and careers in the society. 
About half the student participants in Do's (2009) study indicated that career-oriented activities at their schools focused on providing information regarding programs at college, university, and vocational institutions and how to apply. The study findings also showed that six high schools in the study spent nearly $58 \%$ of content in their careeroriented activities introducing different careers in the society and nearly $50 \%$ for teaching strategies to take high school graduation and university entrance exam. Only $36 \%$ of the content of the current ACGC activities was to introduce the labor market and its demands. In short, while high school students may need to have work experience at real workplaces as well as be aware of labor trends and requirements for their interest careers, Vietnamese high schools have not offered appropriate opportunities to meet these students' needs.

Second, the lack of activities helping high school students explore their interests and capabilities has led to a mismatch between the supply of qualified students and demand of the labor market; a mismatch between students' majors and their interests; and the domination of a certain gender in some fields. In particular, the study by Nguyen (2011) found less than $2 \%$ of the student participants in her study made decisions to attend vocational institutions compared to over $82 \%$ who chose to go to colleges and universities. "Many youths still follow the traditional trend of going to college or university to study law, finance, and banking" for the potential to earn higher wages (La, 2009, p. 57). Consequently, with the majority of students who graduate high school attending academic colleges (over 99\%) and a limited number (nearly 1\%) of students attending vocational centers/ institutions (MOET, 2007), the number of people qualified 
only for the professional and higher-skilled brain labor market opportunities far exceeds the number of available skilled manual workers (Bodewig, et al., 2014).

Moreover, existing ACGC activities for high school students have seemed not to have changed the domination of a certain gender in some jobs in society. Bodewig, et al. (2014) showed there are substantial differences in the choice of fields of study for males and females who continue to post-secondary education. Males are more likely to study administration, IT, science, and crafts while females have a trend to pursue Business, Education, and Health. For example, more than $68 \%$ of females study business in comparison with about $31 \%$ males in the same field. Conversely, the numbers of males who study IT and science was 3.5 times higher than for females who chose to study in the same fields. This refers to a discrepancy among applicants at different types of work in the market, resulting in the unemployment of certain numbers of undergraduate and graduate students, which likely affects Vietnam's economic development.

Next, the lack of professional career guidance staff at most Vietnamese high schools and vocational centers outside schools has contributed to a situation where a number of high school students have found it hard to identify anyone who can provide them with academic and career advising (Do, 2009; Nguyen, 2011). Indeed, up to 88\% of student participants in the study by Nguyen (2011) indicated that no particular school staff including head teachers did anything to help these students get knowledge and experience to explore careers. In a study with about 240 student participants including 10, 11, and 12th graders at six high schools in Hanoi, Ho Chi Minh, and Da Nang, the three biggest cities in Vietnam, Do (2009) gave two explanations for the lack of professional guidance and counseling staff at schools. First individual schools do not have funding to 
recruit a professional ACGC expert. Second, limited numbers of universities have offered ACGC training courses for their students in Vietnam.

As a result of the lack of ACGC staff in and outside schools in Vietnam, findings from Nguyen (2011) showed 70\% of student participants indicated that they learn information about careers from the Internet; up to $60 \%$ from their parents and relatives; and nearly 47\% learn about careers from their head teachers. Do (2009) added many students are not concerned about whether they could find a job after high school graduation or whether careers associated with their majors would be suitable for them. As a result, designing and developing new ACGC activities and recruiting professional guidance and counseling staff at Vietnamese high schools will be a strategy or solution to aid students in the process of exploring careers and their own interests. Overall, findings from both Do (2009) and Nguyen (2011) found that a great number of high school students make decisions regarding their future academic and career based on their parents' expectations and suggestions rather than considering their own interests and aptitude.

In short, research on Vietnamese students' academic and career choices after high school by La (2007), Do (2009), Nguyen (2011), and Bodewig, et al., (2014) show Vietnamese high school students have been struggling with how to navigate their future plans. Specifically, these scholars have emphasized there is a need to provide additional ACGC activities for Vietnamese high school students, because they can avoid secondary education mismatch and find jobs and careers that best fit them. In Vietnam, school leaders are supposed to implement ACGC activities for their students (MOET, 2003; MOET, 2014), thus, it is necessary to learn about their leadership in school in order to be 
able to get an awareness of potential factors which may influence teaching and learning process about careers.

\section{Vietnamese Principals’ Leadership}

Over the past 20 years, studies on school leadership have been well conducted in developed countries (Hallinger et al., 2015; Walker \& Hallinger, 2015). However, in Asia and Vietnam in particular, the effect of school leadership as well as the impact of principals' leadership on teaching and learning processes have not been well explored due to limitations regarding scope, depth, and quality in recent research (Hallinger \& Bryant, 2013; Hallinger et al., 2015; Hallinger \& Truong, 2014). One example of these limitations provided by Hallingers et al (2015) was "the literature on school leadership in Vietnam has been conducted predominately in Vietnamese language, by Master's degree students working in Vietnamese institutions, and published in domestic Vietnamese journals where quality standards remain rather weak" (p. 224). As a result, due to the lack of strong research in the area of school leadership in Vietnam, there is an increasing demand for new research in the area in order to better identify and validate how current principal leadership practices impact students' learning outcomes. In addition, Vietnam and Vietnam's education system need more research to help make necessary changes in the educational system as well as to encourage the active participation of Vietnamese educators to meet students' needs as well as national economic goals, especially in response to the the growing influence of globalization.

The following sections will focus on contextual factors such as the political and cultural factors which shape three main areas of Vietnamese school leaders' responsibilities 1) principal's roles in implementation 2) Vietnamese principalship with 
political factors, and 3) principal leadership practices with cultural factors. Being aware of these three areas will help explicate what principal leadership styles and practices look like, how leaders organize and implement teaching and learning activities, and how these styles and practices may impact educational outcomes for students.

\section{Principals' Role in Implementation}

In this section, I use "Street-level bureaucracy" by Michael Lipsky (1980) as the theoretical concept to explain how Vietnamese principals organize and implement teaching and learning activities at their school in a top-down approach. Indeed, in a Vietnamese political context where "education is a centralised and highly controlled function of the State" (Hallinger \& Truong, 2014, p.47), Vietnamese principals often follow what they are assigned to do, making it difficult to make important decisions to change or create new initiatives without the direct guidance or decisions from MOET or local governments.

In particular, according to Article 14 in Vietnam's 2005 Education Law, educational management in Vietnam is a top-down approach where most aspects of Vietnamese education, including educational goals, programs, content, educational plans, teachers' standards, and examinations, are under the control of the State or the central government, particularly the Central Committee and the Politburo of the Communist Party of Vietnam (CPV). Based on guidelines and agendas promulgated by the government, MOET and its departments formulate and adopt educational policies or instructions and guidance on curriculum and other educational issues in order to help principals of all levels at the street level to organize and implement various teaching and learning activities (Doan, 2005). Basically, although there are certain responsibilities and 
expectations for Vietnamese high school principals, that is to implement all teaching and learning activities at school as precisely as possible based on related guidelines and instructions by the higher authorities, as street-level bureaucrats, they are still able to adapt the policy at his/her can spot by utilizing discretion and autonomy (Lipsky, 1980). This discretion and autonomy opens a way for border crossing educators to make extra efforts to push above and beyond policy ideas to offer better learning opportunities for their students.

Similarly, in terms of career guidance for high school students, the Central Committee and the Politburo of CPV, which is the top governmental authority, made the decision No.126 in 1981 to set the agenda and expectations. Then, MOET is responsible for formulating related guidelines and instructions to help school leaders organize and implement the four career-related activities assigned, which were discussed in some sections above in this chapter. However, research by Do (2009), Bodewig, et al., (2014), La (2007), and Nguyen (2011) showed the ineffectiveness of these activities on academic and career development of students. As the primary person responsible for organizing, implementing, and assessing these activities, Vietnamese high school principals can utilize their discretions and autonomy as street-level bureaucrats (Lipsky, 1980) in order to offer new ACGC activities to their students for the development and achievement of students as well as the national goals. However, there is no literature conducted on the perceptions of Vietnamese high school principals for preparing students for further education and careers and using ACGC activities, and how they would be able to go above and beyond their assigned responsibilities in order to implement these activities while there are many obstacles preventing them doing these activities. 


\section{The Vietnamese Principalship with Political Factors}

According to a study by Walker and Hallinger (2015) on principal leadership in East Asia, understanding the political factors in educational management in Vietnam greatly helps explain behaviors of a Vietnamese principal including what a person does and why he/she does it. In particular, like in China, the State selects and promotes principals (Hallinger \& Truong, 2014; Qian \& Walker, 2011), and the local governments remain the major assessors of principals' work $(\mathrm{Gu}, 2011)$. Therefore, as government officers and party members, Vietnamese principals frequently play managerial and political roles rather than instructional roles (Hallinger \& Truong, 2014; Walker et al., 2012). Indeed, a Vietnamese high school principal is responsible for monitoring and implementing all activities, including the four existing career-related activities for their students and other policies, in a precise way based on MOET's related instructions. As a result, with their managerial role, Vietnamese principals make sure to operate learning and teaching activities including the existing career-related activities as smoothly as they are expected. Additionally, it seems that Vietnamese principals with the managerial principalship style may not think and know much about new quality learning opportunities for students and may not make additional efforts to improve their capabilities and qualifications in order to create those opportunies.

Many research studies on professionalizing the principalship have been done in particular countries in Asia including Singapore and Hong Kong, part of China. For example, since the mid-1990s, Singapore systematically established and refined necessary in- and pre-service preparation such as mentorship programs in order to train successful new principals (cited in Walker \& Hallinger, 2015). The Hong Kong literature 
focused on developing and designing a new leadership competency framework for the school system in order to describe knowledge, strategic thinking skills, and values which principals need to possess in order to make successful school improvement (cited from Walker \& Hallinger. 2015). However, there is a less attention paid on professionalizing principalships or pre-service preparation programs that might provide Vietnamese principals with the necessary knowledge and skills to enhance their professional development like training to lead the design and implementation of ACGC activities at their schools.

\section{Principal Leadership Practices with Cultural Factors}

While political factors help discribe principals' managerial and instructional roles in Vietnam, cultural factors help explain how the country's social norms and values influence principal practices regarding assessing student learning outcomes and organizational decision making (Hallinger \& Truong, 2014). In particular, leadership practices of principals are greatly influenced by Chinese Confucian ideology (Hallinger et al., 2017) where assessing students' learning outcomes is based on examinations and making organizational decisions relys on higher superiors.

In terms of assessing students' learning outcomes, Hallinger et al. (2017) evaluated 27 primary school principal participants from urban area and rural areas of Vietnam for their perceptions of their instructional roles. Most principals monitored student progress by assessing their learning results through academic competitions and national examinations. Hallinger et al. (2017) found that "most principals affirmed the importance of obtaining "certificates of merit," individual student prizes in academic competitions, as essential for their school to be evaluated as "successful" (p.228). 
Focusing on testing and high grades strongly reflect the influence of Chinese Confucian philosophy on Vietnamese education as well as Vietnamese culture for many centuries (Hallinger et al., 2015; Hallinger et al., 2017; Truong et al., 2017; Walker \& Hallinger, 2015). Moreover, most of these principal participants recognized the significance of communicating their school targets to all stakeholders which are framed or influenced by directives coming from higher authorities such as MOET, local departments of education and training, and the People's Committee.

Similarly, it seems that teachers and school leaders avoid decision making regarding the process of learning and teaching, but make sure they have agreement on how to implement daily teaching and learning activities. Hallinger et al., (2017) found instructional leadership as a universal phenomenon that comprises leadership practices that involve the planning, evaluation, co-ordination and the improvement of teaching and learning; however, Vietnamese principals in the study mainly manage curriculum and instruction instead of other activities. Indeed, the leaders in Hallinger et al.(2017)'s study focused on conducting teaching observations and inspection-centered supervision, monitoring teaching portfolios, and ensure the national curriculum and related policy reforms are implemented in order to meet the school's approved targets. This laissez-faire leadership style, which may be applied to many Vietnamese principals, is quite similar to principals' styles in Hong Kong, Taiwan, China and many other Asian countries (Walker \& Hallinger, 2015).

However, despite many principals' absolute obedience to their superiors in the study by Hallinger et al. (2017), which reflects the influence of Confucian values and norms in many Vietnamese people's perspectives, principals in the study were willing to 
offer necessary support to their teachers' professional development. For example, these principals encouraged their teachers and staff to participate in short training courses by providing a flexible teaching schedule (Hallinger et al., 2017).

In short, due to a centralized educational system and the embedment of Chinese Confucian ideology in Vietnamese society, Vietnamese principals in studies by Hallinger (2011), Hallinger and Heck (1998 \& 2002), Hallinger et al., (2017), Hallinger and Truong (2014), Walker and Hallinger (2015) are viewed as taking more managerial leadership roles rather than instructional roles. Leaders spend more time making sure daily school operations are implemented rather than spending time with teachers and other school staff creating necessary changes for their school improvement. Thus, Vietnamese reformers and educational policy-makers may need to make more effort and offer support to school leaders in order to boost related educational reforms which support necessary changes in the organization of the current educational system as well as empower street-level bureaucrats (Lipsky, 1980) in order to boost the reforms for the development and success of students.

\section{ACGC Activities in the United States}

Due to the lack of the variety of ACGC activities, as well as school counseling programs, and literature specific to Vietnam, in this section I will provide a brief overview of ACGC activities in the U.S. where program development has made significant progress. This section includes three sub-sections: A Brief History of ACGC Activities, Mission and Goals, and Activities Associated with ACGC Activities. The purpose of this section is to explain what ACGC activities are and how significant they are, and what it will look like in the U.S. There is potential for high schools in Vietnam to 
look at and learn to first design and develop ACGC activities in Vietnam according to individual schools' contexts. Moreover, this section provides information regarding findings of U.S. research on ACGC activities.

\section{A Brief Overview of the Development of ACGC Activities}

A brief overview of the development of ACGC activities is necessary, because some of the many efforts to establish and develop such activities in the U.S may be transferrable/adapted to Vietnam's context; however, Vietnamese educational leaders will need to evaluate and adapt these models in order to meet needs of the educational system as well as the condition of individual schools. A major step in U.S education was the passage of The Carl D. Perkins Vocational and Applied Technology Education Amendments of 1998. This policy provided support for ACGC activities in U.S. schools, especially for middle and high school students who participate in vocational education programs that focus on three domain areas: academic, career, and personal/social developments (ASCA, 2003; OCTAE, 2017). From the early 2000s to the present, school counseling, including ACGC activities, has been both an integral part and an independent component of the total school program (Gysber \& Henderson, 1988; Cobia \& Henderson, 2003; Gallant \& Zhao, 2011). America's Career Resource Network, including The American School Counselor Association (ASCA), authorized by the Perkins Act, is responsible for providing school administrators, teachers, parents, and especially school counselors with necessary support that includes professional development, publications, research, and other resources to assist students in the three domains above in order to achieve success in school and to become responsible members of society (CSCA, 2004; 
OCTAE, 2017). However, such national policy to establish, manage and development ACGC activities has not been available in Vietnam.

Currently, a newer bill in the Senate to reauthorize the Carl D. Perkins Career and Technical Education Act, known as "Career and Technical Education Act of 2016" was voted to approve in September 2016 (Ujifusa, 2017). Overall, this act is meant to strengthen ACGC activities at schools across the states related to funding, requirements

of the total to complement a single career and technical education program, the reduction in paperwork related to CTE at schools and some others (Ujifusa, 2017). This passage is a sign of continued efforts in this country to support the movement of CTE as well as ACGC activities in the United States.

\section{Mission and Goals of ACGC Activities}

Types of ACGC activities and their focuses are different (ASCA, 2003); however, overall, ACGC activities share the same mission and goals. According to the U.S Office of Career, Technical, and Adult Education (OCTAE) (OCTAE, 2017), the mission and goals of ACGC activities are follows:

to help students make more informed and better educational and career choices. Among other things, activities offer information on high school course offerings, career options, the type of academic and occupational training needed to succeed in the workplace, and postsecondary opportunities that are associated with their field of interest. These activities also often provide teachers, administrators, and parents with the information they can use to support ' career exploration and postsecondary educational opportunities of students. 
Although the mission and goals of ACGC activities are well communicated, research is not consistent with U.S high school students' outcomes.

\section{Research on U.S. High School Students' Outcomes in ACGC Activities}

Research in Vietnam from scholars La (2007), Do (2009), Nguyen (2011) and Bodewig, et al. (2014) has emphasized the importance of developing ACGC activities for Vietnamese students but that the implementation of these activities is ineffectives. This section shows why these activities may be beneficial in terms of improving Vietnamese students' academic and career development by looking at research on students' outcome in the United States.

Academic Development. Regarding academic development, there is increasing evidence that school counseling activities have a positive influences on the grades and academic achievement of U.S students. First of all, students who participate in careerrelated courses are likely to earn higher scores in subjects such as Writing, Math, Reading, and Science (Lapan, et al., 1997; Lapan, et al.,1993; Frone, 2001; Kaufman, et al., 2000). In a study by Lapan, et al.(1993) on a guidance activity at a suburban midwestern high school, the researchers found that for both honors and non-honors-level female students, all166 student participants in the study were likely to earn higher English grades in the result of participating in the activity. Moreover, two studies by Frone (2001) and Kaufman, et al. (2000) on high school seniors in High Schools That Work (HSTW), a comprehensive school-reform initiative that included technical and academic coursework in 1996 and 1998, found positive results in terms of academic counseling. Particularly, there were a increase in teachers' usage of academic skills to complete vocational assignments, teachers' best instructional practices, the numbers of 
students taking mathematics and science class, and these students' overall achievement. Frone (2001) analyzed the achievement of career-bound students from 393 high schools "who [planned] to work, attend a two-year technical or community college, enroll in a four-year college or university with an open admission policy or enter the military after high school graduation" (p. 5). Frone examined students' outcomes in their academic courses and modem career/technical studies. He found that more than $50 \%$ of the student participants met the HSTW goal for the mathematics (59\%), science (55\%), and reading (53\%) in the achievement tests in 1998. These results were 5-10\% higher than those in 1996. Similarly, a study by Kaufman, et al. (2000) showed that students at 424 schools who talked with counselors and teachers about their academic concerns were likely to earn 4 to 13 points higher in the means of Science, Math, and Reading on test scores in comparison to students who did not talk with counselors and teachers.

Moreover, other studies have found that students who spend time talking with guidance staff, school counselors, or vocational teachers are likely to receive more assistance in choosing and scheduling their high school courses and the post-secondary application process. As the result, students who spend time talking to staff and counselors may be more likely to take more college-prep math and science classes (Frome $\&$ Dunham, 2002). Additionally, according to the National Center for Education Statistics (NCES) guidance survey, Parsad et al., (2003) showed that public high schools that have implemented a variety of guidance activities, such as exploratory work experience programs, career days/nights, speakers in class, field trips to higher education institutions or organizations, short-term job experience, guidance/counseling sessions, and 
workshops, provided better assistance to their students regarding their course choices and their post-secondary application.

Career Development. Like the positive findings on students' academic development at activities with ACGC, findings by scholars like Lapan, et al. (1993), Lapan, Gysber, and Sun (1997), Levesque, et al. (2008), McWhirter, Rasheed, and Crothers (2000), Olive and Spokane (1988), Savickas (1990), O’Hara (2000), Wiston et al. (2007), and Whiston, Sexton, and Lasoff (1998) have shown the positive influence of career guidance activities on high school students' career development. First, students in ACGC activities are more likely to develop their future career plans than those who are not participating in career courses. Indeed, in the report by Levesque, et al. (2008) on 11 national surveys from NCES on career and technical education during the period from 1990 through 2005 at high schools across the U.S. researchers found that, as of 2002, most public high schools reported that $90 \%$ of their students had developed a career plan which identified what careers they might be interested in after graduating high school. This likely led to the students' better future preparation after high school graduation. Additionally, $86 \%$ of the students had already selected a career major or pathway during high school. Similarly, in a previously mentioned study by Lapan, Gysbers, Hughey, and Arni (1993) on a guidance activity with 166 honors and non-honors juniors students, 96\% of boys and $97 \%$ of girls agreed that they have at least some particular plans such as job opportunities, training programs, college, or vocational schools after graduation. A few years later, Whiston, Sexton and Lasoff (1998) and O'Hara (2000) reported the same results. That is, high school students could improve career planning when they completed 
computer programs (Whiston, Sexton \& Lasoff, 1998) or career courses or careerdecision making courses (O’Hara, 2000).

While students have received more assistance to develop their future career plans, they are more likely to gain the understanding of additional jobs/careers traditionally held by men and female participants start seeing them as options for them too. Lapan et al. (1993) showed that more than $63 \%$ t of male students and up to more than $70 \%$ of female students in the guidance unit got a better insight on the significance of women' participation in many jobs/careers. Specifically, nearly $80 \%$ of female students understood their opportunities to enter careers traditionally held by men. These positive findings may bring practical experiences for school leaders at the high school level who may be interested in implementing good ACGC activities in order to help female students, in particular, have more future academic and career choices after high school.

Third, student participants in guidance activities are likely to have more college and career information. In the study on the relationship between comprehensive guidance programs and the school experiences of 22,964 students at 236 Missouri high schools by Lapan, Gysbers, and Sun (1997), researchers found that male students and nonminority students reported that they felt that there was more career information available after they participated in guidance activities at their schools. Similarly, the findings by Lapan, Gysbers, Hughey, and Arni (1993) showed that more than 70\% of boys and girls reported that their guidance unit provided them with knowledge about various colleges and their offerings, how to choose colleges and how colleges and certain majors are related. Although the study did not show any evidence about the increasing number of students went to college, with better skills and knowledge about post-secondary education, student 
participants were likely able to make a better career or academic decision after their high school graduation.

Next, students who have participated in ACGC activities also gain other careerrelated skills. For example, a meta-analysis by Olive and Spokane (1988) found that career interventions have a great impact on junior high school students' career decisionmaking skills, careers-related adjustment. Moreover, understanding of the relationship between the present and the future were motivated to achieve long-term goals in a study by Savickas (1990) and vocational skills, self-efficacy, and career-related tasks in another study by McWhirter, Rasheed, and Crothers (2000) were statistically significant.

In short, there has been a strong evidence over time from a body of the literature on the positive impact of ACGC activities on high school student participants. Students in these activities likely have the capability to earn higher scores in Math, Science, Reading, and Writing and to make better choices in course enrollment. Additionally, these students are more likely to consider the relationship between gender and career choice and to apply decision-making skills to identify a specific future path. However, all of the studies noted above emphasized collaboration among school counselors, teachers, family, and communities as a contributing factor in the overall success of ACGC activities.

Although students at the high school level could gain advantages from participating in ACGC activities, some research by Schneider and Stevenson (1999), National Center for Education Statistics (NCES) (2001) and NCES (2002) showed the limitations of ACGC activities. That is, many young people do not develop coherent and realistic plans for their future careers (Schneider \& Stevenson, 1999). Up to two-thirds of high school graduates enter college immediately after graduating; and, among these 
students, the drop-out rate is more than one-third within two years (NCES, 2001; NCES, 2002). Moreover, according to the 2002 survey by NCES, only $8 \%$ of high schools reported that their most emphasized guidance goal was helping students plan and prepare for their school-to-work transition.

There are also certain limitations in the studies mentioned above. First of all, more research has focused on career guidance interventions than those on academic counseling. For example, the study by Frone (2001) was done to evaluate academic and career counseling as a comprehensive counseling program; however, this study focused on vocational focused students. Second, according to Hughes and Karp (2004), some types of interventions such as career guidance and computer-assisted career guidance were "a short-term, low-dosage activity" (p.17), thus, researchers found difficulties in assessing long-term benefits to these group of students. Hughes and Karp (2004) have also explained what makes evaluating the effectiveness of career courses more difficult, which is that even in the same courses, students' outcomes can vary due to the differences in teacher quality or classroom atmosphere at different school settings. Thus, there is a need to have more research on ACGC interventions in other countries including Vietnam to provide a bigger picture about the effectiveness of ACGC activities on the outcomes of high school students.

\section{Activities Associated with ACGC Activities}

Types of ACGC activities are various at U.S high schools; however, there are some types of ACGC which may be relevant to Vietnamese context in terms of career guidance and counseling. These types may include advising students and their parents on optional academic activities, preparing them for college application and admission, 
informing students about postsecondary education choices and available postsecondary financing, assist students with developing career portfolios including student records, student work, resumes, and cover letters to future employers (OCTAE, 2017). OCTAE (2017) also suggests to do ACGC activities, U.S high schools sponsor job skills and personal development related activities such as workshops, classes, and focus group and offer students work experience options at a real workplace in order to explore their potential areas of interest as well as their own capability. Moreover, U.S high schools provide personal counseling and intervention services to all students (OCTAE, 2017).

\section{Theoretical Framework}

In this study, I utilize border crossing theory as the main theoretical framework to explore what Vietnamese high school principals think ACGC activities as preparing students for their future academic and career paths, and their openness to these activities. Because ACGC activities are quite new to many school leaders as well as high schools, based on the border crossing theory, my assumption is that if principals know well about these activities but have not implemented these activities, these principals are likely potential border crossers if they are interested in implementing these activities in the future. Moreover, if principals know well about ACGC activities and are implementing some kinds of ACGC activities at their schools, they are likely to border crossers; border crossing (BC) principals may also be those who are able to challenge many barriers and go above and beyond policy and assigned responsibilities and expectations to implement ACGC activities as an attempt to provide quality educational opportunities for their students. Concurrently, border crossing theory is also applied to help understand what 
challenges BC principals face in the design and implementation of those ACGC activities.

The concept of the borderlands was first used by Gloria Anzaldúa in her book Borderlands/La Frontera: The New Mestiza in 1987. According to Anzaldúa (1987), "the Borderland is a vague and undetermined place created by the emotional residue of an unnatural boundary. It is in a constant state of transition. The prohibited and forbidden are its inhabitants" (p.7). More specifically, the Borderlands, according to Anzaldúa (1987), was produced by feelings of social and linguistic marginalization and unwelcomeness that immigrant students, like herself, suffered due to living in the borderlands. These borderlands are created by the differences in values, religion, traditions, and skin color, power, and privileges from the dominate group or institutions (Anzaldúa, 2007). There are multiple borders which she faced, including gender, race, ethnicity, language, gender, sexuality, power, privilege, and geography. However, by simultaneously challenging social expectations and accepted mores regarding the borders above and then putting them back against the oppressors, Anzaldúa managed to cross her own borderlands, which led to the recreation of her personal identity.

The concepts of borders and borderlands in this study did not emphasized the experiences of marginalized women who are born with the two cultures as those of Anzaldúa (1987) were which; however, the concepts of borders and borderlands in this study and those of Anzaldúa (1987) seemed to be a bit similar because these concepts refer to literal, figurative, psychological, and metaphorical barriers. Specifically, according to border crossing theory, the concept of borders in my study is unnatural boundaries and a metaphor that refers to obstacles/barriers regarding the Vietnamese 
traditional managerial principalship, power dynamics in the structure of the education system. These barriers prevent Vietnamese school principals from acting as BC principals who are able to move beyond the guideline on the implementation of the four existing career-oriented activities and push beyond their responsibility for just being an officer and manager. The borderlands where $\mathrm{BC}$ principals are living and working is "a stage of transition" (Anzaldúa, 1987, p7) and stages of exploration and transformation (Wilson \& Douglas, 2013) where these BC principals confront many obstacles. In the Vietnamese school context, crossing borders includes questioning the four career-oriented activities, leaving Vietnamese traditional principals behind, and being aware of power balances for every stakeholders including school, family, and the community, and being open and willing to implement ACGC activities to get students well prepared for their future academic and career paths. The use of BC in this study sticks with the expansion of border crossing theory by Wilson and Douglas (2013), which focuses on experience of these students' educators who act as pivotal agent to improve quality learning opportunities for students. Specifically, the borderlands in this study emphasis the experience of $\mathrm{BC}$ educators who must have a keen fight to get rid of what is familiar and comfortable with many other educators or leaders in order to put their feet into a new space which enables the BC educators make differentials in their students' learning outcomes. Although putting their feet into a new space is likely not easy for all educators, $\mathrm{BC}$ educators are willing to do it for the development and achievement of students while other educators are not. 


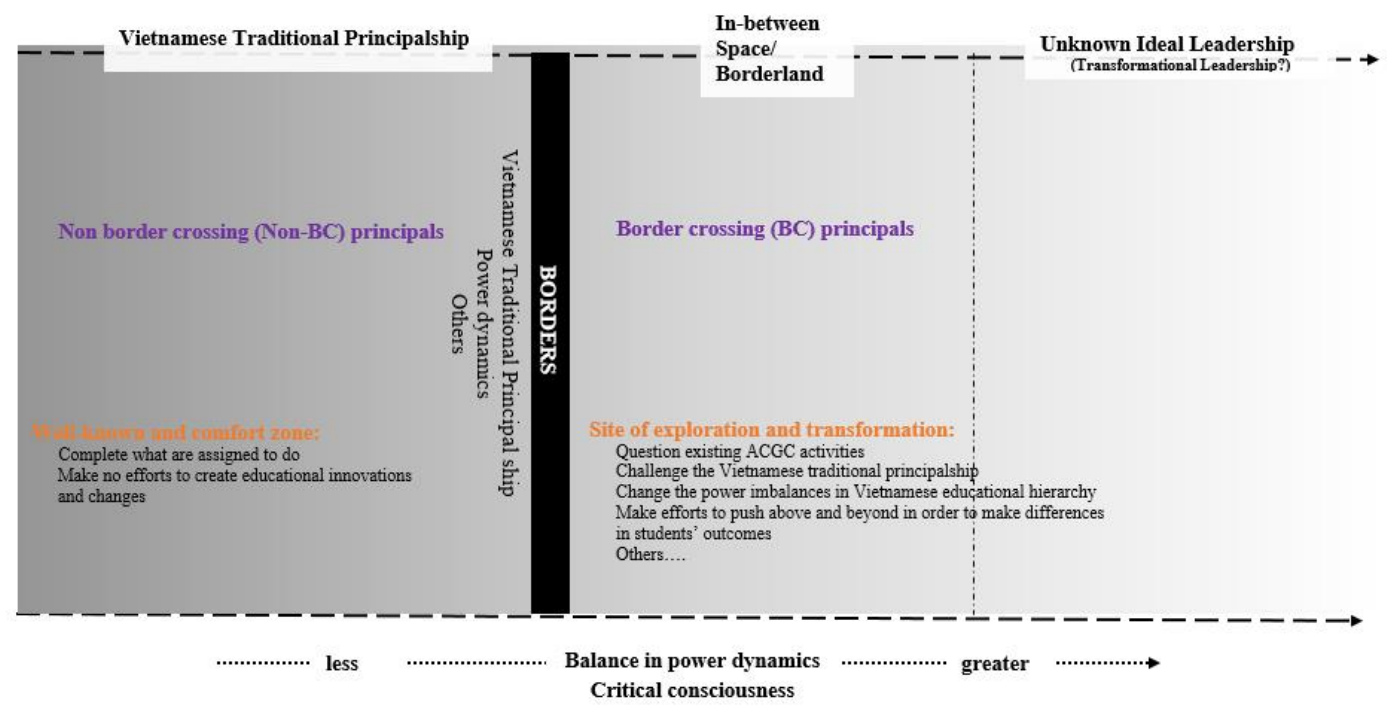

Figure 2: The Virtualization of the Borders in This Study

\section{Border Crossing Theory}

Understanding of the concept of the borderlands and how some scholars adapt and apply it into their study brings me better insight into what border crossing theory is. Specifically, many scholars like Giroux (1992), Luz Reyes and Garza (2005), Lopez, et al., 2006, Douglas and Peck (2013), Douglas (2013), and Wilson and Douglas (2013) have utilized the concept of the borderlands and border crossing in their research, which contributed to the establishment and expansion of a new theory, named border crossing theory. Particularly, while Anzaldúa (1987) mainly focused on conceiving the crossing of Borderlands as the process of transformation where immigrant students navigate different ways to salvage and affirm their identity, Wilson and Douglas (2013) and other scholars applied border crossing to explain and encourage critical educators' efforts to push beyond their comfort and privileged zones to gain what is necessary to help students raise critical consciousness of social justice and its related issues, termed border leadership, and enact a commitment to educational equity by creating transformative learning 
opportunities, also known as border pedagogy, for all students. To do that, the implication from the study of Wilson and Douglas (2013) was that these educators must have an ability as well as a vision to push beyond institutional dynamics, think outside of the box to transform and inspire students including students from a low socioeconomic status background who may not get same access to resources, and encourage their parents, other educators, individuals, and organizations in the community to assist in the process.

Border Leadership. According to Douglas and Peck (2013), Lopez et al., (2006), Garza (2007), Douglas (2013), Wilson and Douglas (2013), and Goldstein (2016), border leadership is the ability and the process where educational leaders work across the national context to prepare themselves with necessary knowledge and skills to better support quality border crossing educational opportunities, called border pedagogy strategies, for students' needs and development. Border leadership is emphasized as "a moral imperative for educators to cross borders ... in a distinct way through which they exist comfortable and privileged zones to better understand, engage and justly serve diverse students" (Wilson \& Douglas, 2013, p. 2). First of all, in order to have a good awareness of the national context, a leader with border leadership needs to make a number of efforts to give themselves have opportunities to really look and emerge into other cultures, challenge power and privilege, and question testing and accountability pressures (Garza, 2007; Lopez et al., 2006). One example of border crossing efforts by leaders from Graza (2007) was to “join[ed] Border Pedagogy’s group of visionary educators from schools on both sides of the U.S./Mexico border" (p.2) to learn about their educational experience with borderland students. 
Educational leaders with border leadership act as "a host of other cultural frontiers" (Lopez et al., 2006, p.65), and encourage other educators to ask for collaborative opportunities (Graza, 2007). These collaborative opportunities among BC educators can attract and encourage other educators and their immigrant students to talk about their own life experience and discuss social justice issues of social class, race, gender or religion in classroom and border crossing events (Douglas, 2013; Douglas \& Peck, 2013; Garza, 2007; Wilson \& Douglass, 2013). In short, having an ability to push beyond institutional dymamics and prepare themselve with necessary knowledge and skills to better facilitate students's future development and achievement, to inspire students and other educators in the process of helping students and themselve have critical consciousness of institution dymamics, power, and privilege as well as establishing and implementing border pedagogical practices is crucial. Similarly, I envision Vietnamese high school principals with border leadership push beyond their traditional principalship and practices and work beyond their current national educational context to think about what is needed to help students prepare for their transition from high school to post-secondary education or career and think about if ACGC activities are valuable to help the students in the transition.

Border Pedagogy. In addition to border leadership, educational border crossers are committed to supporting and implementing border pedagogy strategies for the development and achievement of their students. While Garza (2007), Douglas and Peck (2013), Douglas (2013), Wilson and Douglas (2013), and Goldstein (2016) have focused on discussions about border pedagogy, which refers to the educational methods and practices educators create to meet their students' needs, and its positive results on diverse 
students. Garza (2007) shared his pedagogical practices in an article, Becoming a Border Pedagogy Educator: Rooting Practice in Paradox, saying that using border pedagogy can provide both White students and students of color with richer multicultural knowledge of social justice issues and is related to their future work as future educators. In particular, these border pedagogical practices include discussing students' daily experience as borderland inhabitants, talking with educators from the other side of the border, and writing reflections on these experiences. By sharing deeply, listening to each other as well as challenging social justice issues such as challenging institution dynamic, dominant, identity, privilege, inclusion, exclusion, and social class etc., in border crossing pedagogy practices, the students, especially White students, get a deep understanding of cross-cultural and national experiences, which allow them to "explore and revise their own thinking about multicultural educational issues" (Garza, 2007, p.5). More importantly, such border crossing experiences can become valuable resources and assets to help all students develop their future teaching practice as educators.

Similarly, Douglas (2013) and Goldstein (2016) offer border pedagogy where students are offered opportunities to think about and learn about immigrant students, their daily issues regarding racism and social justice, including priviledge and dynamics and their related issues, in their classroom and life. Particularly, in the work by Douglas (2013), he shared his own border pegadogy strategies where he as critical educators is able to navigate his own identity and future goals as a effective way to teach college students about race. In the essay by Goldstein (2016) where he decribed using performed ethnography to explore the notion of border crossing in courses called "Equity and Activism in Education, some of his students reflected in their writings about feelings of 
empowerment when learning a new language and understanding what others are saying. Through the course, students learned about the internalization of dominant white culture by some immigrant students who are the first generation or came from other countries at very early ages. Students in the course also learned about the difficulties that some immigrant students at the border face to pursue their own religious beliefs which are different from their parents as well as their community. Some immigrant students realized that the journey "to reach back in order to move forward" (p.15) is the way to navigate their life goals when going back to their home countries to serve their communities. More importantly, the study showed that the need of efforts to help students and other educators get to know what difficulties students with different backgrounds meet as a strategy not only to help these students overcome their own difficulties but also help them achieve in their future paths.

In short, by learning from other educators' experience, seeking collaborative opportunities with other educators, critical educators with border leadership are able to create border pedagogy practices at their classrooms to help students gained many precious lessons and border crossing experiences such as challenging power dynamic and identity for the achievement of all students and their future endeavors in education.

\section{A New Application of Border Crossing Theory}

In this study, I borrow and adapt the application of the border crossing theory from Wilson and Douglas (2013) and take from my constructivist approach so that the concept of border crossing in this study includes the extraordinary efforts leaders make to overcome barriers and obstacles in order to create and implement new educational practices for the benefit of their students. Education in Vietnam is a centralized and 
highly structured system and principals act as school managers in the system. Principals often are expected to merely organize and implement teaching and learning process they are assigned to and likely see many potential challenges when making necessary changes for students' needs. In this study, I used border crossing theory as a different lens to look for Vietnamese high school principals as border crossers, called BC principals, who are able to think out of the box, and make educational innovations and changes, particularly in creating new ACGC activities in an effort to help students be prepared for their further education and careers. Border crossing theory enables me to explore the experiences as well as the extraordinary efforts $\mathrm{BC}$ educators could make to overcome barriers to provide their students with quality learning opportunities. Unlike the BC principals, non$\mathrm{BC}$ principals are not be able to have good awareness of quality learning opportunities and not willing or unable to overcome barriers they may perceive or face to create those learning opportunities for students. In particular, interpreted from the previous research by Giroux (1992), Luz Reyes and Garza (2005), Lopez, et al., 2006, Douglas and Peck (2013), Douglas (2013), and Wilson and Douglas (2013), I expect high school principals who are $\mathrm{BC}$ principals to push beyond the Vietnamese traditional principalship as educational managers, challenge the power dynamics in Vietnamese educational hierarchy, Vietnamese BC principals are willing to do what is needed to help students prepare for their future paths. Specifically, one potential way is by learning about new ACGC activities, being open with them, overcoming impediments and obstacles in the Vietnamese school context, and making use of available resources they can perceive, they are likely to only just implement the four existing career-oriented acitivites, but to to adapt, develop and implement new ACGC activities (border pedagogy strategy) for their 
students' future academic and career development. Moreover, in doing that, these BC principals are likely able to inspire students and other educators and others in the community to support ACGC activities (border leadership). As a result, these BC pricipals will likely be able to greatly contribute to necessary renovations and changes to make a difference in their students' academic and career development and achievement as well as increase critical conciousness of not only themselves, but others including educators, parents, individuals and organizations in the community. 


\section{CHAPTER 3: RESEARCH DESIGN AND METHODOLOGY}

In this chapter, I go into detail about this qualitative research design using case study methodology and Grounded theory methods in order to get the above goals of my study. To reiterate, this study asked the following research questions: 1) What are urban and suburban Vietnamese school principals' perceptions of ACGC activities they have in their schools and how they perceive new ACGC activities? 2) What challenges do these principals face in the design and implementation of ACGC activities?, and 3) How do these principals sustain their ability to implement ACGC activities?

\section{Research Design}

In this study, I used a qualitative research design. The reason was that qualitative research seeks to understand a given research problem by exploring the perspectives/experience of the local population it involves, which then allows the researcher to understand how the population's perceptions and experience influence their behavior (Creswell, 2003; Merriam, 1998; Stake, 1995). In particular, this study sought to understand Vietnamese high school leaders' perceptions of ACGC activities and what they think about helping students prepare for their transition from high school to postsecondary education or career. Additionally, because "How" and "What" questions are the most suitable for qualitative case study research to explore what can be specifically learned from participants in each case (Merriam, 1998; Stake, 2006; Yin 2013), this study also sought to explore how these principals' perceptions of preparing students for further education and career and their perceptions of ACGC activities affected difficulties these principals perceive or face in designing and implementing these activities at their schools. It would be difficult to capture people's experiences, ways of thinking, and 
behaviors (Merriam, 1998; Yin, 2013) with quantitative research which often tries to quantify an problem.

\section{Methodology}

In this study, I used a qualitative case study methodology. According to Merriam (1998), a case study is "an intensive, holistic description and analysis of a bounded phenomenon such as a program, an institution, a person, a process, or a social unit" ( $\mathrm{p}$. xiii), and the case is identified in a bounded system (Merriam, 1998; Stake 2006; Yin, 2013). In my study, the case involves Vietnamese high school principals embedded in urban or suburban high schools in Hanoi, Vietnam where they are working (Merriam, 1998). The unit of analysis is individual principal. Choosing a case study design was appropriate, because it allowed me to explore participants' perceptions of ACGC activities as a strategy to help students have a better preparation for their further education and career and the difficulties and advantages they perceived in the design and implementation of ACGC activities in their school context. The reason I chose the high school level is that the high school is the last chance for students to obtain necessary knowledge and skills for their transition to the post-secondary level or career (Noguera \& Wing, 2006).

I also choose exploratory case study methodology for this study, because this is the first time I as the researcher have an approach to learn and explore what Vietnamese high school principals think is needed to prepare students for their transition from high school to post-secondary education or career. This kind of case study helps provide an understanding (Merrian, 1998) of participants' efforts regarding border leadership and border pedagogy and helps explain border crossing theory which I interpreted from some 
previous research by Wilson and Douglas (2013) and other scholars. I borrow and adapt border crossing theory by Wilson and Douglas (2013) and apply it to explore if Vietnamese high school principals in the study are active or potential border crossers. I define border crossing principals as those who overcome barriers in the Vietnamese school contexts and go above and beyond their responsibilities and expectations in order to provide students with additional ACGC activities in order to prepare students for future academic and career paths.

\section{Research Context}

Hanoi, the capital of Vietnam, was my research context. Hanoi is growing in population and increases in private and foreign sector investments and some other areas such as commercial, tourism, and transportation increased in comparison to 2015 (GSO, $2011 \& 2016)$. In particular, Hanoi is the largest city by area $(3328.9 \mathrm{~km} 2)$ and the second-biggest city by population (6.699.600 people) (GSO, 2011). According to the 2016 report on the socioeconomic status of Hanoi, the city's economy in the year kept growing in comparison to 2015 (GSO, 2016) with the gross regional domestic product (GRDP) increasing to more than 8. Particularly, the service sector increased to more than $8 \%$, which had the highest contribution of nearly $5 \%$ of the total increase in the GRDP (GSO, 2011). Moreover, construction-industry sectors and agriculture-forestry sectors also increased $9 \%$ and a bit more than $2 \%$ in turn (GSO, 2011). In terms of investment capital, it was estimated that the capital/equity, mainly from the national budget that was used to invest in Hanoi, was 277.950 billion VND (more than \$12 billion) (GSO, 2011). Also in 2016, Hanoi attracted 445 new projects gathering $\$ 2.8$ billion in foreign capital. (GSO, 2011). 
The primary reason for choosing Hanoi as the research context was because Hanoi is the center of education where MOET is located and where innovation and changes most likely happen first before expanding to other areas. Thus, Hanoi is the opportunity for people including principals, community leaders, institution leaders, teachers, and parents to be engaged in border crossing. Moreover, Hanoi has the highest number of vocational institutions, colleges, universities, and businesses compared with other cities or provinces across Vietnam. There are 27 vocational colleges, 58 vocational high school, 67 universities offering vocational programs, and hundreds of vocational center across Hanoi (MOET, 2016). Thus, high school principals likely find potential resources, including human, infrastructure, and funding to start designing and implementing ACGC activities or to develop ACGC activities they already have for their students. The collaboration and utilization of ACGC activities is imperative, especially where ACGC activities are most likely to be developed first at big cities including Hanoi in Vietnam in the near future according to one of the educational goals the Vietnamese government proposed for the ongoing educational reform which focuses on developing ACGC activities to get students well prepared for their transition to post-secondary education or career (Party Secretary, Nguyen Phu Trong, 2013).

\section{Site Selection}

The specific research sites where I collected data were 11 high and low achieving urban and suburban high schools with different types of schoolings, such as public, private, specialized, and international schools in Hanoi. These 11 school sites were purposively selected because of their positive reputation for their ACGC activities. In Vietnam, there has not been a specific standard to assess or rank high schools with a 
good reputation on their ACGC activities. However, in this study, I assumed these schools with a good reputation for their ACGC activities are the ones where I could to find new ACGC activities rather than or in addition to the four existing career-oriented activities. The primary reason I chose these schools as my research sites was their school leaders were potential border crossers who likely had experiences in building and developing or supporting ACGC activities. I was able to explore what challenges they faced and how they could sustain their ability to implement these activities in the light of the border crossing theory. With 11 high schools of different types of schooling at both urban and suburban areas in Hanoi where my participants come from, I was able to have opportunities to recruit (potential) BC principals and to collect rich data from interviews with the participants.

\section{Participants and Sampling Technique}

I originally planned to seek a range of 10 to 15 Vietnamese high school principals working at both high and low performing urban and suburban high schools with a positive reputation for ACGC activities for their students in Hanoi to participate in this study. However, the final total for my participants was 11 . I determined these participants included seven non-BC principals and four $\mathrm{BC}$ principals (More explannation for defining "BC" will be found later in this chapter). The table below provides demographic data about these participants and their schools.

Table 1. Participants and School Demographics

\begin{tabular}{|c|c|c|c|c|c|}
\hline $\begin{array}{l}\mathrm{BC} / \\
\text { Non-BC }\end{array}$ & $\begin{array}{l}\text { Pseud } \\
\text { onym }\end{array}$ & $\begin{array}{c}\text { Years in } \\
\text { Teachers/ } \\
\text { Staff } \\
\text { Role }\end{array}$ & $\begin{array}{l}\text { Years } \\
\text { in } \\
\text { Admini } \\
\text { strative } \\
\text { Role }\end{array}$ & School Type & Area \\
\hline & Mon & 7 & 20 & Private & Urban \\
\hline
\end{tabular}




\begin{tabular}{|c|c|c|c|c|c|}
\hline \multirow{6}{*}{$\begin{array}{l}7 \text { Non-BC } \\
\text { Principals }\end{array}$} & $\mathrm{Na}$ & 13 & 7 & Private & Urban \\
\hline & Fin & 8 & 21 & $\begin{array}{l}\text { Public Special } \\
\text { Education }\end{array}$ & Suburban \\
\hline & Ben & 6 & 22 & Private & Urban \\
\hline & Bach & 10 & 10 & Public & Suburban \\
\hline & Han & 8 & 20 & Public & Suburban \\
\hline & Long & 8 & 29 & Public & Suburban \\
\hline \multirow{4}{*}{$\begin{array}{l}4 \mathrm{BC} \\
\text { Principals }\end{array}$} & Phan & 13 & 20 & Private & Urban \\
\hline & Anh & 14 & 5 & $\begin{array}{c}\text { Public for Gifted } \\
\text { Students }\end{array}$ & Urban \\
\hline & Fon & 7 & 40 & $\begin{array}{c}\text { Private Special } \\
\text { Education }\end{array}$ & Urban \\
\hline & Hen & 7 & 30 & International & Urban \\
\hline
\end{tabular}

The primary reason I chose principals as the unit of analysis for this study is that they are potential border crossers who are interested in ACGC activities or implementing these activities for their students. Moreover, choosing principals as my research participants rather than others is appropriate because principals are the primary school personnel responsible for managing and implementing career-oriented activities for their students (MOET, 2003; MOET, 2014; MOET, 2018b). As a result, they could likely share critical information for my study.

In terms of sampling strategy, I used purposeful sampling and snowball sampling techniques in this study. Particularly, in terms of purposeful sampling, my research participants were the ones whose schools have positive/good reputations for ACGC activities or extra-curriculum for their students. As I mentioned earlier, the more positive reputations for ACGC activities or extra-curriculum their schools have, the more likely it is that their school leaders are potential border crossers who are well implementing ACGC activities or may be interested in implementing new AGGC activities for their students. 
In terms of snowball sampling, I invited four principals whom I know from my time in Vietnam to participate in my study and asked them to assist me, the researcher, in identifying other potential principals who meet my criteria above, that was those principals who are working at positive reputations for ACGC activities or extracurriculum for their students. One of the four was my middle school teacher, and the other three are my father's former colleagues and friends. The reason I chose these principals I already have an association with was, because these participants trusted me and shared their experiences, including negative ones, which were related to questions I raised in interviews. All of these principals agreed to participated in this study and helped me identify the remaining participants. Using the snowball sampling was necessary to identify potential border crossing principals as well as to explore their experiences in building and implementing ACGC activities for their students.

\section{Data Collection Stages}

My process of data collection had two stages that lasted from May to July 2018. My process of data collection included stage 1 with interview 1 and stage 2 with scenarios followed by interview 2 with each of the participants (see Figure 3 above). For data collection, my decisions regarding the two stages were purposively made in order to help me explore what Vietnamese principals did to prepare students for their transition from high school to post-secondary education or career (stage 1) and to examine if they were active or potential border crossers who view ACGC as valuable activities and try to implement these activities for the academic and career development of their students (stage 2). I describe below specifically what stage 1 and 2 looked like, the time frame, and what purposes of each stage was as follows: 


\section{Stage 1- Interview 1}

At stage 1 of my data collection, I conducted semi-structured interview 1 with each of my participants. The purpose of the stage 1 , interview 1 was to get to know the participant, their background and school context, to explore what they thought about what to do to prepare their students for their transition after high school and the range of activities their school offers. Each interview lasted for 60 to 120 minutes at their school, an appropriate time for both the interviewee and me as the interviewer and researcher (See Appendix A: Stage 1-Interview 1). All interviews were audio recorded for later transcription. As result of stage 1, what my participants said and did to help their students be prepared for their transition gave me a direction for the scenarios at stage 2; for example, the number of new ACGC activities and how detail they were when I introduced them. For example, if I determined that a principal just tried to implement the four existing activities as best as they can, I introduced as many new ACGC activities as I could (three to four), because they might need to learn more about these activities, then think about difficulties they would face if they design and implement them. In contrast, if they were potential BC principals, I introduced one or two new ACGC activities, then spent more time to learn about their difficulties and strategies they used to design and implement their ACGC activities. After each interview 1, I wrote field notes and memos as part of ongoing collection and to start analysis.

\section{Stage 2- Scenarios and Interview 2}

At stage 2 of my data collection, I combined scenarios and interview 2 (Appendix B) with each participant in one session. The sessions were audio recorded for later transcription. While stage 1 primarily focused on getting to know what Vietnamese 
principal participants thought and did to prepare students for their further education and career, stage 2 looked for going beyond their expectation and responsibilities based on the border crossing theory in order to open to additional ACGC activities as well as to insist in implementing them. Particularly, at the beginning of stage 2, I provided each of my participants with a nearly-30-minute scenarios (Appendix B) where I introduced twoto-four ACGC activities I thought the participants could adapt to the Vietnamese school context. The number of ACGC activities introduced in each scenario was flexible based on each principal's perception of ACGC activities during the first stage as well as their openness and interest. For example, in interview 1, if my participant was very openminded, I introduced all four ACGC activities I had in my scenarios, whereas if they were not interested in new ACGC activities, I introduced less than four. In another case, if a principal was able to talk about many good ACGC activities they were implementing for their students, I also introduced two or even one ACGC activities in order to spend more time for interview 2 where I could explore what challenges or opportunities they perceived and had while implementing ACGC activities for students. By doing this, I was also be able to have a deeper understanding of how their process was to become active border crosser. Making the scenarios or introducing ACGC activities to the participants was significant for some reasons. First, at stage 1, if my participants did not know any about ACGC activities, my scenarios at stage 2 provided them with opportunity to learn about such activities. Then, it allowed me to get these principals' perception of ACGC activities as a good strategy to help their students' academic and career development. Second, interview 1 and the scenarios at stage 2 helped my principal participants think about what they could do to prepare students student for further education and career 
especially when these principals did not have opportunities to have training in ACGC activities as well as how to do it. As a result of in the scenarios, participants were able to give better answers to questions regarding what difficulties and advantages they perceive in designing and implementing such activities in the interview 2 right after the scenarios. All of what my participants said and did above allow me to examine their willingness to act as border crossers or their potential to be $\mathrm{BC}$ principals.

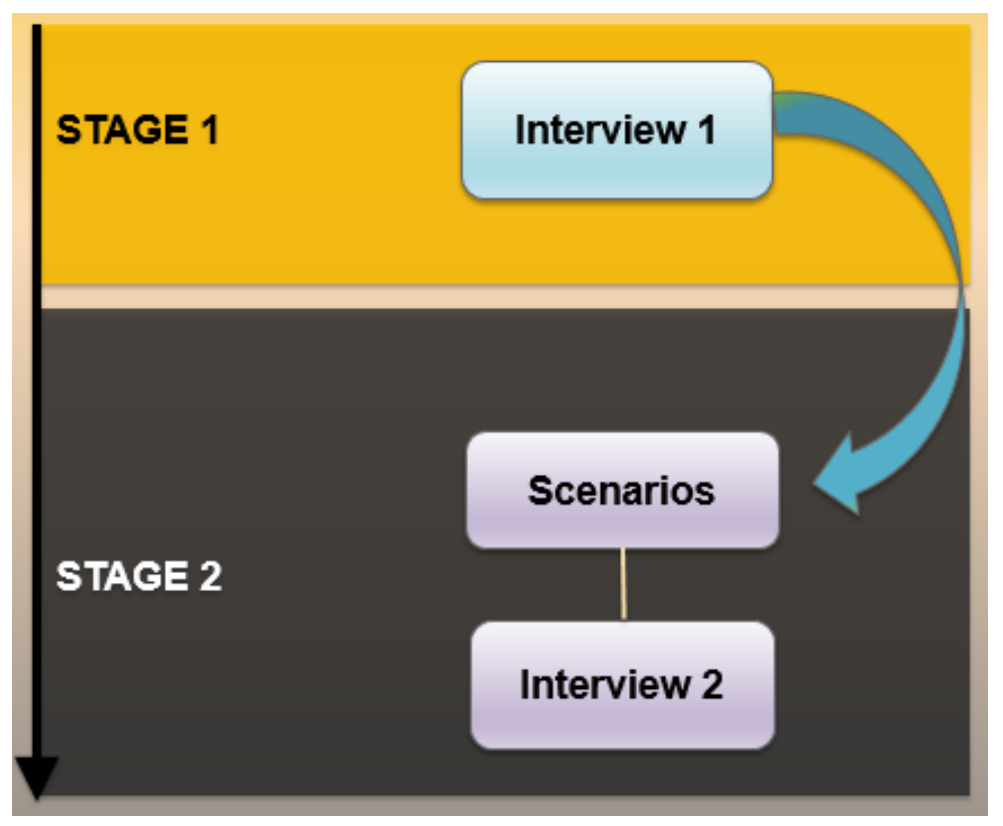

Figure 3. Data Collection Stages

Consequently, after the scenarios, I conducted interview 2 (Appendix B) with each of my participants. Interview 2 lasted about 60 to 120 minutes with an attempt to further explore what my participants think about ACGC activities and their perceptions of opportunities as well as potential challenges to adaptation if they wanted to start implementing these activities. More specifically, while questions in interview 1 in stage 1 looked for the overall understanding of my participants' background, range of ACGC activities they may have, their perceptions of ACGC activities and their roles in such activities, numbers of ACGC activities in the scenarios and questions of interview 2 at 
stage 2 were designed to look for the participants' willingness to become border crossers or what difficulties (border crossing) principals face and how they overcame obstacles to implement ACGC activities at their schools. Moreover, writing memos and field notes were also done before, during, and after the interview 2 .

\section{Data Sources}

My primary data for the research came in two forms, including individual interviews with the participants, career guidance and academic achievement-related documents or data issued by the government and MOET. The two forms of data above in the study were collected and analyzed and were part of an ongoing process to collate the results accurately as well as to confirm the shared experience among the participants.

\section{Interviews}

There were two semi-structured interviews with each of my participants. Each interview lasted between 60 minutes to 120 minutes at participants' schools and were recorded and transcribed for the purpose of data analysis. Most of my interview questions were open-ended ones, meaning I did not expect yes or no and right or wrong answers but "intended to elicit views and opinions from the participants" (Creswell, 2007, p181).

The interview protocol can be viewed in Appendices A and B. Particularly, in interview 1 with the participants, I was able to get basic information about my participants such as their educational background, school context, ACGC activities they are implementing, what they might think is necessary to prepare students for their future paths. Interviews 2 was an opportunity for me to explore what my participants knew about ACGC activities and what were their perceptions of difficulties and advantages in implementing ACGC activities. Furthermore, implementing the two interviews was the way to examine their 
willingness to become border crossers. During and after my interviews, I wrote memos and field notes as a part of the ongoing data analysis. These memos and field notes contained both descriptive information (e.g., my participants' gestures and behaviors, etc.) and reflective information (e.g., my thoughts, questions, comments, etc.) which I saw and got during their interviews, but was unable to get by only reading interview transcripts.

\section{Documents}

In addition to interviews with my participants, I collected data from career guidance instructions issued by MOET and my participants' individual schools, and/or school websites in order to get a deeper understanding of which ACGC activities their schools were expected, then see what my participants said and did not say in my interviews. I also wanted to examine if my participants were just implementing activities which they are assigned to or going beyond them as they indicated to me in the two interviews. With these kind of documents, I had a better understanding of whether or not my participants just got the main ideas from these documents to implement the four career-oriented activities or they were so creative to make a difference, that was implementing additional ACGC activities, as they shared with me during the interviews. Basically, while interviews provided me opportunities to have what they said, documents and observation helped me to confirm what they said.

Collecting documents also provided me with ideas to make better questions for my participants for additional information or clarifications during their interviews as well as helped me have evidence or references while giving necessary analysis after the interviews. Moreover, in order to choose my research sites, I gathered documents which 
show information regarding the schools' academic achievement and the educational outcome in career-oriented activities from the local Department of Education and Training. These kinds of data can also view as good references for my data collection and analysis later.

\section{Data Analysis}

\section{Grounded Theory Strategy}

Like data collection, data analysis was an ongoing process where analyzing transcripts, reviewing related documents, and analyzing my analytical field notes and memos after the interviews occurred at the same time. During data collection, I focused on looking at potential instances of border crossing during the two stages of the data collection in order to answer my research questions. Specifically, in the process, I defined "BC" through my data and in course of answering the research question two, I learned about answers for the research questions three. Using grounded theory methods in qualitative case study research as my analytical strategy allowed me as the researcher to know what procedure and techniques I needed to apply to collect data for my study (Merriam, 1998), as well as to collect rich information in order to answer my research questions. Grounded theory analytic strategies involved coding steps I used in order to look for the refinement and correlation of categories of information (Charmaz, 2006; Strauss \& Corbin, 1990). With grounded theory strategies, researchers are able to compare data with emerging categories and utilizes different individual case(s) to maximize the similarities and the differences of information (Creswell, 2005). In short, for ground theory, I analyzed in an iterative process, working among the data, theory, and methods. 


\section{Use of Theoretical Framework to Guide Data Analysis}

Use of theoretical framework was concurrent with what stage or type of analysis I had below in the section of the analytical process. I use this section to better show how the theoretical framework help guide my data analysis. Particularly, in response to the stage 1 , I was able to get a sense of the principals and their background and how they viewed education or administration broadly, and their role in preparing students for their future academic and career paths in order to in order to answer my research question one. The purpose of stage 1 data collection seemed to not sound like principals are guided by the border crossing theory, however, they actually did. There was a potential for learning or seeing about $\mathrm{BC}$ experience in stage 1. For example, when asked about what they did to prepare students for their future path at stage 1 , if a participant knew about ACGC activities and actually was implementing one or some ACGC activities at their schools, I was able to identify if they are (potential) BC principals and was able to find data to not only answer my questions about their perception of ACGC activities but also see their efforts in terms of border leadership and border pedagogy practices they made to implement such activities for their students. So in terms of border crossing theory, I was able to determine whether principals were going beyond their state expectations to prepare students for more future academic and career options. Or, if they knew or did not know about ACGC activities and did not have any for these activities at their school, border crossing theory helped me make a decision on what questions I asked these potential non-BC principalsat the next stage of my data collection in order to explore their non-BC experience. 
Particularly, aligned with the stage 2 of my data collection, my data analysis was an ongoing process where I made decisions on how many ACGC activities I needed to make in the scenarios (Appendix B) with each of my participants and how I chose my questions to ask during the interview 2 with my participants based on the border crossing theory. Furthermore, based on the theoretical frameworks of border crossing theory, I looked for the willingness or experience in $\mathrm{BC}$ of my participants to overcome impediments and learn about strategies they used in order to design and implement ACGC activities for their students. My participants' responses, which explained the border leadership and border pedagogy strategies they used to over come challenges in the design and implementation of ACGC activities in order to help students be prepared for their further education and career, enabled me as the researcher to explore their BC experiences regarding pushing beyond their managerial principalship. Whereas, if a participant contended learning opportunities as ACGC activities were not valuable at the previous stage and revealed that they were unable to overcome the difficulties they perceived or faced and also unable to use effective strategies to design and develop ACGC activities in this stage, I could get better understanding of their experiences as non-BC principals.

\section{Analytical Process}

While border crossing theory helped guide my data analysis, the process of data analysis primarily contained five basic following steps adapted from Creswell (2007) and Saldana (2009) with the assistance of Dedoose, an online qualitative analysis tool. Before the coding process, I gathered all of the data I had, including transcripts, documents, and memos and field notes; I organized them, read through all data while connecting back to my theoretical framework and my research questions in order to have an overall 
impression of my principals' responses in my interviews and have their demographic information and others ready for the coding process. Indeed, after uploading all interview transcripts to Dedoose, I spent time inserting the description for each transcript such as pseudonyms, school type, gender, and the duration time of tenure as a teacher and principal. Then, I read through the transcripts multiple times in order to recall my memories and thoughts, as well as help connect them to my memos and field notes during and after my interviews. For example, in response to stage 1 of the data collection, I was able to get the overall impressions of the principals' backgrounds and thoughts about preparing students for their future educational and career paths.

Step 1: Initial Coding and Open Coding. According to Saldana (2009), a code is "most often a word or short phrase that symbolically assigns a summative, salient, essence-capturing, and/or evocative attribute for a portion of language-based or visual data" (p.3). To have a code, Creswell (2007), refers to a coding process where a researcher "take[s] data or pictures gathered during data collection, segmenting sentences (paragraphs) or images into categories, and labeling those categories with a term" (p. 186). This was also the reason I spent time reading through each transcript multiple times in every step of my data analysis. In particular, I critically read a transcript, then developed a list of codes (parent codes) which were on the basis of emerging information collected from the participants and predetermined based on my research questions, interview guide, and theoretical framework. Basically, developing codes only on the basis of emerging information or "first impression" phrases from open-ended process (Saldana, 2009) refers to initial coding while developing predetermined or more focused codes refer to open coding (Creswell, 2007; Saldana, 2009). In this step, the initial coding 
included information about demographic information, years of administrative experience, range of activities they had implemented at schools while open coding will emerge from my sense of my participants' perception of ACGC activities, their descriptions of ACGC activities they knew, these activities' effectiveness or not, my participants' openness, challenges, and experience in border crossing. In particular, after multiple times of reading one transcript, I created a list of parent codes as a result of initial coding and open coding as follows:

Table 2. Examples of Parent Codes

\begin{tabular}{|c|c|c|}
\hline \multirow{10}{*}{ Parent codes } & \multirow{5}{*}{ Initial coding } & Educational background \\
\hline & & Administrative experience \\
\hline & & School's context \\
\hline & & Range of existing career-oriented activities at school \\
\hline & & what they look like \\
\hline & \multirow{5}{*}{ Open coding } & BC principals' view of ACGC \\
\hline & & Non-BC principals' view of ACGC \\
\hline & & BC principals' perceptions of challenges \\
\hline & & Non-BC principals' perceptions of challenges \\
\hline & & Non-BC's strategies \\
\hline
\end{tabular}

After having a list of parent codes, I critically read through the transcript, related documents and my memos and field notes again and highlighted important portions of the transcripts including words, sentences, or even paragraph, which was called as "excerpts" in Dedoose, also known as initial codes or open codes, by answering the questions like , 
What was this about? Based on these excerpts' topics, I added these excerpts to the relevant parent codes I already created. With the assistance of Dedoose, all excerpts under the same parent code titles were highlighted in the same colors in systematic ways in this transcript and all of others transcripts. Also, with the assistance of Dedoose, I found it easy to reorganize, remove, and even add excerpts in and across transcripts under my parent codes or remove one or more than one parent code where there was no or a few excerpts from them in order to see similarities and differences for the purpose of themes and category making later. Also in this step, I was able to figure out potential outliners while comparing data in and across cases with emerging categories (Creswell, 2005). Similarly, based on the topics of excerpts or groups of excerpts under different parent codes, I was able to develop, change, or create a few new parent codes merging from the data and have relevant excerpts added to these new parent codes (Creswell, 2007). For example, after this step, I had a parent code and several excerpts as follows:

Table 3. Examples of a Parent Code and Relevant Excerpts

\begin{tabular}{|c|c|}
\hline $\begin{array}{l}\text { Parent } \\
\text { code }\end{array}$ & BC principals' strategies \\
\hline \multirow[t]{6}{*}{ Excerpts } & $\begin{array}{l}\text { I have spent a lot of time to provide professional development opportunities } \\
\text { for them ... (Fon) }\end{array}$ \\
\hline & $\begin{array}{l}\text { I've organized professional development activities for them [the } \\
\text { teachers]...(Hen) }\end{array}$ \\
\hline & Teachers need to enhance their professional lives non-stop .....(Phan) \\
\hline & $\begin{array}{l}\text { Although I have a lot of work, I have participated in seminars at many } \\
\text { classes.... (Phan) }\end{array}$ \\
\hline & $\begin{array}{l}\text { I have collaborated with a number of state or international banks to be able } \\
\text { to organize field trips for the students ... (Hen) }\end{array}$ \\
\hline & $\begin{array}{l}\text { I invited her to come and provide professional development training for my } \\
\text { teachers for a week .......... (Fon) }\end{array}$ \\
\hline
\end{tabular}


\begin{tabular}{|l|l|}
\hline I had to deliver demo sessions for them, the head teacher...(Fon)
\end{tabular}

Step 2: Category-Making. In order to make categories, I needed to organize, link, group, regroup similarly coded data/ excerpts in and across cases of the participants into categories or patterns in order to consolidate meaning and compare excerpts under the parent codes (Creswell, 2007; Grbich, 2007, Saldana, 2009, Yin, 2009). To do that, I exported all of the excerpts I had in Dedoose into an Excel chart, titled "Chart Combined Excerpts". With the chart, I easily saw groups of all excerpts under their relevant parent codes and refine data or categories while seeing their interrelationships, then generate category titles, as known as child codes in Dedoose. The child codes were less general than parent codes but also captured bigger similar topics of many excerpts. For example, based on the table of step 2, I was able to create child code 1 and 2 as the following table: Table 4. Examples of Child Codes

\begin{tabular}{|c|c|}
\hline $\begin{array}{l}\text { Parent } \\
\text { code }\end{array}$ & BC principals' strategies \\
\hline \multirow[t]{5}{*}{$\begin{array}{l}\text { Child code } \\
1\end{array}$} & $\begin{array}{l}\text { Getting Professional Development Opportunities for Teachers and Other } \\
\text { Staff }\end{array}$ \\
\hline & $\begin{array}{l}\text { I've organized professional development activities for them [the } \\
\text { teachers]...(Hen) }\end{array}$ \\
\hline & Teachers need to enhance their professional lives non-stop...(Phan) \\
\hline & $\begin{array}{l}\text { I invited her to come and provide professional development training for my } \\
\text { teachers for a week ... (Fon) }\end{array}$ \\
\hline & $\begin{array}{l}\text { I have spent a lot of time to provide professional development opportunities } \\
\text { for them ... (Fon) }\end{array}$ \\
\hline \multirow{2}{*}{$\begin{array}{l}\text { Child code } \\
2\end{array}$} & Directly Getting Involved in Designing and Implementing ACGC \\
\hline & $\begin{array}{l}\text { Although I have a lot of work, I have participated in seminars at many } \\
\text { classes...(Phan) }\end{array}$ \\
\hline
\end{tabular}




\begin{tabular}{|l|l|}
\hline & $\begin{array}{l}\text { I have collaborated with a number of state or international banks to be able } \\
\text { to organize field trips for the students ... (Hen) }\end{array}$ \\
\hline
\end{tabular}

It was easy to see that all excerpts regarding teacher professional development were grouped under their category or child code 1, titled "Getting Professional Development Opportunities for Teachers and Other Staff'. The topic of this child code is relevant to its parent code of "BC principals' strategies". There was the same to child code 2.

In some cases, I needed to recode and categorize excerpts under the same child code to generate subcategories or great child codes in order to capture smaller topics. According to Saldana (2009), the process of generating subcategories is similar to the process of recoding and recategorizing where my codes and categories are expected to become more refined (p.10).

Step 3: Theme Generating. At this step, I critically read categories or subcategories and used my theoretical framework to generate a small number of themes/detailed descriptions in the interrelationships of a case and/or across cases of my study. A theme is "an outcome of coding, categorization, and analytic reflection, not something that is, in itself, coded" (Saldana, 2009, p,13) and "a phrase or sentence describing more subtle and tacit processes” (Rossman \& Rallis, 2003, p. 282). An example of a theme I can based on step 3 is: The BC principals as instructional leaders. This theme was used as a major finding of this study (Creswell, 2007).

Step 4: Findings. This critical step was the place where I provide larger ideas or pictures for the study by making a personal interpretation or meaning of the data (Creswell, 2007). In particular, I interconnected the themes I had from step 4 and looked back to my theoretical frameworks while asking the question "What was the lessons 
learned?" in order to provide good findings for the study (Creswell, 2007, p. 189). Also in this step, I used the theoretical framework as the border crossing theory and the findings to form an implication which might be useful for potential principals who are looking for strategies or guideline to go above and beyond their assigned responsibilities by higher authorities to create new ACGC activities for the academic and career development of their students.

\section{Trustworthiness and Reliability}

Efforts to increase trustworthiness in qualitative research are significant to enhance the richness of data as well as the quality of findings of the research (Lincoln \& Guba, 1985). Thus, I use several strategies to ensure trustworthiness as well as avoid bias in my study. First, prior to their participation, I provided potential participants basic information about my study in the consent form in order to get them know about my expectations as well as the purposes of the study. That is, I was interested in learning about how they think about preparing students for careers or further education.

Moreover, although there may be concerns about the richness of data due to my snowball sampling strategy in this study, I found these strategies brought specific advantages. Indeed, as mentioned earlier, being a daughter of their colleagues, I may find building rapport and trust with my participants easier. With the association, my participants were likely willing to provide their honest responses during interviews especially some educational issues involving Vietnamese educators' professional ethics have been attracting the attention of media and the society.

In order to provide a thick description, I explained clearly about my chose of my research context, my process of data collection including multiple stages and data sources 
in order to get deeper understanding of my participants' perceptions of ACGC activities as well as challenge and opportunities they perceive in order to prepare students for their future academic and career paths. In my interviews with the participants, I made interview questions to understand my participants' educational background, administrative experience, experience in border crossing, etc. in order to help better explain and explore their perceptions of ACGC activities as a way as a way of achieving a type of external validity (Lincoln and Guba (1985). As a result, readers are able to know whether or not they can transfer my findings and implications to their locations.

During the process of data collection and data analysis, I kept reminding myself that I was only the researcher who sought to explore and understand my participants' perceptions on ACGC activities and challenges and opportunities in implementing such activities, not an expert in the area like I shared in the section on my positionality. Thus, during the data collection and analysis, I tried to avoid showing my experiences in providing career and academic advising for high school students, certain knowledge in how to implement ACGC activities or ask biased questions to lead my participants' answers.

Furthermore, collecting data from multiple sources, known as triangulation, including interviews, artifacts, and double-checking with the participants for interpretations, known as member check, after my findings or claims were other important ways I used in order to assure the validity of research and reduce possible bias in this qualitative research (Charmaz, 2006; Strauss \& Corbin, 1990). In addition, I used peer-check by asking one of some of my peers to take coding-blind tests within Dedoose 
for inter-rater reliability to minimize possible bias from my positionality and reflexivity (Charmaz, 2006; Strauss \& Corbin, 1990).

\section{Research Ethics}

The IRB process was done in the beginning of May, 2018. Once I obtained the approval, I started inviting potential participants and ask them for their consent. Because this study was an international one, the consent forms were written in my participants' native language, Vietnamese, in order to best explain to them the purpose of my research, its risk, and benefits. I wascommitted to conducting an ethical research where my participants' participation was confidential and voluntary. Although I was committed to collecting data for merely the purposes of this study, in the consent forms, I emphasized clearly that all personal information, including names, educational background, and school names, and career guidance related documents issued by their schools, kept pseudonyms and confidential in order to protect them from potential risks which they may concern. Moreover, in order to encourage my potential participants to participate and simultanously build their trust in this study, I as the researcher let my participants know that I was a daughter of their colleagues and I used my snowball sampling strategy, where I seek my potential participants from those I already have association and ask them for their introduction with other potentials. It was significant because some Vietnamese teachers and school leaders' serious derogations had been exhibited by the media and attracted a lot of attention over the past few years, which might increase the possibility where my potential participants refused to participate my study to avoid potential troubles. Moreover, my participants' signatures were not required in this study in order to keep their participation confidential as well as avoid their potential concerns about any 
minimal risk of harm when participating in this study. In terms of data protection, prior to data analysis, all forms of data, including interview recordings, related documents, and notes, were stored in my password protected computer for 7 years after the completion of this study according to university policy. I as the researcher had passed Collaborative Institutional Training Initiative (CITI program) to make sure I have a deep understanding of the protection of the subjects in this research.

\section{Positionality}

My family background and my educational experience in life have a big influence on my positionality. First of all, my family background shapes who I am because I was raised in a family with a strong tradition of working in the educational system. Most of my relatives, as well as my parents, work as educators and have shared a lot about their first-hand experiences at school with me. However, my father has inspired me the most in my choice of educational paths. His contributions to the betterment of our community in Vietnam helped develop my perspective and my point of view on the importance of educators as border crossers and good learning opportunities.

In his twenty-eight years as a middle school principal, my father, an exemplar border crosser, has continued to demonstrate how important his efforts were to make the difference in student achievement. For example, in 1995 when technology in general and computers, in particular, were new to most Vietnamese people as well as educators and students, my father successfully persuaded the local department of Education and Training to supply his school with ten computers which he hoped would improve the teaching and learning process. Due to the lack of technological knowledge among teachers at the time, my father searched for and found computer manual books and taught 
himself about computers and their applications. After that, he taught the teachers in his school how to use the computers and encouraged them to apply technology to their teaching. I remember exactly how excited we as students were in class when our teachers showed us new things with the assistance of the computers. As of 1995, as a 6th grader, I had no idea how lucky we were as students to have these computers until I went to college. Actually, these ten computers out of the twenty available across the entire school system at the same time really impacted my learning. Most of my college peers only started learning how to use computers to create documents for their first time while I was able to apply a lot of other functions of the computer in order to improve the quality of my assignments. His effort not only affected his students at school but also the development of our community.

Another example was that as of 2000, my father was successful in encouraging some teachers to have some night classes and help all of the drop-out and over-schoolage students from our community complete the middle school level. While the nation was still facing a lot of difficulties in helping students across the country complete the elementary school level, what my father and other teachers did helped make a positive difference in many people's lives. Because of the two examples above and many other opportunities I have had to listen, observe, and ask my father about educational issues, I started to learn how an educator, especially a school leader, may impact school improvement, students' lives, and society.

While opportunities to listen, observe, learn a lot from experience of my father, a great educational border crosser, inspired me and nurtured my passions for being a great educational leader, my identity and experience in life later has also greatly influence my 
research interest on students' academic and career development as well as the role of school leaders in facilitating students' academic and career achievements. As I mentioned earlier in this study, my first experience regarding ACGC was the difficulties regarding the lack of school personnel for guidance and counseling as well as the lack of careerrelated activities at my school where I as a high schooler encountered when I had to make the decision for my future educational and career path after the graduation. Looking back at my time as an a self-employed academic and career advisor working with more than 300 Vietnamese high school students, I am a border crosser, both an insider and outsider, and am able to see the significance of small effort by educators that can guide high schoolers, like I experienced a few years ago, to assist students in getting better prepared for their transition from high school to post-secondary or other routes. I highly appreciated the support from the school leaders who allowed me to actively create and develop academic and career sessions for their students. Being first a student and later as a self-employed academic and career advisor who had particular experience with ACGC activities, I have remained interested in exploring high school principals' experiences in how to build and develop ACGC activities for Vietnamese students. All of my early experiences with ACGC contributes as one of the main reasons I decided to choose Vietnamese high school principals as my research participants in this study.

However, my time studying in the United States for a Master's degree in Learning, Teaching, and Curriculum, and then a doctoral degree in PreK-12 administration and policy helped me the most in developing the necessary knowledge and skills in order to do my research on ACGC activities. First of all, a few years ago I had an opportunity to do a pilot study on U.S high school students' experience in their ACGC 
activities and had preliminary results for the pilot study. To get the results, I met some difficulties in entering the field due to being not able to get the approval from the school district to interview and observe my under-18-year-old participants. However, overcoming all of these barriers in this pilot study, I have gained many research experience about data collection and analysis as well as some understanding of U.S students' experience in ACGC activities as well as the activities itself. All of the experiences regarding ACGC I have had, first as a student in need of ACGC activities, later as a self-employed advisor, as a PhD student in the U.S. and as a researcher, have helped me explore more about myself as well as develop a stronger understanding of the importance of quality educational opportunities like ACGC activities for high school students' development and achievement. As a result, as both an insider and outsider, I will share with my participants what I have learned about ACGC activities and its impact on U.S students' development, at the same time I want to listen to my participants' experience regarding career-related activities at their schools in order to understand how such activities look like in Vietnamese context, then would like to use my own and research experience in order to inspire and encourage them to design and develop ACGC activities for their students' development. Interacting with my participants seems like a conversation between educators who are willing to share and willing to learn from each other with the hope we can do something useful together for the development of Vietnamese students. Interacting with my participants with the purposeful attitude above also explains another aim of this study, which is to propose some policy recommendations in order to help my principal participants, then other principals, 
policymakers, as well as future school counselors in Vietnam if they are looking for implications in order to design and implement ACGC activities for their students.

In short, my family background, my identity, and life and study experiences have shaped my multi-positionality. Learning how to listen, observe, and learn from as many people as I could in the field of education has helped me see develop my research interest. However, only by experiencing as well as interacting with students and educators provide me as both insider and outsiders with more opportunities to develop my lens of views, gain more experience, identify and confirm my own assumptions, passions, and goals of my life. For me, my journey as a researcher and a future educator is an ongoing process.

\section{Limitations}

The study had some limitations. First of all, the findings and implications in this study are not generalizable to other countries, because these findings and implications are just to the schools in your study and other schools in Vietnam. Regarding the research context and participant recruitment, I chose 11 high schools in Hanoi as my research sites and simultaneously 11 Vietnamese high school principals as my participants to explore what these Vietnamese high school principals think and do to prepare students for their future paths. The reason for choosing this research context was that there was potential to learn and explore more $\mathrm{BC}$ experiences of these Vietnamese participants in particular.

Moreover, my research timing was not the best time for data collection and analysis. In particular, I collected my data in May to June, the last month of the school semester, when most of ACGC activities had not been implemented. Thus, as mentioned earlier in the section of data collection, althought I intended to observe any ACGC 
activities at my participants' schools, but I was unable to do it. As a result, I did not have opportunities to make in-depth observations on ACGC activities at two-three schools to examine my participants' answers in their interviews.

In terms of sample size, besides high school principals, I was unable to include multiple perspectives from organizational leaders, including domestic and foreign employers and universities, experts who are brought in, teachers, parents, and students. If I was able to include perspectives from various stakeholders, the findings and their implications might have provided better strategies for school leaders, other educators, and policy-makers to implement ACGC activities as well as to better prepare students for their transition after high school.

I primarily made use of a snowball and purposeful sampling to invite 13 Vietnamese high school principals to participate in my study. As explained earlier in the section above, some teachers and school leaders in Vietnam have made many serious derogations over the past few years, which have been exhibited by the media and attracted a lot of attention from the public. Thus, it seemed that two of the principals I approached refused my invitations to participate in my study because they might want to avoid potential troubles which might be caused due to potential negative feedback and experience regarding teaching and learning. Moreover, with my partipants, specially nonBC principals, who agreed to participate in this study, it is likely that some of their answers might lack accuracy and authenticity due to their avoidance potential later trouble. This may have jeopardized the richness of the data, although I think that this did not happen. 
Moreover, considering myself as a border crosser, a doctoral student in the U.S. and the daughter of highly respected educators, who did not find much difficulty in inviting some of school leaders to my study or ask them to introduce others, I might have over expectations of what my school leader participants were able to think and did to prepare students for their future paths as well as think about challenges and opportunities to implement ACGC activities for their students. If so, this research's findings and its implications might not be as valuable and beneficial to multiple audiences as I expected.

\section{Summary}

This qualitative case study was designed to explore what Vietnamese high school principals think about ACGC activities as preparing students for further education and career, their role in preparing students, and to understand what challenges and opportunities these principals perceive in the design and implementation of these activities. The case is embedded in Vietnamese high schools in both urban and suburban areas of Hanoi, the prime city of Vietnam where renovations and changes made by potential border crossers are expected to happen first. The choice of a qualitative research with case study design and grounded theory methodology fits for many reasons listed in this chapter. My data came from many forms including interviews, physical artifact, and my field notes. In the process of data analysis in this study, I adapted the four basic following steps by Creswell (2007) and Saldana (2009), including Initial Coding and Open Coding, Category Making, Theme Generating, and Findings, with the assistance of Dedoose, an online qualitative analysis tool. 


\section{CHAPTER FOUR: FINDINGS}

Chapter Four presents the findings of my study, which 1) explores how Vietnamese high school principals think about preparing their students for their future academic and career paths, 2) describes the difficulties these principals perceived or faced in the process of the design and implementation of ACGC activities, and 3) explains strategies they used to implement ACGC activities. In the study, 11 Vietnamese high school principals from eight urban and three suburban areas of Hanoi were invited to the study. As mentioned in chapter 3, these 11 principal participants were broken into two groups, with seven non-BC principals and four BC principals (See Table 1, p.83). In this chapter, the findings explicated through discussions of three themes and three subthemes, to answer the following research questions of this study:

1) What are urban and suburban Vietnamese high school principals' perceptions of ACGC activities they currently have in their schools and how they perceive new ACGC activities?

2) What do these principals perceive as their challenges in the design and implementation of ACGC activities?

3) How do these principals sustain the ability to implement ACGC activities?

In general, findings in this chapter showed the differences in what the non-BC and BC Vietnamese high school principals in this study thought about ACGC activities, viewed difficulties and what they made their efforts to design, implement, and sustain these activities. More specifically, the non-BC principals thought about ACGC activities as extra-curriculum to increase students's academic achievements at schools. These principals viewed many difficulties they faced and perceived as barriers which prevented 
them from designing and implementing current ACGC activities in a effective way. The ways these non-BC principals viewed their difficulties reflected their traditional principalship where they avoided disagreements, decision making, additional efforts to make changes regarding students' learning opportunities. As a result of not being able to reject their traditional principalship, these non-BC principals expressed their unwillingness and their lack of readiness to design and implement additional ACGC activities. Thus, they relied on a limited internal and external resources to sustain a limited range of ACGC activities. Unlike the non-BC principals, the BC principals in this study have good awareness of ACGC activities; thus they integrated these activities into their main school curriculum. Although the BC principals faced a lot of difficulties in the process of the design and implementation of ACGC activities, these principals had abilities to push above and beyond the traditional principalship to become instructional leaders in ACGC and active social and educational change agents, which helped them to navigate many strategies to design, implement and sustain new ACGC activities for their students.

Finding 1: Principals Viewing ACGC as Either Integrated into the Curriculum or as Extra-Curriculum

In this section, especially through the first of the two interviews with the 11 principal participants, the data showed differences in how the non-BC and $\mathrm{BC}$ principals' perceptions of ACGC activities and the roles they fulfilled at their schools. While all seven non-BC principals viewed ACGC activities as extra-curricular, the four BC principals saw these activities as integrated within the school curriculum. As a result, these differences in perceptions of ACGC activities led to a difference in the ranges of 
ACGC activities non-BC principals and BC principals offered for their students, and how these activities were implemented within the respective schools.

\section{Non-BC Principals Viewing ACGC as Extra-Curricular}

Regarding non-BC principals' perception of ACGC activities, the data showed that all seven non-BC principals (Na, Bach, Long, Han, Fin, Mon, and Ben) thought of ACGC activities as only extra-curricular. Particularly, when asked what ACGC activities their school offered and what these activities may look like, all seven were only able to mention or offer one-to-two types of ACGC activities, including a few ACGC mainly outlined by MOET and a few limited, non-academic-focused activities not required by MOET (see Appendix D and E). The non-BC principals' ability to know only one-tothree types ACGC activities showed these principals seemed not to have a good understanding of ACGC activities and their significance to help students for the future academic and career explorations.

Activities Preparing Students for College and Exam. The first ACGC activity that six of the non-BC principals (Bach, Long, Han, Fin, Ben, and Mon), had been aware of and/or offered referred to monthly academic and career-related discussion sessions led by their head teachers. This was an activity outlined by MOET. This activity was a school-based one where the head teachers spent nine periods within a school year either introducing their 10-12th graders to careers in society or leading discussions on some given themes (MOET, 2006b). Although all seven non-BC principals mentioned their school had implemented this activity, it seemed that they did not focus on helping students attain the necessary knowledge and skills for future academic and career paths. Instead, they only made sure this activity was implemented in the simplest and easiest 
way. Principal Ben described the way his school's teachers implemented such activities:

"Teachers have the information about the numbers of admission from universities [from MOET]. Information about careers is on MOET's website. Teachers just introduce this information to their students." Based on Ben's explanation, the only effort he and his teachers made was to show students what and where the resources could be found. Ben and his teachers did not exert any additional effort to provide particular counseling or guidance in order to estimate the effectiveness of this activity. Principals Long and Fin admitted that they themselves did not implement this activity, saying, "The implementation of this activity depends on teachers. However, it is [the] reality. They cannot do it" (Long) and, "If students find a job suitable, they choose that job. My school has not organized any useful ACGC activities in order to help them prepare for [their] future" (Fin). In general, Principals Ben, Long, and Fin did not make efforts to implement this activity in a systematic and effective way. In part, it appeared that they were not convinced of the efficacy of such ACGC activities on student decision making.

Similar to the activities above, Principals Fin, Ben, Long, and Mon had also been aware of career or college fairs, one of the ACGC activities MOET outlined; however, these principals implemented these activities in a spontaneously and inconsistent way. Principal Fin described the career fairs he was aware of as follows: "the Vietnamese Youth Association or the local department of education and training have annually organized big career fairs where many universities, colleges, companies, [and] organizations participate. High schools also have arrangements for students to attend." Fin, Ben, Long, and Mon had organized and implemented these career or college fairs career or college fairs in an inconsistent way, perhaps because they were unable to see 
values in such activities as a good resource to help students learn more about their future choices, both educational and vocational. For example, Principal Fin, with 21 years in his administrative school position at suburban public schools and a special education school urban public model, revealed that "Sometimes my students participate in career fairs," but he did not specify how many students nor across which grades. Ben, with 23 years of administrative school experience at both public and private schools, shared similar information regarding fairs at his school, saying that "the Vietnamese Youth Association organizes college fairs. They will inform students. [If] any student is interested, they will attend." While "sometimes" was how Fin described the infrequency of career fairs which he could help students attend, Ben left the responsibility of organizing career/college fairs up to others. By saying “[If] Any student is interested, they will attend," Ben appeared uninterested in encouraging his students to attend such type of activity at that time or in the future. Principal Long, in contrast to Fin and Ben, shared that he did not encourage students to attend, because he had learned that most college fairs are "like check-in and check-out events... where [his school], for example, is responsible for taking 200 students to come to attend."

While Principals Fin and Ben were aware of career fairs and their purpose, they thought it was the students' responsibility to attend/or pursue more information. Principal Long did not encourage his students to attend such fairs, because he contended the organizers of such fairs were interested in how many students attended rather than students gaining useful experiences or information. Similar to Long, Fin seemed skeptical about this activity's influence on his students' future academic and career interest when he said: "There has not been any specific statistics on students who could find their future 
career interest after such fairs. Maybe there were some, but the percentage was not high. There have been more universities [and] colleges while fewer companies." In general, six of the seven non-BC principals perceived career or college fairs as an extra-curricular and not a critical part of students' exploration of future careers.

While the non-BC principals tried to complete the two MOET required activities listed above, five of the seven non-BC principals (Na, Mon, Long, and Bach) had offered college application advising sessions/school-based college fairs for their students as additional ACGC activities, which MOET does not require. Principal Na shared, "My school has offered only college fairs with the purpose of introducing universities, local and international, their programs, and their admission requirements to students and parents." At Principal Na's school, this activity was quite new, "since we have the new school [open a few years ago], the school leaders approved this activity. Before that, there was not such activity. You know it [the old school] was so small." While Principal Na knew about this ACGC activity previously, she did not or could not implement it until the school moved to a larger building with resources to accommodate these activities. Prior to the school infrastructure improving, Na maintained a focus strictly on student learning rather than additional activities like ACGC but planned to implement such activities later. Principal Long, at a similar sized suburban public high school as $\mathrm{Na}$, did not have specific plans when hosting college application advising sessions. Long shared about hosting these sessions, saying, "When universities such as RMIT, Foreign Trade, and National University come and ask [to organize college fairs or college application advising sessions"], I often give approvals." Although Long "often gives [had given] approvals" for college fairs or college application advising sessions, it seemed he just 
gave approvals but relied on the universities to reach out with the opportunities. Principal Mon focused on student learning in his organization of college fairs/college application advising sessions, saying:

I support them [college fairs/ college application advising sessions] to be implemented appropriately. If these activities happen during school time, they will be organized and should replace physical education sessions, for example. It means if they [college fairs/ college application advising sessions] do not affect students' learning courses in class, we will be able to arrange a time to make them.

Like Principal Long, Principal Mon explained that some university representatives often came to his school to organize college application advising sessions for his students with his approval. However, Mon allowed these sessions to replace students' physical education sessions. This seemed to indicate that he saw the order of importance as 1) student achievement 2) ACGC, and 3) physical education. While Principal Bach, along with the head teachers, organized advising sessions at his school, he seemed to place a specific priority on the ACGC activities by limiting attendance to $12^{\text {th }}$ graders only. According to Bach, "10th and 11th graders are unable to self-evaluate their ability to study. Only 12th graders need ACGC activities, college application advising activities in particular, because they know their interests and abilities." While Bach did not replace students' physical education sessions like Principal Mon, he severely limited his students' ability to develop the necessary knowledge, skills, and experiences to explore their abilities, interests, strengths and weakness in many areas over the course of their three years in high school. Instead, Bach focused on helping only students in twelfth grade 
determine their academic abilities to apply suitable universities, which might increase their chances to gain college admission.

Field trips were another ACGC activity that only non-BC Principals Fin, Na, Ben, and Mon organized for their students. The main aim of these field trips was to introduce students to some universities and university programs. Principal Fin, from a special school model in a suburban area, shared how he and some universities used to organize a college campus visit for his students few years ago. However, Fin did not offer this activity anymore, because he contended his low performing students did not gain much from it. Fin described field trips at his schools as follows:

Now in the era of openness, [and] competition, even famous universities have to do marketing to promote their images to [high] schools. So they are willing to pay for the organization and transportation. When we got there, they welcomed us by preparing water, having an $\mathrm{MC}$, inviting their former students to share their experience with the university. This kind of activity was also what I used to do. The thing I saw was that it is very effective with the high-level input schools whose students are well aware and educated, so when they participate in those activities, the students gained much from what the university wanted to convey in order to help students choose what is right for them. But at the schools where most of the students are low performing like mine, this is really a challenge for me. It is very difficult [for low-performing students to value and gain useful experience in this activities] because I saw and I was very sad. 
Fin was aware of the significance of field trips to students, and he felt sad when realizing that his efforts to organize these activities for his students did not give rise to strong results. However, instead of committing more to his efforts to help his low-performing students to make them be aware of what these activities might bring, Fin gave up and chose not to offer these activities any more.

Unlike Fin who no longer offers field trips to universities, Principal Na, at a private school in an urban area, offered this field trip activity: "My school sometimes has also organized a day for students to be students at RMIT or FPT universities, for example". However, the fact she solely offered these activities "sometimes" showed that $\mathrm{Na}$ was able to inconsistently organize them. She did not further explain whether these activities made a particular influence on students.

Principal Ben, at a private school in an urban area like Na, was the only one who offered field trips as opportunities to provide students with real-world experiences rather than universities, different from the field trips described above, which focused on student achievement. Ben said that: "Sometimes the students have field trips to Cuc Phuong National Park, [and] Tam Dao; however, these activities do not happen very often." However, similar to other non-BC principals, through what Ben shared about the infrequency of these field trips, he also seemed unable to specify an exact time frame that his students had opportunities to participate in these activities.

\section{English-Focused Activities to Promote Student Achievement. ACGC}

activities, like English advanced classes and English-focused events, were prioritized over other ACGC activities by Principals Mon and Ben, likely because English is one of the required skills for college admission at high-ranking universities in Vietnam and also 
in other countries. Principal Mon, a public school leader with more than 20 years' experience, proudly shared his success as well as the reason for the design and implementation of English advanced classes, saying, "I think that my success in implementing only them [English advanced courses at his school] met my expectation. The reason is that I am able to only maintain my students' high academic performance and, most importantly, to train national excellent students. I am so proud of all three schools." Principal Mon was actively designing and implementing English advanced class with the hope of increasing his students' English ability as well as increasing his students' academic achievements and promoting the school's reputation. Unlike the other ACGC activities at his school, Mon developed and maintained these classes for students, focusing on student achievement rather than offering more opportunities for students to determine or explore their interests in other areas. Similar to Mon, Principal Ben prioritized activities focused on testing and high grades over ACGC activities. His reasoning was to:

help students have less stress while the [national] curriculum is too heavy, and also to help the students improve their presentation skills [in English]. In a lot of situations, students understood the English but did not know how to express their ideas. [They] understood but did not have words to express themselves. This goal will take time; so, if teachers do not help organize these activities [English-focused events] earlier, it will negatively affect students' learning results. The reason is that they [students] need to focus on learning to take the national exam [as completion of high school level]. 
Ben realized there was a need to organize English-focused events to help students develop English language presentation skills. However, he expressed uncertainty about his school plan to implement these English-focused activities and about his related efforts to help students explore their interests and abilities related to studying English in the future. His priority was students having time to learn and prepare for national exams.

Like the two other principals (Ben and Mon), Principal Long also provided tutoring sessions for high performing students, including English tutoring, to increase student achievement. Instead of offering tutoring sessions for low performing students, Long offered them to high performing students in order to make them more motivated to compete with each other academically. He described that he had "nine groups of three high-performing students at each grade", who "provided tutoring sessions from the beginning of the semester to late February or early March". Long also added that those groups "will participate in school competitions in many some subjects [including English] with particular awards for high performance". It seemed that organizing highperformaning students groups and tutoring sessions for these groups might be ways to increase student achievement and the school's overall reputation.

\section{Non-academic Clubs and Activities as a Break from the Heavy Curriculum.}

Despite not prioritizing ACGC activities, some non-BC principals (Han, Long, and $\mathrm{Na}$ ) did recognize the need for non-academic clubs and activities whose focus is on comprehensive human development rather than solely on student achievement. These principals offered non-academic activities like soccer, guitar, and dance. In order to explain the reasons for offering such activities, Principal Han from an urban public school shared: "Students and parents suggested [them], because the students found the 
time for learning at school was too much. They wanted extra-curriculum to develop their hobbies". Principal Long explained, "I support these activities in order to help students improve their personality...[and] to ensure the minimum task of comprehensive human development." Han and Long perceived their students needed to develop in other nonacademic areas to support their comprehensive development in addition to learning courses in the mainstream curricula. However, the organization and implementation of these activities seemed to not fulfill the goals above. Principal Han and Principal Long shared, "After school, students are able to participate in sports clubs such as soccer and others," (Han) and "Every Sunday at 5 PM, students can come to join guitar club...and dance sport, Hip-hop" (Long). It seemed like for these two principals, these sport and art clubs happened quite frequently like "after school" and "every Sunday." However, these activities were dependent on student interest. Principal Han admitted that in terms of effectiveness, "These activities [sport and art clubs] are not well prepared, just occasional.” The principals' responses demonstrated a lack of guidance and counseling that might help both high and low performing students participate and explore their talents or interests.

As an outlier of the seven non-BC principals, Principal Na was able to offer a number of new ACGC activities, such as workshops on life and leadership skills, sports clubs, and others, which are not outlined by MOET. However, Na did not have much awareness of the significance of these specific ACGC activities that were offered in her school. She explained,

These activities were to [help students] improve physical, gain teamwork skills, working for a team. Sport-related activities will help them to work 
for the entire group, not for their ego... Students will feel more comfortable [at school], love school more, and students will gain life skills for the student body, not for themselves.

From Na's explanation, it seemed that the activities were not designed with a specific focus on choosing a future career or education, but rather to help students to develop school community-based skills. While the benefits of these activities could aid students both in the present and the future in terms of the importance of teamwork and certain life skills, she did not strongly correlate them with the goals of ACGC programs--that is, to help students prepare for their future career or educational path based on their skills, interests, and abilities.

In short, all seven non-BC principals did not have much knowledge of the variety of ACGC activities available to them. They implemented MOET's minimum requirement for ACGC activities and/or limited any new ACGC activities, which they considered to be a way to focus on student achievement. Because of the focus on student achievement, the frequency and variety of the ACGC activities that were offered were limited to extracurricular activities which were infrequent and failed to fully achieve the purpose of ACGC activities or prepare students for future paths.

\section{BC Principals Viewing ACGC as Curriculum}

While the non-BC principals considered ACGC activities as extra-curricular and students' performance in class were viewed as the highest goals, the four $\mathrm{BC}$ principals, Fon, Phan, Hen, and Anh, integrated ACGC activities as a part of their schools' main curriculum. They viewed ACGC activities as strongly supporting their schools' educational vision, mission, and goals. Unlike the non-BC principals, all four $\mathrm{BC}$ 
principals had been designing and implementing a number of useful new ACGC activities that were not required as part of the compulsory curriculum (see Appendix D and E). BC principals offered their students anywhere from five-to-nine new types of activities compared to the one-to-three types that the non-BC principals offered. These new ACGC activities included, but were not exclusive to, interventions and/or activities led by professional guidance and counseling staff (e.g., life skill and living values education activities), experience activities (e.g., field trips and career fairs), test-based career orientations (e.g., Dermatoglyphics, blood type, and Horoscope), student-led activities (e.g., mentorship, school website project, astronomy-based activities, and leadership skills), seminars led by experts, parents, celebrities, or alumni; academic-based events (e.g., debate contest and science day), sports and art clubs, and other activities (e.g., School's Got Talent and Volunteer day). The BC principals implemented these new activities, because they could offer students opportunities to explore their abilities and interests, help students develop motivation to study, and for students to make individual career plans for their future.

\section{ACGC Interventions and/or Activities Implemented by Professional and}

Counseling Staff. Two private school principals of the four BC principals, Fon, and Phan, were able to offer new ACGC interventions and/or activities that were designed and implemented by professional guidance and counseling staff. These activities may have been possible in part because private schools' finances are not controlled by the government. In this type of ACGC interventions, BC principals and groups of professional staff, along with teachers and experts, organized seminars to provide students with necessary information as well as to encourage them to think about their 
values, skills, and responsibilities to others and to society, to create a safe and caring school climate, and so on. The goal was to provide students with opportunities to explore their academic, future career, and life aspirations. Specifically, Principals Fon and Phan, who work at private schools, recruited some professional guidance staff who had the specific knowledge, skills, and experience to provide counseling and guidance to students. Principal Fon described:

I have a counseling and guidance office and I have four professional staff. While in the U.S, the ratio is 1 guidance staff /1000 students, I have the ratio, up to $4 / 700 \ldots$ They are individuals who graduated with psychology majors .... Or they are retired teachers with many experiences. I recruited Ranh, a retired vice principal, who is good at horoscopes...My former student who worked as a teacher at the University of Haiphong was recruited in order to do guidance and counseling at my school [because of her capacity]. ... Their work is totally specialized [they do not participate in teaching work].

Principal Fon was aware of the significance of professional guidance staff in designing and implementing activities, which included guidance and counseling. Fon decided to recruit qualified professional guidance staff. He saw recruitment as necessary and useful, because qualified professional guidance staff, along with his teachers, to help "make living skills and living values education-related activities part of the main curriculum". Fon further explained his school plan to implement this ACGC activity, saying, "Every month we have two periods to do them [these activities]." Unlike non-BC principals, Fon was consistent and scheduled ACGC activities regularly. Specifically, he provided the 
following example of their impact on a student's educational path to show that life and living values education-related activities at his school provided his students with opportunities to learn social skills including living skills, leadership skills, and teamwork skills:

After high school graduation, he studied abroad [at the U.S]. Later, he [The student] shared my friends who graduated from high schools with high reputation and 'I was so proud to say I was a student at Principal Fon's school [name of the school]. My friends asked why I was able to adapt to a new environment where friends came from many different countries.' He answered that, because, at my former school, I already had opportunities to learn about life skills and living values education.

For Principal Fon, ACGC activities helped prepare many students for any real-life situations and issues they may encounter in their future paths. In fact, Fon saw that many of his students managed to overcome these issues to succeed in their future education as a result of his efforts in the design and implementation of ACGC activities.

Similar to Principal Fon, Principal Phan proudly explained that, "I invited and pay for the six professional staff including masters, bachelors, and doctors of psychology in order to provide counseling and teach life values and life skills for students", who were responsible for "organizing hundreds of ACGC activities around the school year." Like Fon, Phan shared an example where he and one of his professional staff worked together to design a good intervention with guidance and counseling elements. It also helped a student who had a psychology issue, as he explained: 
One characteristic of Vietnamese culture is to avoid sharing [psychological] issues. They rarely talk about their issues. A lot of time students were in bad situations, they did not go to the psychology office for help. What if the professional staff stays at the office and waits until students come and ask for help? A situation might be that if one student goes to the psychology office, other students may ask him or her what issues he/she had. Thus, professional guidance staff has to figure out students with issues, listen to them, provide counseling advising and help. There are so many ways to solve an issue. For example: when we know a student is having a psychological issue. Although the head teacher may help in this situation, I worked with a psychology staff and the staff was assigned to be the co-head teacher of this class. She [the psychology staff] got involved in activities with students. Later, the students with the issues talked and shared with the staff, but did not need to go to the psychology office and nobody even knew.

Through the examples above, Principals Fon and Phan and their professional guidance and counseling staff showed a holistic focus on students, particularly around student mental wellbeing. They made many efforts to work together to offer the best interventions, part of ACGC, for their students.

Field trips and Community Support as Resources for Students' Academic and Career Exploration. Like the non-BC principals, the four BC principals (Hen, Anh, Phan, and Fon) are implemented field trips. However, unlike the non-BC principals, these four BC principals actively collaborated with a number of universities and academic and 
vocational centers/colleges, and business/factories to provide experience days. At those organizations, as Principal Phan shared, "Students have opportunities to explore those colleges and business, participate on-hand experience, and explore their interest and ability, build up experiences and dreams, and be determined to pursue their career plans." Furthermore, in order to emphasize the significance of the implementation of these field trips, Phan added: "They [the students] will gain much more experience and knowledge rather than listening to their teachers in the classroom or learning from the textbooks by the Ministry." Phan contended that students need more than just theoretical learning to make decisions about their future; they also need exposure to learning like immersion in real-life situations and working environment at universities and businesses in order to fully explore a major or career.

According to all four BC principals, making field trips possible for their students was not difficult due to various kinds of community support. Particularly, Principal Fon, who works in a special education model school, where most of his students were lowperforming and come from low-income families, explained how: "universities and organizations in the community are willing to sponsor field trips to their places." Principal Hen, who leads an international school, where the students are from highincome families, shared the same outlook as Fon about collaborative opportunities between his schools and organizations and organizing field trips for students, saying:

At my school, an advantage [when designing and implementing field trips] is that if students want to have field trips, their parents will support. As business owners, the parents of my school are able to offer financial support. Here, the school has 100 students, less than public schools. Each 
class has 25 ; thus, organizing field trips is easy. I've learned from some foreign schools where educational quality has been more focused than public schools in Vietnam. For example, I organized a field trip for a class of 15 or 16 students to a tourism business where a parent is an owner. The parent sponsored all the fee such as accommodations and meals.

Based on the four BC principals' responses, especially those of Principals Fon and Phan, they perceived that field trips provided particular benefits to their students in terms of potential careers and futures. These principals were able to conduct field trips because they sought the partnerships with the community and parents unlike the non-BC principals.

\section{Test-Based Career Advising Activities to Support Students' Decision}

Making. The third type of new ACGC activity, which was only applied by Principal Fon, referred to was test-based career advising activities. These activities help students identify their own natural talents, values, skills, and personality to find their potential future educational and vocational ability, then help students make personal plans as well as give appropriate interventions for individual students. Some examples include 1) Dermatoglyphics, a scientific study of fingerprints which provides assumptions on which characteristics, behaviors, abilities a person has, 2) a scientific study discovering the relationship between types of blood and career orientation, which helps to determine a person's personality and career, 3) horoscopes which used information about date of birth to infer individual character and personality traits, then help students think about how their character and trails will fit in with specific careers and 4) Holland theory, which helps students match their interests and skills with some different categories of 
occupations in order to provide students with more potential career choices (Reardon \& Lenz, 1999). Principal Fon, with more than 40 years of experience as the school leader at his special education private school, has integrated all four activities, because he explained that "helping students prepare for their future academic and career paths is a scientific study" that "help[s] students explore and assess their strengths and weaknesses, abilities quickly" and that "the more useful methods we [he] apply, the more effective ACGC is [in terms of helping students make better decision on their future paths]."

\section{Student-Led Activities for Students' Future Academic and Career}

Development. Principal Anh, with 14 years of experience as a teacher and five years as a principal at her gifted public school, was the only principal who was able to develop project-based activities led by students. Some examples of these activities included mentorship, school website project, astronomy-based activities, leadership skills and so on. When asked about the purposes of these activities, Principals Anh emphasized:

I developed a variety of student-led activities based on students' desires/needs in order to develop students' full potential, [and] encourage their high creativity...At my generation or your parents' generation, learning was to build and create a reputation for family, [and] ancestors. Today's students think differently. They want to make contributions to the community. They shine, and they want others to shine with them, to attract as many others as well as the community as possible to shine.

This training goal of Principal Anh was also found at the slogan of "learn to do, learn to know, learn to live together, learn to be" by UNESCO (Delors J. et al.,1996) in every classroom in her school. She recognized the significant impact ACGC activities could 
have on students, particularly project-based activities. By supporting student-led activities as a means of meeting student needs, she was able to "help students learn about how to study, live, and work as global citizens," which in turn reflected her school's vision, mission, and goals. Regarding how these activities have been supported and implemented in her school, Anh further explained "These activities change based on [students'] needs. In the last few years, students needed this activity but currently, they need others.” In general, according to Principal Anh's descriptions about student-led activities and their roles as well as how she had implemented them, Anh wanted to emphasize the role of ACGC activities as part of the main school curriculum. Creating as many learning opportunities including these ACGC activities as she could for the educational and career development of her students was aligned with her school's mission and goals. In general, Anh prioritized student-led activities, part of ACGC activities. Thus, she was sure to take ACGC seriously as she believes it can impact students' future academic and career development.

Seminars Led by Guest Speakers. Next, some principals like Principals Anh, Hen, and Phan also organized seminars led by guest speakers as experts, celebrities, parents or school alumni. The purposes of these seminars were to help students develop career and life aspirations by listening to the guest speakers' success and failure stories as well as through interactions between the students and the guest speakers. Particularly, Principal Phan shared an example about some seminars where Phan or other school leaders participated as guest speakers, sharing their life stories and one of his students raised a lot of questions such as "Have you ever met difficulties? Ever been disappointed and wanted to find another job?" After asking questions and answering questions by a 
guest speaker, one student declared that "I [the student] will develop a business to compete with yours [Phan's school] and in fact, he [the student] did it." Through these examples, Principal Phan wanted to show that ACGC activities, including seminars led by guest speakers designed for their students, could help students spark ideas and new interests for their future career paths as well as help students "discover paths to success, [and] see reality is not just pink (i.e., rose colored)." When successful, the seminars aided students in their consideration of all possible outcomes and inspired them to make the necessary preparations for pursuing their interests or dream careers in the future.

\section{Additional Types of Activities to Supplement Student Career and Future Readiness.}

In addition to the groups of ACGC types above, annually, Principals Anh, Hen, and Phan had organized many school-based events (e.g., Debate Contest, Science Day, School's Got Talent, Sport Day,), sports and art clubs, and some other activities (Volunteer day) according to their school activity plans. All of these activities were designed to help students gain soft skills, promote creativeness, build up interest, abilities, and skills not focused on in the national curriculum. Instead, they were ones principals perceived were important to make contributions to the academic and career development of the students in the future. In order to design and implement these activities, in addition to students' active participation, teachers, staff and school leaders played important roles in providing advice and support.

In conclusion, while the non-BC principals had implemented ACGC activities as an extra-curricular way to increase student achievement, the $\mathrm{BC}$ principals designed and implemented useful ACGC activities as part of routine school doings to help students explore their abilities and interests to prepare them for future academic and career paths 
in addition to putting their students' academic achievement. BC principals appeared more focused on students' long-term paths rather than students' short-term high school achievements.

Finding 2: Non-BC Principals Viewed Their Challenges as Barriers Preventing Them from Designing and Implementing ACGC activities; BC Principals Knew

\section{There Were Challenges but Proactively Found Ways to Overcome Them}

Both non-BC and $\mathrm{BC}$ principals perceived particular challenges in the process of implementing ACGC activities. While there was some overlap in the perceptions of the two groups, the approaches these two groups used to identify and view their challenges were different. Those challenges seemed to be perceived based on differences regarding school types and their related factors (e.g., parents' educational levels, or parents' socioeconomic status). In particular, the non-BC principals, mainly from public schools, claimed factors such as principal's heavy workload, a lack of professional guidance and counseling staff, a lack of agencies, and the overwhelming family impact on students' career choices as the main challenges preventing them from designing and implementing ACGC activities. The BC principals, however, described challenges related to traditional social norms, a lack of support from parents and superiors, and a lack of school autonomy as barriers they needed to overcome to design and implement new useful ACGC for their students.

\section{Non-BC Principals' Views of Their Challenges to Designing and Implementing}

\section{ACGC Activities}

The seven non-BC principals, Na, Fin, Ben, Long, Han, Mon, and Bach, discussed four main challenges to designing and implementing current ACGC activities or in considering new 
ACGC activities. The challenges included a heavy workload for principals, a lack of guidance staff, a lack of support from agencies (e.g., universities, companies, organizations in the community), and families' influence on students' future academic and career choices. The non$\mathrm{BC}$ principals viewed these challenges as the barriers that made them unwilling to design and implement more useful ACGC activities for their students.

Heavy Workload. First, Principals Mon, Fin, Long, and Ben stated that their workload was too heavy to design and implement more useful ACGC activities for students. Principal Fin explained his school responsibilities as follows:

Because Vietnam [schools] receive so many decisions and directives, most of the time, the fact that schools has done all those activities [requirements] has been very stressful. The number of subjects/courses [at Vietnamese schools] is more than that of foreign schools where there may be 5 basic courses. Their students have opportunities to learn and develop based on their own abilities. In Vietnam, at the high school level, there are up to 13 courses, a big number. Teachers are making much efforts to transfer such heavy knowledge to their students.

As a result of his stress and pressure to make sure the school meets the expected requirements, Fin contended he was too busy with spending his time to ensure students and teachers follow the current national curriculum--which is too rigorous and involves a large number of subject areas - to take more time to implement more ACGC activities. Fin also contended that the heavy curriculum, with up to 13 required courses, took all of the students' and teachers' time at school. Thus, even though Fin and his school 
personnel wanted to design and implement more ACGC activities, he perceived students did not have time for those activities.

Similar to Fin, Long stated that his main time or responsibility at school was to improve the effectiveness of teaching and learning processes. The knowledge students got from courses was a priority:

I was assigned the vice-principal to be responsible for it [providing approval or not to college advising sessions]. Any university wants to come to promote their programs, I will ask the vice-principal to do it. I did not do such time-consuming things. I only concentrate on how to teach students. The main thing on which I focus is how to help the student build a good foundation of knowledge. I also have to change methods of teaching, [and] assessment.

Because of Long's priority to help students gain knowledge from required courses to later take exams, he admitted a lack of time for other activities, like ACGC activities.

Like other non-BC principals, Principal Mon perceived a heavy workload.

Although he was aware more could be done, he refused to improve the effectiveness of college fairs:

Honestly, if I looked for and collaborated with more colleges [in order to host college/career fairs], it would be better. However, my [his] work is heavy, I feel satisfied with what (the ACGC activities) I [he] already have. So, I do not want to do more.

In general, Principals Mon, Fin, Long, and Ben similarly perceived a heavy workload at school and prioritized meeting national curriculum requirements. Thus, they perceived 
little time left to improve the effectiveness of the ACGC activities they had implemented or implement any new ACGC activities.

A Lack of Guidance and Counseling Staff. In addition to the heavy workload, non-BC principals perceived a lack of professional guidance and counseling staff at the school was another challenge they faced in designing and implementing ACGC activities. According to Na, Mon, Fin, and Bach, they wanted to have professional guidance and counseling staff available at their schools because of students' demands and teachers' lack of knowledge skills in ACGC—-but they could not hire due to either a lack of funds or the general difficulty of hiring qualified staff. Particularly, Principal Na, with 4 years of experience as a teacher and 7 years as a school leader at a private school, described the particulars needs within her school for a qualified staff:

I realized there is an increase in the number of students who have signs of autism and stress. In the past, I did not find such much. Currently, every students' issues, regarding sexuality and broken family for example, is entrusted to the headteachers. Many of the headteachers have not worked effectively, because they were unable to communicate well with students, unable to let students understand their goals. For example, there is a particular student whose family are broken. He did not want to learn at school. So, in order to raise him up, it is not easy. Teachers need psychological knowledge and experience to help him. ...Students [in their teenage years] were wondering what their learning was for. Some [students] from wealthy family thought they didn't need to go to school; so, how to help them live as useful people was not simple. It is difficult for 
teachers to help them...If a student was upset, he/she may get trouble, he/she may want to go to [see professional guidance and counseling staff at] the psychology office.

Na realized her school needed professional guidance and counseling staff to help students in need, because teachers were unable to do it. However, $\mathrm{Na}$ emphasized that although "my [her] school is private and financially independent," finding and recruiting a qualified professional guidance and counseling staff was not easy. Similarly, Fin, with nearly 30 years of experiences as a teacher and school administrator at a few public schools, and Mon, with the same experiences, expressed interest in having staff with particular expertise; however, it was hard for these principals to recruit such staff due to financial issues. Fin actively shared his interest and expectations of a future school counselor as follows:

I and most of the other school principals used to express our interest in having a school position as a school counselor. The person [school counselor] needs to be very knowledgeable, proficient, knowledgeable, skilled, artistic in it and must have provided research-based interventions. For example, if this student has this particular talent and learned this program, it will be very useful later, or if a student is oriented towards business, she/he is better to follow this direction. The school counselor is expected to provide such advising. School managers are only able to read books. Very few teachers, who are interested in this work, are those who are enthusiastic, however, generally speaking, they may be able to provide 
advice like you should consider your interest and ability, but nothing specific.

Unlike $\mathrm{Na}$, leader of a private school who found it hard to get a qualified school counselor even with financial independence, Fin contended that he was unable to recruit any, because he was working for a public school where there were many regulations regarding school budgets. Han, who works for an urban public school, also expressed a need for a professional guidance and counseling staff at his school, because both students and their teachers did not possess necessary knowledge and skills in making decisions regarding the students' education or career paths. Han explained how:

In Vietnam nowadays, making decisions on students' future paths is like a trend which is based on an individual's own feelings, not on society's need... No school staff is responsible for college advising. The head teachers are closest to students. They know students' abilities, but the headteachers are not able to figure out the society's needs... This person [the professional in guidance and counseling] must be good at school psychology and society needs to provide guidance and counseling. Han contended that due to a lack of a trained guidance staff, teachers and students relied on their feelings to make decisions about students' future education and career options, regardless of societal need. Instead, if his students had opportunities to receive advising from a qualified professional advising staff, their decisions about their future career and educational paths would be more useful because they could take into consideration many factors, including societal need. 
In general, the non-BC principals, including Fin, Bach, Na, and Mon, expressed their interest in recruiting qualified school counselors or professional guidance and counseling staff to help their students' academic and career exploration. However, they saw challenges in that their teachers were unable to advise students as expected. However, none of them shared any effort to figure out ways to self-fund a school counselor though they thought it was important. In other words, instead of figuring out ways to raise funds to recruit a school counselor in order to meet their needs as well as students' needs, they waited for a change from the superiors, which they understood would not happen soon.

A Lack of Support from Community Agencies. Furthermore, another perceived challenge to implementation was a lack of agencies that were able to get involved in and help implement ACGC activities at the schools Principals Mon, Bach, Fin, Long, and Na oversaw. Specifically, after listening to this study's interventions where principals were expected to look for and build a group of volunteer experts or business leaders from the community, Principals Mon, Bach, Long, Fin, and Na seemed to feel pessimistic about these experts' participation and cooperation in designing and implementing new ACGC activities. Principal Mon, a public school leader, stated: "if we are able to design and implement them [these new ACGC programs] right at the beginning of the high school level, students gain more knowledge and skills would be so useful. However, I am wondering if the business owners or businesses want to do unpaid work for students." Similarly, Principal Bach stated that, "It would be difficult to do [this activity] at the current time, but a few years later, it may be possible [when businesses will be interested in getting involved in school activities as a contribution to the betterment of the society]." 
While Mon and Bach appeared skeptical about possible cooperation between their school and agencies, because it had never happened before, Principal Long strongly affirmed such activities were impossible. Long jokingly stated, "You think that [participation and cooperation of volunteers/experts from the community]" is possible? "Such an idea of the youth". Then, Long continued to walk me, the researcher, through his explanation, saying:

I already told you about reality earlier. There are individuals who work for the community, but only crazy enthusiastic ones could achieve. Those who have enthusiasm after returning to Vietnam will also decrease their enthusiasm because they cannot change reality. The successful people are also many, but they have no time for us, and we find hard to reach them or contact them. These people even did not participate in their class meeting or school anniversary... You are telling me about the positive side, but the negative side belongs to historical issues. This empire was created and protected so it is impossible to change.

Long felt really dejected with the reality of Vietnam where individuals' efforts to change or direct society to follow a better or different path is unfeasible. As a result, he thought it was too difficult to design and implement new ACGC activities due to the difficulty in finding agencies willing to support schools' activities when needed.

Principal Fin appeared less pessimistic than the others, as he assumed that he had found some colleges who were willing to cooperate with his school to implement schoolbased college fairs for their students. However, Fin hesitantly revealed that 
representatives from these colleges had limited capability to collaborate. This could make the college fair itself potentially ineffective and uninteresting to students:

If those colleges have staff who can give ideas, make plans to cooperate or collaboration based on what I suggested, it would be great. However, if the staff members' capability is limited, their session will not useful. For example, I had 10 groups of representatives and only one or two of them worked ineffectively; the overall college fair was still organized successfully. However, 50\% of them worked ineffectively, the fair was not impressive, not attractive, did not leave anything good for students.

It seemed Fin felt uncertain about the professional and capabilities of college or/and universities' representatives to collaborate with his school; he was skeptical these representatives would design and implement good advising sessions.

Like other non-BC principals, when recommended to look for collaborative opportunities with experts from the community in order to design and implement some new ACGC activities like workshops or seminars, Na contended it was impossible:

In Vietnam, to do anything, they [individuals in the community] think about their benefits first. To be honest, in other countries, they think it is happiness [to go to school to do something meaningful for students]. If such people are out there [in Vietnam], there are a few and it is not easy to find them. Like you want to implement such activities [workshops and seminars led by local experts], I also want them very much, but I must go back to my family at 5 o'clock. My first thing is to fulfill my responsibilities for my family. I am available from two to five o'clock. If 
students come for advising, I just can try to make it only one or two days, not always.

Na perceived personal responsibilities were a barrier that made asking for help and support from experts from the community to implement new ACGC activities impossible. $\mathrm{Na}$ also confessed that she gets done what she can during her work hours, and it's a hard to do more outside work hours. In general, the non-BC principals, including Mon, Bach, Long, Fin, and Na found difficulty in looking for agencies and partners to assist or participate in new ACGC activities, which may have contributed to the failure in offering useful ACGC activities at their schools.

Family's Influence on Students' Choices. Principals Bach, Long, Na, and Mon also perceived families influence students' choices more than do schools. For example, Principal Long explained the ineffectiveness of ACGC activities at his school as follows:

Career orientation in Vietnam has been mainly done by the family. Parents have a great influence on students' personalities and careers. The influence of family accounts for $70 \%$, school $20 \%$, and society $10 \%$. [However,] How effective career orientation by family depends on the family's socio-economic status. With families with a strong socioeconomic status, their parents have a good network and social relationship and are able to provide very good career orientation. Others with lower socioeconomic status or low income have fewer social relationships, which is most of our current population in this group. These families provide career orientation by their feelings. If their children have 
the right decisions on their future career, it must be due to their children's faith; so the effectiveness here is low.

Long made a distinction with family socio-economic status (SES). Long contended that low SES families do not do the orientation for their children as well as families with high SES can. However, there were nothing in the quote about the principal were stepping up to compensate with useful information on job opportunities or skill requirements to help students, whose families may not have the relationships, could compete with other applicants in the future.

Similar to Long, after hearing about seminars led by experts, Principal Na, who leads a high performing private school, appeared unready to implement such seminars due to the impact of parents and others by saying, "Students are following what their friends said. They are following what social media shared. They are following what their family suggested. Thus, building habits where they come and hearing a counselor talk will be an issue. Your activity idea is very good but how to implement it is difficult." Principals Long and Na seemed to not believe it is the role of the school to challenge the influence of parents on students' decisions for the future despite the effect ACGC activities have in attracting students' participation as well as the potential positive influence these activities may bring on students' academic and career exploration.

In short, although the seven non-BC principals were able to identify the challenges preventing them from improving the quality of current ACGC activities or designing and implementing new ACGC activities, most did not indicate possible efforts to change or adapt such activities at their school in the future. They seemed not to believe they were capable of changing their current issues regarding the design and 
implementation of ACGC activities. These non-BC principals seemed to be satisfied with the current ACGC activities they had offered to their students.

\section{BC Principals' Challenges in Designing and Implementing ACGC Activities}

While non-BC principals seemed to view the challenges explored above as reasons for not improving the quality of current ACGC activities or adding new ACGC activities, $\mathrm{BC}$ principals considered challenges they faced as good ways to help them find strong strategies to sustain their ability to implement ACGC activities. The challenges BC principals perceived included deep-rooted traditional educational ideology, social norms about student achievement, a lack of collaboration between school and parents and superiors, and a lack of best practices in ACGC activities.

Deep-Rooted Traditional Vietnamese Educational Ideology. The first difficulty the $\mathrm{BC}$ principals met was the deep-rooted traditional Vietnamese educational ideology, which values teacher-centered teaching and learning and assessment of student achievement through student performance on standard tests or exams (Hallinger et al., 2017). As Principal Fon said, "the society has not had an adequate awareness of the role of ACGC activities" in terms of preparing students for their future academic and career paths." Specifically, regarding the traditional educational and ideology, Principal Phan explained that, "Vietnam society values academic achievement. Current educational training is not for academic and career exploration and preparation, but for achievements and certificates", Principals Fon and Hen, in turn, complained that, "we are spending too much time for heavy knowledge [rigorous academics] which students even have never used later on," (Fon) and "At the current high school level, learning and teaching are too stressful. All days students learn and learn, [so they] are not having enough time for other 
activities" (Hen). Through their statements on the intense mainstream curriculum, these principals wanted to describe a big issue in the current curriculum where both school leaders and parents want to make sure students focus on learning courses and getting high grades at school. As a result, Fon and Hen found it difficult to find an appropriate time to organize ACGC activities. Moreover, even after the educational reforms started after 2018, these principals will have to continue to face this big challenge. Principal Fon speculated when asked of a follow-up question of how to offer more field trips for his students as follow:

Time to implement these activities [field trips] will need to be planned in the national curriculum. According to the new curriculum, which has been designed and will be applied after 2018, the high school level is considered a career-oriented one. It is right. However, the new curriculum is actually trying to complete science programs. Career-oriented programs will be just for grades 11 and 12, which will lead to a lot of challenges for schools. To be honest, programs designed and implemented to help students have a career and academic exploration during three years of the high school level is even not enough...Students have to learn because eventually, they have to take graduation exams.

In short, due to the deep-rooted traditional educational ideology which led to the existence of a heavy curriculum and a lack of policies which support the development of ACGC activities (Bodewig, et al., 2014; Hallinger, et al., 2017), Principals Fon, Phan, and Hen did not make additional effort to design and implement ACGC activities as part of their main school curriculum. 
Lack of Collaboration/Support from Parents. Another difficulty the BC principals Fon, Hen, and Phan were able to address was the lack of collaboration with or support from parents, the community, and superiors to fulfill the schools' goals, including implementing ACGC activities for students. Regarding family involvement in school activities, Principal Fon found that at a special education school model like his, where there is a high proportion of the students from low-income families with low educational levels, most of students' families did not pay enough attention to their children's learning at school, nor did they get involved in school activities. He described the issue thus: My school did not assess on students' achievement as a requirement for school admission. My students are low performing. The majority of my student population are the children of workers, small traders, [or] low-paid employees. A small percent of them come from high-income families or families whose parents are officials is low. Especially I see the proportion of families separated, living apart, divorce is quite a high rate. Previously, when investigated, the proportion was only $5-7 \%$, but now $30-40 \%$ in particular classes... Normally, parents often wake their child to go to school. Here, parents are different. Even in some cases, parents stood by their children by telling a lie that their children were unhealthy in order to help them have more days off... we rarely could find collaboration from parents.

In contrast, the majority of parents at Hen's school were from high-income families; however, Hen expressed uncertainty about their involvements in ACGC activities, because "with successful people, their time is gold, so I am not sure if they 
accept [my invitation to participate in month talks as guest speakers/experts] or not." Through these principals' explanations, it seemed that due to the school type as well as the student backgrounds, Principal Fon had difficulty finding support and collaboration from students' families, and Hen was unsure of what support and collaboration the students' families were willing to invest.

Similarly, Principal Phan explained he spent a lot of time persuading the community and parents to support the school's goal and mission, where "students are offered opportunities to gain experience, to live as a human [with good living values]. And people are now modern, they must know how to make a career." Phan shared from his personal experiences, saying, "This society values achievement, [and] examinations. I have gone on my own path, I was not supported. It seemed like I lost my way, thus people refused to support me. It took me 20 years with barriers, enticements, persuasion, communication to make people understand many things." Phan expressed the feeling of being alone while making effort to change a social norm, which could show how difficult his path was. Without a community support (either from parents or people in the community) it was nearly impossible for Phan to implement ACGC activities successfully. This need for support remained a barrier for Phan.

Lack of Community and Educational Leader Involvement. Regarding support from community leaders and higher authorities in the educational system, such as the local department of education and training, or school investors, for ACGC activities, Principals Phan, Hen, and Fon, all at private schools, found different difficulties regarding persuading these community leaders, superiors, or investigators to offer practical decisions to support their schools' goals and mission including ACGC activities. 
Specifically, Principal Fon, leader of the first private special education high school in Vietnam, provided a related example where superiors refused to figure out possible solutions to help his school model grow better as follows:

National leaders, [and] knowledgeable persons are interested in and excited about my school model. When my school just started, all the party secretaries came to visit my school...[However,] No. [they did not offer any practical help]. They came to give verbal incentives, compliments. For example, the party secretary at the period of 90-95, he viewed my school was a shining star in the educational system. However, he was just saying this [but did not help anything] because my school is non-public...The vice-president of Hanoi made the decision for me to open this school. She told me that if I was successful with this school model after three years, she would help me with school's infrastructure. However, sadly, she moved her position to work for the national community then. I relied on her words and I, myself, was so committed to develop the school and did not pay enough attention to school finance...Vietnam is different from Western countries at this point, because the public and non-public sectors work together to solve common issues...As I speculated earlier, if my school was changed into a public school, it would fail. I do not have any requirement for school admissions, thus, if the school is like a public school, all of my low performing students will be expelled from school...I used to share my school issues and asked for help from the director of the local Department of Education and Training. He responded that if I found 
it difficult [to maintain my school model], I could ask to change it into a public school.

Fon expressed his disappointment with the superiors' responses when he reached out to them for help, specifically to improve the conditions of his school to get better infrastructure for teaching and learning. The reason was that while the superiors provided much support and help to public schools, including providing land and facilities without fee, private schools like him did not get the same advantages. His school was renting facilities that were too small and cramped for most of the school's learning activities, including ACGC activities. Fon was sad, because while the superiors understood "his school's goals and missions which were to help low-performing students who did not receive the society's enough attention and care", his superiors did not provide practical support or help, just because his school was private. Fon further added, "Public school and private schools should work together to solve shared problems. The superiors need to focus on such big goals. However, Vietnamese superiors did not think that way. I think [in Vietnam], if any superior is able to say that [public and private schools need the same treatment], she/he must be very knowledgeable, have a steady viewpoint, [and] dare to make decisions."

Principal Hen was in a different situation where he found it difficult to persuade his school's investors to get approval for implementing useful activities including ACGC activities, saying:

In my opinion, when I see issues at school, I will discuss them with the investors. The investors often care about finance. They understand me to some extent, but sometimes they do not understand what I said. They 
thought that I exaggerated the issue or idea of ACGC activities. But in fact, they are not people with educational knowledge, and sometimes they do what other people suggest. If they listen to highly educated professionals, it's easy for me. But when they listen to public school experts, it will be very difficult, because they are different. In general, school investors are not educators. They hired a school principal to mainly sign paperwork. The investors will do all.

Hen contended that investors had limited awareness of educational leadership, because they were business-minded; thus, they were not always giving approvals to implement useful ACGC activities as they did not understand how important they might be to students. This caused particular barriers in designing and implementing useful ACGC activities Hen wanted.

Unlike the perceptions of Principals Fon, Phan, and Hen about the involvement of parents, educational superiors, or school investors in terms of implementing ACGC activities for students, Principal Anh found a lot of cooperation and supports from students' families and graduated students to design and implement students' activities including ACGC ones. Principal Anh proudly stated that, "At my school, the four highlighted features of my school over other schools are students, parents, school leaders, and alumni." The fact that Anh received a lot of support from family and alumni students at her high performing school makes sense, because most of the students' parents, as well as alumni, were of a high socioeconomic status. In addition, Anh's school was one of few public schools in which the local government and the local department of education and training had invested in more than others in infrastructure, teaching methodology, 
managerial and teaching staff, high-quality curriculum, and high-quality services. This included career-oriented activities and other extra-curriculum (Hanoi People's Committee, 2013). The reason for this investment was to assist these schools in training and providing "good" students for universities as well as a good workforce for the country in the future. Thus, Principal Anh, as well as other school leaders, may have likely been able to provide many additional ACGC activities beyond the four MOET requires due to the high requirements from the superiors, the school' good infrastructure, good teaching staff, and high-performing students.

Lack of Best Practices in ACGC. A lack of best practices in ACGC was another specific difficulty which the BC principals, Fon, Phan, and Hen perceived in implementing new ACGC activities. They noted it took a lot of time and effort to learn and implement some new ACGC activities, but the activities' effectiveness was not as expected due to costly expense, long duration of complementation, a high degree of complication, or low reliability. Principal Fon provided some examples when he said:

I had to stop use Dermatoglyphics. At the beginning, they [experts] voluntarily helped me, then when I needed to do with a large population of students, they asked me for fee. Actually, I realized this method was not effective and costly. Dermatoglyphics become popular...but its reliability has not been well researched...I also used to apply a method a Ph.D. graduate from the U.S suggested. However, it was so complicated, and its reliability was not high.

Principal Fon was determined to apply Dermatoglyphics and other tools to help students identify their own natural talents, values, and personality. However, eventually, Fon 
stopped using these methods, because the reliability was low and it was time-

consuming. Moreover, the method which uses information about an individual's blood types to see which career choices that person best fits was another example of a lack of best practices Fon provided. He carefully explained that, "I did not have the original document about this method in order to learn more about it. I had to ask friends in Japan for help [to find the document]." What Fon wanted to explain was it took him time and effort to learn about the method; however, what Dermatoglyphics could bring to his students was not as high beneficial as expected, and it was costly. Like Fon, Phan and Hen also admitted that they made additional effort to design and implement new ACGC activities, because they were "doing while learning" without instructions or information about best practices.

In conclusion, both the two groups of the non-BC principals and $\mathrm{BC}$ principals perceived particular challenges in their process of designing and implementing current or new ACGC activities. However, it seemed that the four BC principals determined their own challenges in a more reasonable way than the non-BC principals. Since then, these $\mathrm{BC}$ principals were able to find good strategies to sustain their abilities to offer use activities including ACGC for their students, which will be discussed in the next finding.

\section{Finding 3: BC Principals as Instructional Leaders in ACGC}

Despite the difficulties regarding the deep-rooted traditional educational ideology and the social norms of student achievement, a lack of collaboration between school and parents and superiors, and a lack of best practices, the BC principals, including Fon, Phan, Anh, and Hen, took steps to overcome these challenges in order to offer a variety of useful new ACGC activities for their students. In particular, as instructional leaders, 
the $\mathrm{BC}$ principals 1) ensured professional development opportunities for teachers and professional guidance and counseling staff, 2) engaged in self-learning about ACGC activities and their implementation, and 3) looked for alignment to their school's goals and missions, including ACGC activities. Furthermore, the BC principals actively worked at becoming social and educational change agents, making efforts to get parents, individuals, and local community organizations change their perceptions of student achievement and support ACGC activities at their schools.

\section{Getting Professional Development Opportunities for Teachers and Other Staff}

As instructional leaders, the BC Principals Fon, Phan, Anh, and Hen found it was not difficult to provide some kinds of professional development opportunities, including bringing in experts and directly leading these opportunities for teachers and professional guidance and counseling staff, to deliver ACGC activities in effective ways. Principals Fon and Hen perceived the main reasons for offering teachers professional development opportunities was because teachers were not trained to design and implement ACGC activities and were also unfamiliar with such activities. Thus, they believed teachers found it difficult to participate and organize ACGC activities at their schools. Particularly, Fon shared:

Many teachers [in Vietnam] are still keeping an old habit [of going to school to provide knowledge in the course they teach], still looking at each other, just trying to complete assigned tasks without commitment, not for their own joy, [and] not for the happiness of the students... The teachers at my schools are supposed to spend all the time with students, they are responsible for educating students...Teachers' roles are so important. 
They have been asked to participate in ACGC activities...I have spent a lot of time to provide professional development opportunities for them...[as] they did not have knowledge and skills in designing ACGC sessions.

Fon realized teachers in Vietnam had not been trained to design and deliver ACGC activities and were keeping "the old habits" where they often solely completed their assigned responsibility for teaching their courses. As a result, it was difficult for teachers to know what they needed to do, or to engage them in organizing ACGC activities. Thus, Fon was determined to provide the teachers at his school with professional development opportunities to help them gain the necessary knowledge and skills in ACGC. This was also Principal Hen's explanation about why he made efforts to provide his teachers with professional development opportunities: "I've organized professional development activities for them [the teachers]. It is difficult for them to meet the school' needs right after recruiting."

Similar to Fon and Hen, Principal Phan also contended it was imperative to provide their teachers with professional development to support their schools' activities including ACGC. For example, Principal Phan explained the benefit of offering professional development activities for teachers, saying,

Teachers need to enhance their professional lives non-stop. They develop professionally, then their students change their learning methods. As a result, this makes a difference in learning and teaching. Thus, the ongoing responsibilities for principals and other school leaders are looking for professional development opportunities, providing initiatives, being 
creative, making differences [in teaching and learning], [and]looking for new methods for teaching and learning.

Principal Phan contended offering professional development opportunities for teachers not only helped teachers gain necessary knowledge and skills in terms of academic and career guidance and counseling but also had a positive influence on students' learning methods in general and in ACGC activities in particular. Unlike Principals Phan, Fon, and Hen's schools where it was easier to recruit guidance and guidance staff to assist and support ACGC activities with teachers, Principal Anh, who was working at a public school with no such guidance and counseling staff, clearly realized the significance of providing teachers with professional development activities, and expressed her desires to organize these activities in the near future. Anh explained the need to offer teachers opportunities to gain knowledge and experience in ACGC, because "Headteachers and subject teachers are responsible for organizing ACGC activities under the supervision of the principal and the vice-principal."

Due to teachers not having the knowledge, skills, and experience with ACGC activities, the $\mathrm{BC}$ principals initially offered to host professional development training courses. In these training courses, principals invited Vietnamese experts and international experts from the U.S, Germany, Denmark, Israel, or others to come to help their teachers and professional guidance and counseling staff team learn about useful ACGC activities. They helped them improve their professional knowledge and skills to deliver those ACGC activities. Principal Fon explained one example of his efforts to organize professional development activities for the teachers and staff at his school, saying: 
As of 1991-1999, Mrs. Trish Summerfield from the living values program [which is managed by the Association for Living Values Education International (ALIVE), ['a collective of organizations and associations and individuals in over 40 countries that provide professional development workshops and curriculum resources to educators around the world' ] came to Vietnam. I invited her to come and provide professional development training for my teachers for a week... They [her team] led a professional development course. I did not need to pay them. Just provide some meals and help them with travel. Nothing was difficult. My teachers were so excited [with the training]... Any activity is useful or whoever has good ideas [for ACGC activity], I will learn and look for collaborative opportunities...I am always active to look for collaboration without waiting until the opportunities come to me. I, myself, need to look for these opportunities, persuade experts that I can collaborate or implement those activities, then they will support me. All of these opportunities would be the best professional developments opportunities [for me and my school staff].

Because Fon and his team did not have the knowledge, experience, and skills in certain ACGC activities like living values education, he had been "active to look for collaboration without waiting until the opportunities come" in order to "persuade them [experts] that [he] can collaborate or implement those activities." As a result of Mrs. Trish Summerfield's professional development training and Fon's commitment to implementing ACGC activities for his students, Fon not only helped his teachers and 
other staff manage to design and implement living values education activities as part of ACGC activities at his school, but also become an instructional leader in these activities who provide a lot of support regarding related technical skills when teacher needed (will discuss more in the next section). Like Fon and Phan, Principal Hen "invited experts to come and help the teachers" in order to get the teachers, especially new teachers, trained in knowledge, skills, and experience in ACGC.

In short, unlike the non-BC principals (Fin, Bach, Ben, Long, Han, Mon, and Na), Fon, Phan, and Hen, as school leaders and instructional leaders, perceived it was their responsibility to bring in experts offer teachers professional development and learn as much as possible about ACGC. These three principals did not find it difficult to look for support, help, or collaboration from organizations or experts to organize professional development activities for their teachers. However, it seemed that these principals' commitment as instructional leaders, rather than having strong financial resources, was why these $\mathrm{BC}$ principals were successful in offering their teachers and staff useful professional development.

\section{Directly Getting Involved in Designing and Implementing ACGC}

In addition to bringing in experts on ACGC activities to help teachers, guidance staff, and themselves learn about ACGC, the BC principals Phan, Hen, Fon, and Anh actively participated in the design and implementation of some of ACGC activities as experts or guest speakers. Particularly, as mentioned earlier about the range of ACGC activities BC principals offered their students, Principal Phan had made particular plans to participate in many seminars or other ACGC activities as a guest speaker. Phan proudly described, "Although I have a lot of work, I have participated in seminars at 
many classes. We have 68 classes. I have participated in such activities as a guest speaker for more than half of the classes for one period or 15 minutes. "

By sharing particular plans and what he had done, Phan expressed his commitment to being an instructional leader who was able to directly design and implement particular ACGC activities for his students. Similarly, Principal Hen also described one of his efforts in the design and implementation of field trips for the students at his school as follows: "I have collaborated with a number of state or international banks to be able to organize field trips for the students. I needed to discuss with these banks like if they may introduce a particular job, job requirements, the presentation duration of 40 minutes, for example, because if longer, the students will not hear any more." Hen had also directly designed and organized some field trips to provide students with more opportunities to explore career options in the future. Hen revealed one of his advantages in designing and implementing such activities, which was "previously when working for the local Department of Education and Training, I used to visit some Vietnamese schools and have opportunities to visit some schools at other countries [where there were useful ACGC activities]". Like Phan and Hen, Principal Fon had directly contributed to providing initiatives, making lesson plans, and providing demo ACGC sessions for teachers who were responsible for leading particular ACGC activities, like living values education for their students with low performing in both academic and moral aspects. Fon said:

New teachers found it difficult to organize living values education activities... For example, they had to look for evidence and facts when teaching how to love others. The professional guidance and counseling 
team and I helped to make lesson plans for these teachers. The teachers just followed the lesson plans. However, if the teachers did not have enthusiasm and commitment, they would have focused on completing their teaching. Thus, I had to deliver demo sessions for them, the head teachers. Then, they practiced and gained experiences [in facilitating these activities].

The data showed that Fon was greatly committed and enthusiastic about participating in designing and developing ACGC activities as an instructional leader who offered necessary support when needed to his teachers. As a result of his commitment and enthusiasm, eventually Fon saw his expected result. He reported, "my teachers have organized such activities well."

Like other BC principals, Principal Anh supported ACGC activities-projectbased learning activities in particular-by developing topics for projects every year. Anh shared:

I have supported my students' project-based learning activities in order to help students learn more about their schools' aspects, learn how to develop and manage these [project-based learning] activities, and know how teachers could assist them, how they become trainers for students at lower grades. [One example was ] I have developed multiple topics based on students' needs. And the range of these activities changes every year to meet students' needs.

As an instructional leader, Anh actively participated in designing ACGC activities to make sure ACGC activities' quality and implementation met students' needs, which 
changed after every year. Through the way Anh confidently shared about her responsibilities in these activities, it seemed she was highly committed to developing these activities at her school.

In short, in addition to bringing in experts to organizing professional development activities for school staff, all four BC principals, Fon, Phan, Hen and Anh, made additional efforts to be directly involved in designing and implementing ACGC activities at their schools, helping their teachers gain more experiences in delivering ACGC activities and providing best practices. This showed not only the principals' competence and their influence with teachers as instructional leaders, but also their high commitment to their school's goals and mission in terms of helping students get well prepared for their future academic and career paths.

\section{Ensuring Self-Learning about ACGC Activities and Implementing Them}

To make sure their teachers and other guidance and counseling staff gained the necessary knowledge about organizing ACGC activities and well organize these activities, three out of four BC principals (Phan, Anh, and Fon) ensured their own selflearning about ACGC activities and implementating them well. To make ACGC activities sustainable in their school, they used different strategies such as observing students' classrooms, reading books, doing research, or writing papers and books to enhance their own understanding of ACGC. Particularly, Principal Phan shared his efforts in learning, noting, "I have read about school leadership and research by U.S and German scholars in order to have good reasoning and provide research-based evidence in the process of implementing ACGC activities", "I have observed classes", and "I listened to others 
sharing useful activities." Phan tried to learn about ACGC activities as much as he could to implement more new ACGC activities and better support these activities at his school. Principal Fon, who was trained and had teaching and working experiences in the psychology, researched career orientation education and published research papers and books, first to serve his school and his teachers and students and then to serve other schools. Principal Fon described some of his strategies to research and learn best practices in ACGC activities as follows:

As of 2000, I successfully got funding from the city of Hanoi to do research on career orientation education in order to figure out how to implement useful ACGC activities at school... Next year, I will be finishing a guide book for my head teachers. The book will also be published to support any individual who is interested in [designing and implementing ACGC activities for high school students].

The data showed that Fon did not only depend on possible help from experts to provide professional development for his teachers.

In short, in order to design and implement useful ACGC activities for their students beyond some limited career-oriented activities outlined by MOET, all four BC principals (Fon, Phan, Hen, and Anh) made particular efforts to provide professional development activities for their teachers. Three of them (Fon, Phan, and Hen) initiated self-learning to improve their understanding of ACGC activities and how to implement them. These efforts did not only come from being good educational managers, but also great instructional leaders. 


\section{Using Instructional Leadership to Align ACGC and Teaching Methods to School Goals, Mission, and Vision}

In order to directly align teachers' practices with school goals and missions, including offering students useful learning opportunities to develop their abilities, interests, and careers, the BC Principals Phan, Fon, Anh, and Hen paid special attention to helping teaching staff understand their schools' goals and mission as a stategy toward sustainability of ACGC activities. The strategies Principals Fon, Anh, Hen, and Phan used were dissimilar. Specifically, when responding to the question "How did you recruit guidance and counseling staff at your school?” Principals Fon said:

I have a former student who was not an expert in guidance and counseling for students. She used to teach a subject [which did not relate to ACGC]. [However,] she is good at figuring out students' issues. She is still not good at others. But I encouraged her to work here [as guidance and counseling staff]. I said "You have the capability of doing it; however, do you want to do it or not? Are you interested in? If yes, I would like to offer you an opportunity" for example... I also recruited Ranh, a retired vice principal, who is good at the horoscope.

As an instructional leader, Fon asked the candidates some questions in order to understand their strong and weak points and to figure out if her/his experience could support ACGC activities. It was not only the way Fon conveyed the organizational vision and mission to new staff but also the way he found the right person who fits the organization. Moreover, Fon further explained his efforts to get every teacher aligned with his school's goals and mission as follows: 
If my school chose students, only accepted high-performing students like Luong The Vinh school, only focused on teaching for testing to help students go to college, I would not have a lot of work and have more money. Right? However, I did not choose that way. You know my pressure is big and what I am facing is also big. Even teachers did not want to work with me. I have been determined to do it [develop the special school model to educate low-performing students]. I showed teachers how to do provided good conditions for them, inspired them. I showed them how to do and in what ways in order to get the targets.

In short, as an instructional leader, Fon not only made many efforts to recruit qualified staff but also had a strong commitment to helping teachers and staff gain a deeper understanding of their school's goals and mission in order to build up a good team for ACGC activities.

Principal Phan chose a specific training strategy to ensure every teacher, including new teachers, had opportunities to learn about and discuss the school goals, mission, and vision, which included supporting ACGC activities as part of the main school curriculum. Phan noted: "Every school staff is expected to have a good awareness of the school's goals and missions. If a new staff has just been recruited, he/she will participate in a training course" to get the given goal. In addition to offering the opportunities for school leaders and teachers to discuss the school's mission, goals, and vision, functioning as an instructional provider, Phan also encouraged the teachers to apply new methods in the learning and teaching process at their schools. Phan emphasized: 
With teachers at my school, I have discussed with teachers that the role of teachers is not going to the class and open the textbook and follow all things in the books and then going home. With such a traditional teaching method, students do not gain anything, they can learn by themselves. The important thing is teachers have to become educators who have knowledge and skills about students' psychology, to provide good responses in many situations.

By clearly communicating with teachers about how his school's goals and mission is aligned to ACGC activities, Phan wanted to see necessary pedagogical changes from the teachers to better meet students' needs. As a result of this alignment, Phan shared his expectation of his teaching team and how he envisioned their learning extending to students and parents, saying:

Each teacher is like an amplifier. When the amplifier sends out the message, there are ten persons who can hear. When the ten persons become other amplifiers, we will have other 100 amplifiers, so we have good communication with students and parents around us. We have 500 students, so we have 500 amplifiers and then have 3,000 supporters. And when we have 3,000 supporters, I will have 30,000 other supporters, so in 20 years, how many will we have?

In general, according to Fon and Phan's perception, helping teachers enhance their understanding of school's goals and mission not only challenged their daily pedagogical practices, but also helped spread out the school's core values to other teachers and even students and their parents. Such an effort was not made by non-BC 
principals who focused on students' achievement based on academic scores; non-BC leaders also appeared to avoid decisions regarding changes in school culture and teaching and learning methods.

Principal Anh did not share much about her efforts to ensure her teaching staff had insight into her school's goals and mission that included ACGC activities. However, the large range of ACGC activities which were implemented consistently and systematically at her school might best show how her teaching staff and other school staff's practices supported the school goals and missions. In addition, the total range of ACGC activities at her school might indicate how well the students were prepared for academic and career development in the future.

In conclusion, to offer necessary support to school staff in the process of designing, implementing, and sustaining ACGC activities, all four BC principals Anh, Hen, Phan, and Fon functioned as instructional leaders in ACGC who were able to ensure many strategies. These strategies included getting teachers trained in ACGC, directly participating in designing and implementing ACGC activities at their schools, learning about ACGC and its implementation as much as they could to offer necessary support when needed, and looking for alignment regarding ACGC and teaching methods to their school goals, mission, and vision. As a result, these $\mathrm{BC}$ principal were able to offer various sustainable ACGC activities with the participation and support from their teachers and other staff. 


\section{Finding 4: BC Principals as Active Social and Educational Change}

\section{Agents}

In addition to being active instructional leaders, the $\mathrm{BC}$ principals were also active social and educational change agents. They made efforts to help parents, the superiors, and students have a better awareness of student achievement as well as learning and teaching methods. Then, as educational partners, these parents, the superiors, and even students would be able to provide necessary supports for learning and teaching activities at schools like ACGC activities.

\section{Viewing Parents as Educational Partners}

The four BC principals, Fon, Phan, Hen, and Anh, made efforts to help make parents "the companions and partners of the school" as Phan said, and have appropriate insight into student achievement in ways that cannot be assessed by student scores and test results, as Principal Phan shared. Principals Anh and Phan explained the importance of good communication and collaboration with the parents at their school, because they perceived "Once parents understand the school's goal and mission, then they will become educators" who can share the core values with the school and support its activities. BC principals Anh, Fon, Phan, and Hen shared many different strategies to inform parents. For example, Phan shared one of the related experiences when he said:

We had to persuade them [parents], make them change their perceptions of student achievement at school, their methods of educating their children, [or] sharing things in life. To do that, my schools have organized many activities attracting parents' participation... At typical teacher-parent conferences, parents come and listen to teachers' feedback related to their 
child for 15 or 10 minutes, then pay tuition and get back home. Teacher and Parent conferences at my school are not the same. In the beginning, the teachers will report the school's activities, inform them of school plans, of what the school did well or not, and say thank you to them. Doing so helped parents have a feeling of belonging, of being respectful and know their voices were heard. Later, the parents visit their children's classrooms, having a meeting with not only the head teacher but also all students of the class. Students may make a video, or read letters in order to share their interest and concerns [with the parents and teacher]... Or the parents participate in activities like games to learn more about their children, such as their interest, [and] hobby. Actually, this was a session at a particular class I observed. I found it good, thus, I asked the teacher to organize the session again for parents. The parents will believe [in what we teach at school].

Phan contended getting parents involved in school activities helped the parents have good awareness of how their children learn at school, how the school applies new teaching methods, and then the parent would be willing to support school activities which are aligned with school's goals and mission. Phan gave another related example, talking about a parent's thoughts after a teacher-parent conference, which his school purposefully organized, as follows:

A parent came to talk to me about her experience regarding respect and democracy in the school they found. She [the parent] said "I think I had experience learning at school, for so many years ago, but I did not live 
right with my youth, did not live as a human due to pressure on achievement, a pool of stop signs: do not do this and that. I did not have opportunities to learn with self-discipline or live in an environment with values. But there [ at this school], teachers just observed and facilitated students' learning activities".

Through the example of a parent's thinking, Principal Phan wanted to say that his efforts to impact parents' perceptions of student outcomes and the teaching methods used brought particular expected results. Specifically, in their support to his schools' changes in learning and teaching methods, as well as in assessing student achievement at school.

Like Phan, Principals Anh and Hen stressed the significance of parents' support and participation in her school's activities, including ACGC activities. Specifically, Anh and Hen emphasized: "The four outstanding features of my school which make a contribution to the success of the school activities are students, parents, school leaders, and alumni" (Anh) and "Here, there is an advantage where the students want to participate field trip, parents will support" (Hen). However, both of these principals did not explicitly describe the efforts they made to receive the necessary support from parents.

In conclusion, all four BC principals, Fon, Phan, Hen, and Anh, focused on creating opportunities where parents had the chance to hear and discuss the school goals and missions. This effort was made to get the parents involved in and support the school's activities, including ACGC. Thanks to such an effort, these principals perceived that the parent was able to see positive changes in her child's learning as well as support new ACGC activities. As a result, these principals viewed parents 
as their educational partners as a way to sustain their abilities to implement and develop ACGC activities at their schools.

\section{Viewing Individuals and Local Community Organizations in the Community as}

\section{Educational Partners and Supporters}

While the non-BC principals (Fin, Bach, Ben, Long, Han, Mon, and Na) found it too difficult to work with individuals and local community organizations to design and implement ACGC activities and viewed a lack of collaboration with individuals and organizations as a barrier preventing them from designing and implementing new ACGC activities, the BC principals, Hen, Phan, and Fon, did not have the same experiences. Three of the four BC principals actively looked for and created opportunities to help educational superiors or organizations and individuals in the community have a better understanding of their school's goals and mission. They made effort to get these groups and individuals to become involved in creating useful activities for their students. For example, Principal Phan shared their efforts to organize workshops at his school and invite superiors to attend or raising their voices at forums as a way to "persuade" or inform these superiors of the significance of initiatives and innovations in education including new ACGC activities. He said, "I have persuaded everyone. I have had speeches on forums. I showed my perceptions of education. I have organized a variety of conferences and always invite superiors to come to attend." By being actively involved in forums and inviting superiors in the field to attend workshops on educational reforms, Phan hoped his supervisors would see value in ACGC activities. The hope was this could lead to make necessary changes from the top soon in the future to promote the development and achievement of students. While Phan further shared "it has been taking 
[him] up to 20 years to fight with the social norms [which values certificate-merits and assessment based on examinations], seeking support, persuading everyone, and communicating in order to help people understand my perceptions", he had managed to implement some activities including ACGC with particular support from the superior. Phan said: "They [some superiors] could not create new policies or new changes, but they did not protest my new activities. It means they allow me to do those activities". The data showed that Phan's effort in the last 20 years had started to bring some positive results where the superiors regularly see and support his school's goals.

Principal Fon shared some similar experience to Phan's when he had made effort to change community perceptions regarding teaching and learning. In addition to doing research and having books published as mentioned earlier, Fon had also participated in many interviews with many newspapers and forums and had also looked for young people who had the same passion for educational reforms to collaborate with them. Fon revealed:

I founded a team named "Young Parliamentarian". I want to collaborate with them in order to influence educational policies. We need to do some very specific things to help Vietnam reflect on its educational issues. Why should we do it? I have limited knowledge of educational theories, because my English is poor. I just think that I have to do something practical to help a little and then everyone changes. I did not dream about something too big. That is my job...I had been invited to participate in many interviews about educational problems that are happening. I always 
wanted to find long-term steps, and I hoped that I and young persons like you will collaborate for a long time.

Fon valued collaborative opportunities and expressed his commitment to working with individuals and local organizations in the community to raise their voices with the hope of figuring out potential solutions for existing Vietnamese educational issues. This included getting more attention to the design and implementation ACGC activities.

Principal Anh also made effort to look for collaborative opportunities with local and international organizations to provide her students with new ACGC activities. Anh explained, "My school is always actively looking for partners in order to create as many new learning projects for students," although she did not provide any specific examples of what kinds of ACGC projects she had in mind. It seemed that persuading and creating such collaborative opportunities with local and international organizations was a strategy Anh used to start building up a new culture where individuals and organizations in the community and in the world got involved in school activities and made contributions to the development of the school and the society, as well as the world. Like Phan, Fon, and Anh, Principal Hen also looked for collaborative opportunities which not only offered new ACGC activities for his students as he talked about field trips at his school, but also offered local organizations opportunities to engage in his school's activities. Furthermore, Hen expressed his desires to "offer advising on the design and implementation of school activities as well as school administration to any individuals or organizations who need without taking a fee." It seemed like Hen wanted to make contributions to change the 
society's perception of the roles of individuals and organizations toward schools in Vietnam.

\section{Finding 5: Non-BC Principals' Relying on Limited Internal and External Resources and Parents' Interest to Implement ACGC Activities}

Unlike the BC principals who used various useful strategies to design, implement, and sustain a larger range of ACGC activities, the non-BC principals revealed some ineffective ways of implementing and sustaining ACGC activities for their students. These ways included 1) using head teachers as the main human resource responsible for organizing a few of ACGC activities, 2) rely on MOET or universities to reach out opportunities, and 3) relying on students and parents' interest.

\section{Relying on Head Teachers to Organizing a Few of ACGC Activities Outlined by MOET}

It seemed that the non-BC principals, as school managers responsible for implementing MOET sanctioned activities, relied on their head teachers for the organization of ACGC activities. As analyzed earlier, when describing ACGC activities preparing students for college and exam, most of the non-BC principals contended that "The implementation of this activity depends on teachers" as Long explained. Ben described the way his head teachers implemented this activity as follow: "[Head] Teachers have the information about the numbers of admission from universities [from MOET]. Information about careers is on MOET's website. Teachers just introduce this information to their students." With Ben's explanation, his head teachers seemed to do no more than pass information without providing particular counseling and guidance to meet individual students' needs. Also as mentioned earlier, the non-BC principals, $\mathrm{Na}$, Mon, 
Fin, and Bach, were aware of the head teachers' limitations in knowledge and skills in ACGC; however, the non-BC principals even seemed to accept "the reality. [where] They [head teachers] cannot do it [the design and implementation of ACGC activities]" (Long) and "students find a job suitable, they choose that job" (Fin). Long and Fin let their teachers, the main internal resource, organize ACGC activities in the way the teachers wanted, even though the two principals did not provide necessary help when knowing their head teachers did not make the activities for students due to the lack of training in ACGC. The response of the non-BC principals was different that of the $\mathrm{BC}$ principals who made many efforts to provide teacher professional development opportunities when they were aware of teachers' limitations in ACGC knowledge, skills, and experience.

\section{Relying on External Resources (e.g., MOET and Universities or Organizations) to Reach Out ACGC Opportunities}

Also mentioned earlier when describing the range of ACGC activities the non-BC principals offered their students, the seven non-BC principals (Ben, Fin, Long, Mon, Na, Han, and Bach) relied on MOET' guidance and universities' proactivity to implement ACGC activities. For example, in terms of school-based activities that prepare students for college and provide information about exam, Ben explained: "Information about careers is on MOET's website". It was the main external resources from MOET that Ben

and his teachers used to show students. In addition to these activities, Fin, Ben, Long, and Mon "sometimes" implemented college fairs for their students. Ben explained the inconsistent way of organizing these college fairs because "[if] any student is interested; they will attend." Ben and other non-BC principals relied on ACGC activities which were organized by other organizations and these principals' responsibility was to inform 
students of the opportunities. Principal Long and Mon did not encourage their students to attend such fairs but "gave approvals [for universities who] come and ask" to host college fairs or college application advising sessions at their schools. Thus, these two principals seemed not make much of an effort beyond giving approvals to these organizations.

\section{Relying on Students' and Parents' Interest}

In addition to implementing a few ACGC activities outlined by MOET such as activities preparing students for college and exam information and college fairs, the nonBC principals, Han, Long, and Na, organized some non-academic clubs (e.g., soccer, guitar, and dance) to meet parents and students' interest as a break from the heavy curriculum because "The students found the time for learning at school was too much. They wanted extra-curriculum to develop their hobbies" (Han). However, both Han and Long admitted that they solely organized such activities which "are not [were] well prepared, just occasional" and let students make them happen "after school" (Long) or “every Sunday" (Han) depending on students' interest. Based on the way these activities were organized and implemented, it seemed that Han and Long did not need to make effort, such as asking school staff to facilitate or provide advising to help students explore their potential interest or strengths as one of the values of providing ACGC activities.

Moreover, although Principals Mon, Long, and Ben were able to offer students two types of additional ACGC activities, including English-focused activities (e.g., English tutoring and English advanced courses), it seemed that these principals did not design them for the purpose of helping student explore their abilities and interests in the language of English, but increasing student achievement and the schools' reputation. Although hese activities might require Mon, Ben, and Long to take more time and effort 
to design and implement than other ACGC outlined by MOET, these principals did not need to reach out for help with individuals or organizations in the community in order to provide these opportunities, but used their teaching staff and parents' interest in increasing student achievement and their opportunities to attend colleges to create these activities.

In short, in order to implement ACGC activities at their schools, the non-BC principals seemed to choose ways that required less effort to improve the quality of ACGC activities, such as time to train teachers or look for collaborative opportunities from parents and community organizations.

\section{Summary of Findings}

In summary, unlike the traditional leadership style, which avoids disagreements, decision making, and efforts to change, create, and sustain new useful student learning opportunities which traditional principals like the non-BC principals in this study often used, the BC principals, especially Fon, Phan, Anh, and Hen, made many efforts to make a difference in students' learning outcomes by not only their particular actions to nurture their schools' culture where every member of the school is committed to its core values, but also to raise their voices, look for, and collaborate with individuals and organization in the society in order to figure out effective strategies to design and implementation use activities including ACGC at their schools and simultaneously to boost Vietnam's educational reforms.

The findings show that the ways the principals think about and implement ACGC activities may help determine the relative success and failure of ACGC activities at their school. Particularly, the ways the seven non-BC principals (Na, Bach, Long, Han, Fin, 
Mon, and Ben) viewed ACGC activities as extra-curriculum led to the small range of ACGC activities they offered their students at their school. Moreover, the finding also indicates the ways these non-BC principals saw the difficulties, including their heavy workload, the lack of guidance staff, the lack of agencies, and family's greater influence on student's choices than schools, as the barriers preventing them from creating useful ACGC activities. Due to these difficulties, these principals expressed their unwillingness and their lack of readiness to design and implement additional ACGC activities for their students. Instead, they sustained ACGC activities by relying on a few internal and external resources. In contrast, the four BC principals (Fon, Phan, Anh, and Hen) were able to recognize ACGC activities as part of their main curriculum and perceived their alignment with their schools' goals, missions, and visions. Thus, although these BC principals faced many difficulties such as the traditional Vietnamese education ideology where students' achievements are assessed by high scores as well as certificates (Bodewig, et al., 2014; Hallinger, et al., 2017), the lack of support from parents, the community, and educational leaders, and the lack of best practices in ACGC, they were committed to navigating strategies to sustain their ability to implement useful ACGC activities for their students. The strategies these BC principals used were 1) offering professional development opportunities to teachers and staff, 2) directly getting involved in designing and implementing ACGC activities with teachers and staff as ACGC experts. Additionally, these $\mathrm{BC}$ principals used some other strategies such as 3) using instructional leadership to get every school members and their practices be focused on ACGC activities as a way to align these activities to their schools' goals, missions, and vision, 4) viewing parents as educational partners, and 5) viewing individuals and 
organizations in the community as educational partners and supporters. Moreover, to successfully use these strategies above, the $\mathrm{BC}$ principals pushed above and beyond the Vietnamese traditional principalship to be able to function as instructional leaders and active social and educational change agents. 


\section{CHAPTER FIVE: DISCUSSION AND IMPLICATIONS}

This study sought a deeper understanding of Vietnamese high school principals' perceptions of ACGC activities in terms of preparing students for their future academic and career paths. It also sought to understand the difficulties principals perceived and faced in the design and implementation of additional ACGC activities, and explored the strategies or efforts principals use to sustain their abilities to implement these activities. In Vietnam, high school principals are responsible for helping help students be prepared for career explorations and academic choices after high school graduation (MOET, 2003; MOET, 2014; MOET, 2018b). However, the findings show that there were differences in the ways the non-BC and $\mathrm{BC}$ principals in this study thought about ACGC activities and viewed overcoming challenges to designing and implementing these activities; there were also differences in the strategies the principals used to sustain ACGC activities at their schools. Additionally, the differences in what Vietnamese high school principals in this study thought and did for ACGC activities affected the relative success or the failure of ACGC activities. Specifically, this study's findings included:

1. Non-BC principals viewed ACGC activities as an extra-curricular, but BC principals integrated them into their main curriculum.

2. Non-BC principals viewed their challenges as barriers preventing them from designing and implementing ACGC activities, while BC principals knew there were challenges but they were proactive in finding ways to overcome these challenges.

3. As instructional leaders, $\mathrm{BC}$ principals used a number of strategies to sustain ACGC activities (e.g., offering professional development opportunities to 
teachers and staff, getting directly involved in designing and implementing ACGC activities with teachers and staff as ACGC experts, ensuring their own self-studying in ACGC activities and using instructional leadership to get every school member and their practices focused on ACGC activities).

4. As active social and educational change agents, the $\mathrm{BC}$ principals were able to use additional strategies, including getting parents, individuals, and organizations in the community involved in ACGC activities to support the development and sustainability of these activities, the non-BC principals relied on a few universities for some ACGC activities in an attempt to increase students' achievement and their opportunities to attend college.

5. Non-BC Principals' Relying on A Limited Internal and External Resources and Parents' Interest to Implement ACGC Activities

To get the key findings above, this study utilized the Border Crossing theory which focused on educational border crossers' efforts in pushing above and beyond a managerial principalship style in order to understand their experience in offering educational opportunities, including ACGC activities.

In this chapter, I discuss the key findings of this study and their implications. Particularly, I discuss the differences in what non-BC and BC principals thought about in terms of preparing students for their future path. I also discuss what these principals have done to help their students prepare for their academic and career future paths and how they have gone about going that. The findings of this study have implications for current and pre-service Vietnamese high school principals, and may help these administrators get 
a better understanding of how to become border crossers and $\mathrm{BC}$ principals who know the value of ACGC activities and how to effectively design and implement ACGC

Next, I discuss the implications for practice which will be beneficial to high school Vietnamese principals who are interested in effectively designing and implementing ACGC activities. This study's findings also have implications for MOET, other Vietnamese educators, policymakers, individuals, and community organizations, who may use the study to help raise awareness of their own roles and provide appropriate responses to better support school leaders and teachers in the process of designing and implementing ACGC activities. Finally, I will discuss the implications for future research.

\section{Non-BC Principals Viewed ACGC Activities as an Extra-Curricular, but BC} Principals Viewed These Activities as Part of the Main Curriculum.

In Vietnam, at the high school level, school principals are responsible for helping students be prepared to explore career and academic options/opportunities (MOET, 2003; MOET, 2014; MOET, 2018b). While research has not yet shown what all Vietnamese high school principals know about ACGC activities, the findings of this study showed that 11 Vietnamese high school principals in the Hanoi area did not think about or implement ACGC activities in the same way. Particularly, while all seven non-BC principals in this study perceived ACGC activities as an extra-curricular, the four BC principals integrated ACGC activities into their main school curriculum because of the significance they placed on preparing students for future academic and career opportunities. The differences in the two principal groups' perceptions of ACGC activities and these activities' importance may have led to differences in the number of 
ACGC activities the two groups organized and the design and implementation of these activities at their schools.

In viewing ACGC activities as extra-curricular, the seven non-BC principals infrequently and inconsistently offered mainly 12 graders one-to-three kinds of ACGC activities that focused on student achievement. These findings is consistent with the findings by Do (2009), Nguyen (2011), and Bui (2014), which mentioned earlied in Chapter Two, on the ineffectiveness of career-oriented activities at Vietnamese schools. Unlike to the non-BC principals, the four BC principals integrated ACGC activities as part of the main school curriculum and committed to implementing five-to-nine types of ACGC activities systematically for the academic and career development of all students (See Appendix D). This finding indicated that the difference in the ways the school principals in this study perceived ACGC activities as either extra-curricular or part of school's routines doings may have affected the ways these principals unsystematically or systematically organized these activities.

The findings also indicate some possible reasons for the difference in the principals' perceptions of ACGC activities. First, the non-BC principals' viewing ACGC activities as extra-curricular was partly because they did not find them to be integral or important. It might be that many of the Vietnamese principals, including the non-BC principals and even the BC principals in this study, were not equipped with the necessary knowledge and skills of what ACGC activities could look like, sufficient understanding for why ACGC activities are important, and how they might consistently implement ACGC activities. There is a need for Vietnam National University and other universities to include required courses related to learning about ACGC activities in school 
administrator preparation programs. Offering required courses about ACGC in school administrator preparation programs at Vietnam National University is feasible because since 2018 only, Vietnam National University was were able to train experts in school counseling with Masters' degree according to the standards by Council on the Accreditation of Counseling and Related Educational Programs (CACREP), American School Counseling Association (ASCA), and International School Psychologist Association (ISPA) (Vietnam National University, 2018).

Unlike the non-BC principals, the $\mathrm{BC}$ principals' view of ACGC activities as part of the main school curriculum showed that the principals value these activities because of their particular experience or knowledge in this area. Specially, Principals Fon studied educational psychology and had a lot of experience working with low-performing students, providing and implementing many initiatives to help these students have more learning motivation and life aspirations. Furthermore, Fon was very active to develop his own professional growth in ACGC; thus, he gained a better understanding of the function and meaning of these activities than perhaps most other principals. Hen, Phan, Anh, and Fon, also BC principals, had had many experiences learning about ACGC activities through visits to foreign schools. As a result, the $\mathrm{BC}$ principals might be able to reflect on the current ACGC activities they were presented with in this study and may be more opened-minded to new learning opportunities including ACGC activities than the non-BC principals.

Moreover, the findings showed that more than half (seven) of the total 11 school principals in this study did not have good awareness of ACGC activities and the need to design and implement such activities. This raises a concern in the larger context of 
Vietnamese education about whether or not Vietnamese high school principals have sufficient knowledge and skills with ACGC to help students prepare for their future academic and career explorations and opportunities. To address this issue, it appears that MOET will need to do better to ensure at least school principals at urban areas, get training or professional development activities. Helping these school principals at urban areas trained in ACGC is feasible, because their students likely come from families with middle or high socioeconomic status background; thus, their school principals may get more access to ACGC resources than other school principals in other areas. This effort by MOET may be a good start to help school leaders gain the necessary knowledge and experience in ACGC, develop a better awareness of ACGC activities, and gain the experience needed to implement them. Simultaneously, MOET and its lower departments also need to be aware of the importance of ACGC activities in relation to other required courses (e.g., Math and English). This may help school leaders pay attention and make efforts to learn about ACGC and navigate ways to effectively design and implement such activities. Additionally, MOET needs to more explicitly emphasize the significance of ACGC activities not only at the high school level, but also in other levels of the national education system so that implementation of ACGC activities is systemic. Lastly, school administrator preparation programs at Vietnamese universities might design appropriate courses to provide current and per-service principals with necessary knowledge, skills, and experience in ACGC activities. With these changes from MOET and school administrator preparation programs, school principals may have a better attitude toward ACGC activities in terms of preparing students for their future education and careers. 


\section{Non-BC Principals Viewed Their Challenges as Barriers Preventing Them from \\ Designing and Implementing ACGC activities; BC Principals Knew There Were Challenges but Proactively Found Ways to Overcome These Challenges}

Similar to the differences in the non-BC and $\mathrm{BC}$ principals' perceptions of ACGC activities and the activities' significance, there were dissimilarities in the barriers that the non- $\mathrm{BC}$ and $\mathrm{BC}$ principals perceived and faced while designing and implementing ACGC activities. There were also notable perceived differences in their openness to additional ACGC activities beyond MOET's requirement. Specifically, the seven non-BC principals, who did not have good awareness of ACGC activities and were unable to offer a large range of ACGC activities, contended they met many difficulties. The difficulties they cited included their heavy workload, lack of guidance staff, lack of community agencies to support ACGC activities, and the view that families' held greater influence on students' choices than schools. In other words, non-BC principals revealed they had a lack of time resources, human resources, and social resources to assist them in effectively designing and implementing current ACGC activities. Regarding their lack of time resources, non-BC principals explained that most of their school time were spent for helping students and teachers meet learning standards given by MOET. Therefore, it may have led to the issue where these school principals viewed ACGC activities as extracurricular and these principals indicated they did not have time to think much about or effectively implement ACGC activities. To address this issue, MOET needs consider reducing learning expectations for each grade and course that students have to take. Principals will then likely have more time to improve current ACGC activities and design and implement additional ones. 
Regarding the lack of human resources, specifically, professional guidance and counseling staff, the non-BC principals revealed that while they had the right to recruit such staff, they did not have enough funding to sustain those positions and needed to rely on MOET to give more money. The lack of human and financial resources might also explain the reason why the non-BC principals were able to offer only a limited number of ACGC activities. Except for Bach, Fin, and Han's schools which were located in suburban areas where many of residents were low-income families, other non-BC principals at urban schools might have found ways to raise funds to recruit a professional guidance and counseling staff. However, all seven non-BC principals did not reveal they made any effort to figure out possible strategies to overcome the barriers they perceived and faced to effectively implement current ACGC activities or additional ones.

A possible explanation for the non-BC principals' unwillingness to implement many of current and additional ACGC activities may be consistent with earlier findings which show that the non-BC principals did not understand the value of ACGC activities. Another reason might be that some of the non-BC principals wanted to privilege and protect their reputation regarding student achievement; thus, they did not plan to invest time and efforts in ACGC activities. In Vietnam, to sustain the school title as a good performing school, a high school principal needs to make sure his/her school meet some requirements, including greater than $95 \%$ of students passing the mandated graduation exam and 90\% of students attending college (People's Committee of Ho Chi Minh City, 2014). As a result, school principals likely put their priority to help students increase their academic achievement. The priority seemed to be a way to protect their schools and their own reputation and sustain a good student enrollment rate. However, a concern that 
should be raised for Vietnamese educators and policymakers about the capability of Vietnamese school principals, including the non-BC principals, to push beyond the managerial style in order to do more than what is assigned and overcome difficulties to create and improve students' learning opportunities, including ACGC activities. In relation to this concern, changing Vietnamese school principals' mindset toward the value and the need of implementing ACGC and changing their ways of working likely takes time and requires sustained and intensive professional development activities and a lot of guidance on ACGC from MOET. Moreover, because relying on financial and human resources to implementing ACGC activities from MOET may take times; school principals may need to figure out their own ways to meet their needs. One potential way to increase school budget which Vietnamese school principals at both high- and lowincome communities in Hanoi may consider is asking for financial contributions from community organizations such as businesses, companies, community associations, and factories. Asking for financial contributions from community organizations to the implementations of school activities, including ACGC, may be more feasible than asking for such help from parents, including those with low SES. This implication is consistent with that of Nguyen (2011) regarding the need of financial community contributions to support the implementation of ACGC activities at Vietnamese schools. Also like Nguyen (2011)'s implication, MOET may consider providing financial support to public schools, especially those from low-income communities, to sustain a position of school counselor or professional guidance staff in order to assist school leaders with knowledge, skills, and experiences in designing and implementing ACGC activities. 
Similar to the ways the non-BC principals viewed overcoming difficulties regarding the lack of human and financial resources, these principals described their lack of social resources but did not reveal any effort to circumvent the issue. It seems that the cooperation between their schools had rarely happened before. Moreover, they did not seek out the contribution of individuals and organizations in the community to organize ACGC activities because they might be so focus on student achievement, thus, they had a lack of time and did not know the value of these activities as mentioned above. Additionally, some of the non-BC principals like Han, Bach, and Long believed that because parents' influence was central to their students' future educational and career choices, schools did not need to make additional effort to help students. The non-BC principals' lack of attention to get parents and communities engaged in ACGC activities which might partly had led the ineffectiveness of these ACGC activities at their schools seems to be consistent with findings from a body of literature, including Dauber and Epstein (1991), Epstein, Clark, Salinas, and Sanders, (1997), Epstein and Dauber (1991), and Epstein and Sheldon (2002) which emphasized the need and the positive impact of family and community involvement in school activities on the quality of school programs or activities. For example, Epstein (1985) and Epstein and Dauber (1991) showed the increase in school and family connections helps school administrators and teachers conduct more effective school programs in order to improve student success. As a result, there may be a need to build Vietnamese school principals' capacity and knowledge of community involvement to improve school activities including ones with ACGC. Simultaneously, the need for intensive professional development for school leaders may need considering as soon as possible to help them change their mindsets regarding the 
significance and need for diverse resources toward enhancing the quality of teaching and learning and to improve their skills, such as fundraising and community collaboration building, to create financial and social resources for ACGC activities. With schools in low-income communities, it may be still a big challenge; thus, MOET will need to consider giving special policies to support human and financial resources to their schools,

Like the non-BC principals, the $\mathrm{BC}$ principals also faced many difficulties regarding the lack of social resources (e.g., traditional Vietnamese education ideology which assess students' learning result and outcome through examinations, a lack of support from parents, the community, and educational leaders) and the lack of best practice resources in ACGC in designing and implementing ACGC activities. However, unlike the non-BC principals, the $\mathrm{BC}$ principals recognized there were difficulties, but they were proactive to find ways to overcome these challenges even if it took them "up to 20 years" or longer to implement change, like Phan shared. Additionally, although these $\mathrm{BC}$ principals were able to provide students with many different ACGC activities, they still looked for more such activities to better facilitate their students to explore future educational and career opportunities. One reason perhaps was because they saw how effective ACGC activities had been for students. For example, Fon, Phan, and Anh described stories about some of their students who achieved much partly because these students had opportunities to participate in one of the ACGC activities their schools designed and implemented.

An additional explanation for the case of Fon may be that he studied educational psychology, furthered his self-study of ACGC, and had had hands-on experience working with low-performing students. Fon, Anh, Phan, and Hen went abroad to visit some 
schools that utilized useful ACGC activities, and they had opportunities to learn about best practices. Therefore, the $\mathrm{BC}$ principals seemed to have strong knowledge and experiences to confirm the value of ACGC activities. Moreover, the BC principals, specifically Fon and Phan, wanted to find additional useful ACGC activities for students to create additional opportunities to help students become well prepared for their future paths. Three of the four BC principals, including Hen, Phan, and Fon, likely had more discretion and autonomy than the non-BC principals to create learning opportunities that they wanted without MOET's approval nor seemed to experience extreme pressure to implement "so many decisions and directives" like Fin, who worked at a public school. Fin had described the pressures from higher authorities that he experienced. Anh, another BC principal, worked at a public school for gifted students, her school, which had better city investments, had more resources (e.g., qualified teachers and infrastructure) to design, implement, and sustain ACGC activities than Fin, Bach, Mon, Han, and Long, the non-BC principals at other public schools, might have. Therefore, the BC principals had the capacity to consider innovation.

As mentioned earlier, all of the principal participants in this study were purposefully chosen from schools with positive/good reputations for providing ACGC activities for their students; the assumption was these principals would show higher potential to border cross and who would be willing, interested in, and able to overcome barriers to design and implement ACGC activities. However, the findings showed a bigger proportion (seven) of the sample population (11) were not open to additional ACGC activities. As a result, these findings raise a concern about school leaders' qualifications and capacity in facilitating the development of ACGC activities and other 
student learning opportunities. Ensuring school leaders have the necessary qualifications to facilitate the development of new learning opportunities for students is necessary, because current Vietnamese educational reform relies on the capacity of the individual schools and school leaders to design and implement many new learning opportunities, including ACGC activities, for students (MOET, 2018b). Furthermore, in relation to the big picture of the changing educational environment in Southeast Asian countries, including Vietnam, there is a need to enhance school leaders' capacities to adapt and meet learning and teaching requirements (Hallinger, 1998). Thus, a solution may be to offer more sustained and intensive professional opportunities to Vietnamese school principals as soon as possible to help them get not only a better understanding of ACGC activities, but also equip them with the capacity to build their school's own capacity to facilitate the development of these activities.

\section{Functioning as Instructional leaders, BC Principals Used Many Strategies to Sustain ACGC Activities}

The findings of this study showed that while non-BC principals found it difficult to effectively implement the current ACGC activities they were aware of and that they were unwilling to design and implement additional ACGC activities, as instructional leaders, the $\mathrm{BC}$ principals managed to use many strategies to sustain their capabilities to design and implement a large range of useful ACGC activities for their students. The strategies the principals used included 1) offering professional development opportunities to teachers and staff, 2) directly getting involved in designing and implementing ACGC activities with teachers and staff as ACGC experts, 3) ensuring their own self-studying about ACGC activities; and 4) getting every school member and their practices be 
focused on ACGC activities as a way to align these activities to their schools' goals, missions, and vision. The purpose of this section is to demonstrate the difference in the BC school principals' resources, particularly human, time, and financial resources, and how these principals have utilized their resources. These resources likely made a positive difference in the success of ACGC activities at their school.

This study's findings support the literature which agrees that, functioning as instructional leaders (Blasé \& Blasé, 2000) and as a school's head learner (Hallinger, 1998), school principals are able to create learning organizations where every member, including school leaders, teachers, staff, and students engage in continuous learning. In this study, as resource providers, the BC principals (Fon, Phan, and Hen) knew the strengths and weaknesses of their teachers in terms of organizing ACGC activities; therefore, the principals encouraged them to improve their professional growth by participating in professional development activities to help them gain the knowledge and skills in ACGC. This may have contributed to the teachers' and guidance staff's abilities to promote their delivery of ACGC activities in school. The reason the BC principals used professional development activities for teachers was because they recognized their teachers' limitations regarding the lack of training and experiences in the design and implementation of ACGC activities. The principals understood the benefits that professional development activities could bring to their teachers.

The BC principals' offering these professional learning opportunities for teachers seems to be a useful strategy which is associated with findings in the literature. For example, in a report by Darling-Hammond, et al. (2009), that examined what research has shown about professional learning for teachers and which provided an analysis of data 
from multiple sources (e.g., National Center for Education Statistics' 2003-04 Schools and Staffing Survey (SASS) and others), indicated that sustained and intensive professional development for teachers helped improve teachers' practices and also student learning. One thing which the BC principals and other Vietnamese principals, including the non-BC principals, could learn from this report and other studies such as Supovitz and Turner (2000), Vescio, et al. (2008) may be to make sure these activities are intensive and sustained for the maximize of their impact on their teachers' practices and their students' learning.

In additional to being instructional resource providers who offered teacher learning opportunities, the findings also showed the $\mathrm{BC}$ principals functioned as instructional resources who were able to get directly involved in the design and implementation of ACGC activities. Specifically, Fon had the capacity to provide feedback and use demonstration sessions to help teachers better deliver ACGC activities. Phan participated in the role of guest speaker at many seminars related to ACGC, while Hen and Anh were active to contribute content and take initiative for many new ACGC activities, including field trips and student-led projects, at their schools. These principals were able to function as their schools' instructional resources for both teachers and students, because they had engaged in training themselves as head learners. In turn, they wanted to facilitate teachers' practice and the development of these activities. In the context of my study, the BC principals' ability to function as instructional leaders and head learners was necessary when the teachers did not have enough necessary knowledge and skills in ACGC to deliver ACGC activities before, so that, the teachers and staff could receive technical support in learning about the ACGC activities and how to 
organize them. The $\mathrm{BC}$ school leaders acting as resource providers and instructional resources above are the necessary characteristics of instructional leaders according to Whitaker (1997). This finding is also consistent with the research findings from Heck's (1992), Blasé and Blasé's (2000), Fink and Resnick’s (2001) studies, which emphasized the roles of principals in serving as instructional leaders to enhance the quality of teaching and learning at schools. In short, as a result of offering well-developed development activities, getting involved in designing and implementing ACGC activities, and also participating in self-training in ACGC, the BC principals successfully sustained the capacity of their schools to facilitate the delivery of ACGC activities at their schools.

Unlike the $\mathrm{BC}$ principals, the non-BC principals (Fin, Bach, Na and Mon) did not make efforts to get their teachers trained in ACGC, even though they knew their teachers did not have enough knowledge, skills, and experience in ACGC and school counseling; nor did these principals have the ability to recruit a professional guidance staff due to financial issues. Thus, some of these non-BC principals seemed to accept the ineffectiveness of the ACGC activities they had at their schools. Additionally, these principals also did not reveal they made effort to self-educate in these areas in order to provide support to teachers and students when needed. As a result of not offering professional development opportunities for teachers or actively training themselves in ACGC, the non-BC principals will likely negatively contribute to the ineffectiveness of the current and future ACGC activities. There are some possible explanations for why the non-BC principals did not provide their teachers with professional learning opportunities in ACGC. First, these non-BC principals appeared to function as school managers who made sure required school learning and teaching implemented appropriately; they might 
not know how to provide solutions for issues occurring in the process of learning and teaching, like creating professional development activities for teachers when needed, as instructional leaders are able to do. Secondly, they seemed to not have a good understanding of the value of these professional development opportunities for teachers. Thirdly, they might think creating professional development for teachers was not their responsibility, but rather their superiors' and MOET's responsibility. For these explanation above, the implication for Vietnamese educators and policymakers is that they will need to think about ways to help school principals, including the non-BC principals, be aware of issues regarding the lack of teacher professional learning opportunities. Additionally, this finding also indicates the significance of school leaders enhancing their own professional growth in ACGC, which likely enables them to better support teachers and students in ACGC activities.

In addition to offering professional development activities for teachers, selfstudying in ACGC, and participating in the design and implementation of ACGC activities as instructional leaders, the BC principals also understood the importance of hiring qualified faculty or staff who had strong qualifications and could deeply commit to the core values and goals of the school. This included preparing students for their future academic and career explorations. To recruit qualified teachers, the $\mathrm{BC}$ principals in this study communicated well with potential candidates about their school's core values. For example, Phan shared with her potential candidates that the goals and mission of his school were to "offered [offer] opportunities [to student] to gain experience, to live as a human beings[with good living values]. Fon also spent time discussing with all current and potential staff about "[help] each student explore their own abilities, pursue their 
dreams, which help students get good learning motivation”. Also to attract qualified candidates, Anh and Hen emphasized their schools' mission of "help [helping] students learn about how to study, live, and work as global citizens" (Anh), and "train [training students] to become global citizens. No matter where they are, they can work and live. They know how to live and how to think as a human, [and] know how to work and know to get better life later. Knowledge is only an initial training" (Hen). With the capacity for communicating well with all potential and current school members about the schools' mission and visions, these $\mathrm{BC}$ principals thought that they inspired and encouraged their teachers to support the design and implementation of ACGC activities, then helped them make the necessary changes in their traditional teaching methods and spread out their schools' organizational messages to the community, including students' parents. Additionally, the $\mathrm{BC}$ principals contended that the outcome when all school members (teachers, students, and even parents) understood the shared school value was that they were willing to support schools' activities, including ACGC activities. The significance of recruiting qualified school members by communicating the organizational vision and mission well is consistent with one of the lessons McKinney and Capper (2010) suggested when they discussed ways to make an organization's mission and vision central to an organization's policies and practices. The authors also explained that hiring the qualified candidates conveys organizational messages to other potential school members (McKinney \& Capper, 2010) as what Principals Fon, Phan, and Anh saw at their school members when they helped students, parents, and the community better understand their schools' goals in preparing students for their future education, careers, or other paths. For example, Phan provided an example talking about a parent's thoughts 
after a teacher-parent conference, and felt so happy because the parent understood his schools' vision and mission and supported the schools' changes in learning and teaching methods, as well as school' activities.

In contrast, although all seven non-BC principals expressed disappointment that MOET had not assigned a professional guidance staff for their schools, none of these principals revealed efforts to recruit potential teachers or staff who may be committed or may have the ability to help with the design and implementation of ACGC activities. This was surprising because in Vietnam, school principals at both private and public schools have the right to make decisions on which teachers and staff will be recruited, according to the State's regulations (MOET, 2011b). One possible reason for not paying enough attention to recruiting school members who can support ACGC activities likely came from the non-BC principals' focus on student achievement as a great priority and lack of understanding of the ACGC activities and their value as the other findings showed earlier.

In short, the findings of this study indicate the benefits of school principals who have the capacity to be instructional leaders in ACGC, which may make a contribution to the successful design, implementation, and development of ACGC activities. This finding is consistent with implications of many studies by both Vietnamese scholars and international scholars on the significance of instructional leadership toward the quality of teachers' practice and student learning. However, the findings of this study which came only from school principals' perspectives, contained limitations. Thus, in order to have a better insight into the strategies which Vietnamese school principals used to effectively design, develop, and sustain ACGC activities, there is a need to include teacher, parents, 
or students' voices to get more shared perspectives in terms of how they may think about those strategies.

\section{Functioning as Social and Educational Change Agent, the BC Principals Used Many Strategies to Sustain ACGC Activities}

In addition to building an instructional team as good internal human resources for ACGC activities in their school, the BC principals made efforts to collaborate with families and the community in order to create more external human resources to facilitate for the development of ACGC activities. As the BC principals described family and community participations at their schools, these collaborative opportunities with families and the community helped these stakeholders have a better understanding of the importance of ACGC and to prepare students with knowledge of careers and academic paths. The findings of this study showed the BC principals viewed parents, individuals, and organizations in the community as school partners. The principals tried to engage parents and community organizations in school activities, including ACGC activities, although looking for support from families and the communities was not easy. The BC principals described challenges due to some parents' low educational level (e.g., in Fon's special education school), or the community leaders' lack of interest in ACGC, like Fon and Phan shared. However, the BC principals committed "up to 20 years with barriers, enticements, persuasion, communication to make people understand many things," as Phan said. They did not give up, however, because not only they think it was their responsibility as educators for their students' education, but they also understood the significance of having collaborative opportunities with the community to support the success of ACGC activities. 
As a result of their capability to get parents and the communities involved in ACGC activities as school partners, the BC principals stated they were able to create additional resources (e.g., community agencies and financial support to ACGC) and raise the awareness of the parents and community about the significance of school, family, and community involvement in ACGC activities. The benefits of getting parents and the community involved in school activities have been shown in the literature over the past three decades. According to Van Roekel (2008), school, family, and community collaboration offers better opportunities for each partner to learn more from and about each other to support and share the responsibility for educating children and improving schools. The author also found that building, developing, and maintaining school programs or activities with supports from family and community involvement may help children gain their academic achievement and their overall success in later life. Among a few of the pioneers studying in the field of Family and Community Partnerships, Dr. Joyce L. Epstein, director of the Center on School, Family, and Community Partnerships and the National Network of Partnership Schools (NNPS), has conducted a number of research over the past 30 years which emphasize various positive effect of partnerships among school, family, and the community toward students, parents, and even teachers. For example, studies by Epstein, Clark, Salinas, and Sanders, (1997) and Epstein and Sheldon (2002) have shown that children whose parents support and engage in school activities have more advantages in terms of attitudes toward school, regular homework habits than other children. The parents who closely engage school activities have better knowledge about child development, parenting skills, and the quality of parent-child, parent-parent, and parent-teacher interactions and relationships (Epstein \& Daube, 1991; 
Dauber \& Epstein, 1991); further, teachers found it easier to conduct useful activities to improve student success while families involved in schooling (Epstein \& Dauber, 1991). These are western-based studies which use western-based frameworks; however, the findings of this study indicate that the $\mathrm{BC}$ principals' views of parents, individuals, and organizations in the community as school partners may be a good strategy that other Vietnamese school leaders can learn from to better facilitate the design, implementation, and development of ACGC activities.

Among the four BC principals, Fon was the only one who was active and committed to providing guidance and publishing papers and books to assist other schools in creating ACGC activities. Fon's efforts was not all about a head leader, but also were a positive signal of creating a network of schools which have started to share the same missions and vision regarding the design and implementation of ACGC activities as well as possible support for each other in the process of delivering these activities. An implication of Fon's work is that while helping family and community organizations be engaged in ACGC activities, Vietnamese school principals, including both the BC and the non-BC ones, may create collaborative opportunities among other schools to together effectively design and development these activities.

Unlike the $\mathrm{BC}$ principals, many of the non-BC principals in this study thought it was impossible for them to get families and organizations such as business and universities in the community involved in helping organize new ACGC activities. They had difficulty finding agencies willing to support their schools' activities when needed or assumed that individuals and organizations in the community did not have the capacity to help or were unwilling to help. While there is a common consensus among the literature, 
including studies by Dauber and Epstein (1991), Epstein, et al, (1997), Epstein and Daube, (1991), Epstein and Sheldon (2002), Houtenville, (2008), and Van-Roekel (2008), about the significance of families and others' involvement toward the quality of school's activities and student success. Some of the non-BC principals did not believe in the contributions of families, individuals, and organizations in the community could make to support ACGC activities. These non-BC accepted a reality they perceived without making effort to change it. None of the non-BC principals described trying to meet, communicate, or persuade families and organizations to organize ACGC activities. The outcome of not having a belief in the involvement of family and the society and looking for collaboration may lead to many of the ACGC activities not being designed or implemented effectively. These findings raised issues regarding Vietnamese school leaders' capacity in figuring out what they can think and do differently to build collaborative opportunities with families and the community for the success of many learning opportunities such as ACGC activities. Additionally, these findings indicate professional development activities for school leaders to help them gain a better awareness of the significance of school, family, and community collaboration and to help them learn about possible ways to create these collaborative opportunities may be beneficial.

In conclusion, the findings of this study indicate the difference in school leaders' perception of ACGC activities, the difference in the way the non-BC and BC school principals created and sustained different resources, including human, time, financial ones, and how they spent these resources makes a difference in the success or failure of ACGC activities. Moreover, the findings of this study also indicate issues regarding the 
non-BC school principals' capabilities in dealing with the barriers they perceived and faced to design, implement, and sustain the activities, simultaneously, the findings also show many useful strategies the BC principals used to sustain ACGC activities. In summarizing and discussing the key findings of study above, some implications were given to help Vietnamese educators and educational policymakers determine possible solutions to solve the given issues. The next section especially may be beneficial for current and pre-service individual Vietnamese school leaders who want to look for implications to improve their capacity to facilitate ACGC activities.

\section{Non-BC Principals' Relying on A Limited Internal and External Resources and \\ Parents' Interest to Implement ACGC Activities}

Unlike the various strategies the BC principals used to design, develop, and sustain required and additional ACGC activities, the non-BC principals relied on head teachers, the main external resource, MOET's guidance and community organizations (e.g., universities), the external resources, and parents' interest as their ways to implement ACGC activities outlined by MOET and a limited number of additional ACGC activities. This finding was not surprising because it seemed to be the consequence of the lack of understanding about ACGC activities and the lack of these school principals' capacity to design and implement these activities as mentioned in the previous findings of this study. Additionally, like the explanation for not knowing other forms of leadership rather than the traditional managerial style, these non-BC principals had not had opportunities to learn about useful strategies like the BC principals had and used to design and implement ACGC activities. Thus, the non-BC principals might find it difficult to overcome their barriers and navigate useful strategies in the design and 
implementation of ACGC activities. Another explanation, which also mentioned earlier, might be that the non-BC principals had significant pressures to help students prepare for exams to protect their schools and their own reputations; thus, they did not have time to invest in ACGC activities. All of the reasons above may help explain why the non-BC principals chose the three ways to organize and sustain ACGC activities and simultaneously what might make them not useful strategies.

First of all, the finding showed that using head teachers to implement ACGC might not be good strategies. The non-BC principals were able to be aware of the ineffectiveness of replying on this external resources because teachers were not ACGC experts who were trained in knowledge, skills, and experiences in ACGC. This finding was consistent with findings by studies, such as Do (2009) and Nguyen (2011), on students and teachers' experiences in ACGC activities. Particularly, In Nguyen (2011), a study on the status of vocational consultancy for 223 students in three high schools in Ho Chi Minh, Vietnam; $26 \%$ of student participants contended that head teacher did not do anything to help them gain knowledge and experience to explore their future careers and educational paths. Do (2009)'s study, a study with many groups of participants, including students, teachers, national educational leaders, and school leaders showed that the participans found that head teachers might have likely experienced a number of difficulties in implementing ACGC activities due to a lack of opportunities to attend intensive and sustained training courses.

In this study, an additional reason for why head teachers in Fin and Long's schools and many other schools even did not implement any ACGC activities might be because Fin and Long and other school leaders in Vietnam, did not put these activities as 
their priority but focused on student achievement instead. As a result, their teachers might not need to effectively implement these activities for their students but might need time to teach them for exams. An implication for this finding may be that there is a need for the non-BC principals and other Vietnamese school principals to look for opportunities to discuss with BC principals like Fon and Phan about useful strategies to recruit or bring in ACGC experts to train teachers or provide ACGC sessions. For instance, Fon may be willing to share his experience in seeking financial support or building up financial resources for these activities although most of the students of his schools came from families with low-income background. In addition to offering school leaders training in the design and implementations of ACGC, MOET may consider providing teachers with sustained professional learning in ACGC in order to help them better facilitate these activities.

Moreover, the non-BC principals relied on external resources including college and exam information from MOET's websites and college/career fairs organized by community organizations (universities, the Vietnamese Youth Association, the local department of education and training, or business) to reach out ACGC opportunities. These resources might have been good resources if the non-BC principals had known how to collaborate with these organizations to help students find their potential future career and educational interest. Instead, for example, the non-BC principals six of the non-BC principals (Bach, Long, Han, Fin, Ben, and Mon) solely passed the information regarding activities preparing students for college and exam and field trip activities to their students and letting the students participate in these events if they were interested. Additionally, the non-BC principals seemed to not be aware that types of ACGC 
activities were more than the content from MOET's website or textbooks or a few opportunities organized by a limited numbers of community organizations. Looking for opportunities to discuss and seeking collaborative opportunities with other principals in Vietnam like the $\mathrm{BC}$ principals who were doing well with the design and implementations of ACGC may be a good way to help the non-BC principals learn more about best practices and gain useful ideas for ACGC activities. Opportunities to have discussions with community and organization leaders about students and teachers' needs may bring about collaborative opportunities between schools and these organizations in order to facilitate new ACGC activities.

The non-BC principals (Mon, Ben, Han, Long, and Na) depended on parents' interest to organize some non-academic clubs (e.g., soccer, guitar, or dance) as a break from the heavy curriculum and English-focused activities as a way to promote student achievement. These non-BC principals might find it easier to organize such activities because they came from parents and students' interest. While the traditional Vietnamese education ideology and social norms value student achievement and assess student achievement through their performance at mandated exams (Bodewig, et al., 2014; Hallinger, et al., 2017), the design and implementations of ACGC activities which solely depended on parents' interest may not always be a useful strategy for Vietnamese school principals, including the non-BC principals. The reason is that Vietnamese parents, like those at Mon, Ben, Long, and Han's schools, supported school activities, like the nonacademic clubs and English-focus events because these activities might help their children increase their academic performance at schools and exams rather than explore their potential interests and abilities. Therefore, the non-BC principals may need to be 
proactive in seeking out opportunities to learn from the $\mathrm{BC}$ principals and other principals' experiences about how to get parents involved in ACGC activities and create a shared vision, goals, and missions which support the development of ACGC activities. To support this learning community, MOET may need to bring in ACGC experts to facilitate their professional growth.

In sum, due to the lack of the capacity to overcome the barriers (e.g., heavy workload, lack of professional guidance, and family's central influence on students' choices), the non-BC principals seemed to choose ways which did not take much time and effort to sustain a small range of ACGC activities. In other words, the non-BC principals left their barriers in place and seemed to use a few of external resource (e.g., teachers) and internal resources (e.g., MOET's website or guidance and universities) which were already available to make ACGC activities happen. However, due to the low quality of teachers in providing ACGC knowledge, skills, and experience, the limited guidance from MOET's website, the lack of collaborative opportunities with community organizations (e.g., universities and business), depending on parents' interest, the non-BC principals, and pressure to sustain student achievement, it seemed that the non-BC principals were able to offer a small range of ACGC activities in ineffective, inconsistent and unsystematic ways. The overall implication for these non-BC principals may be looking for opportunities to join a learning community where they are able to learn from experiences, knowledge, and skills that ACGC experts and other Vietnamese school principals, including the $\mathrm{BC}$ principals, used to effectively design and implement ACGC activities. Moreover, some other implications (e.g., providing intensive and sustainable professional development opportunities for school leaders, offering ACGC courses in 
school administrator preparation programs, considering reducing learning expectations for students at many current courses, providing special policies to support human and financial resources to their schools) may be beneficial to MOET and policymakers who may want to learn about school principals' challenges in the design and implementations of ACGC activities and provide appropriate support to school leaders.

\section{Implications for Practice}

In this section, I provide some specific recommendations which may help current and pre-service Vietnamese school leaders to be more apt to support students and help schools achieve goals of implementing ACGC well without waiting for changes from MOET. The recommendations include 1) self-studying, 2) building a shared organizational vision, mission, and goals, and 3) creating their own school improvement plans to improve their school's capacity to design and implement ACGC activities and others learning activities (See Appendix E).

\section{Self-Study}

Vietnamese school principals were not been trained in knowledge and skills in ACGC activities while they were in school administrator preparation programs (Vietnam National University, 2015). Thus, in order to equip principals and better facilitate teacher and staff personal and professional growth in ACGC, as well as better support the process of designing and implementing ACGC activities for students, Vietnamese school principals would do better to self-studying/ training in ACGC. This was one of the strategies which the BC principals used in this study. In this study, Fon was an example of ensuring his own self-studying in ACGC by reading, doing research, publishing books and papers, learning from experts, and even sharing knowledge with others in the 
community. Fon took initiative to learn about ACGC activities for more than 40 years in the position of a school leader at a special education school model. All of the professional learning opportunities he organized for teachers and himself came from domestic and international experts and organizations who agreed to offer professional development activities to him and his teacher for free. Some organizations provided Fon with funding to implement some initiatives for ACGC activities at his schools. To successfully make these individuals and organizations support ACGC activities at his schools, Fon determined that he could learn and do ACGC activities. Fon's efforts showed that he not only self-studied in ACGC as a head learner who inspired and encouraged his school members to continuously gain their knowledge and skills in ACGC by participating professional development activities at his school. He also functioned as an instructional leader who had the capability to provide specialized support in ACGC when his teachers needed it. In short, the characteristic of being able to self-study was a critical element that helped Fon and other BC principals stay committed to ACGC activities.

In the context of Vietnam, it is necessary for all school leaders to keep improving their capacity to self-studying as a head learner in order to nurture a learning community (Hallinger, 1998). According to Hallinger (1998), in a learning community, by selfstudying, a school principal will likely continuously enhance their professional growth and can position themselves to influence the personal and professional growth of other educators including their teachers and other school leaders. As a result of self-studying or training, school principals may be able to get every member, including other school leaders, teachers, staff, and students engaged in continuous learning (Hallinger, 1998), which can make a difference in the quality of teaching and learning. In the study, the BC 
school leaders like Fon, Phan, Hen, and Anh seemed to able to change their teachers' perceptions of students' achievement, traditional ways of working to complete assigned tasks, and traditional teaching practices because of their capacity for continuous learning. Thanks to having the capacity of self-studying, these BC school leaders were likely able to figure out what they can do and how they can think differently to create useful learning opportunities-not just for ACGC activities, but for students in other ways.

The difference in the capacity for continuously studying ACGC between the BC and non-BC principals likely explained the difference in their perceptions of preparing students for their future paths and of their capacity to become border crossers, educational $\mathrm{BC}$ principals, who were able to navigate ways to overcome difficulties in the design and implementation of ACGC activities. However, like changing the mindsets of school leaders with a managerial style of leadership, building the capacity to selfstudying in ACGC or other areas may take time, efforts, support, and a high commitment from school leaders, maybe because they do not know other forms of leadership as it has not been modeled for them. By sustained self-studying/training, Vietnamese school leaders may get a better awareness of less pressure to increase student achievement. They also will be able to spend time looking further over their individual school borders to learn more about how and why the BC principals in this study and other educational border crossers at other education systems in the world had created better learning opportunities, including ACGC activities. In addition to the capacity for self-studying, Vietnamese school leaders will likely need professional development opportunities from MOET to able to gain knowledge and skills to improve their overall qualifications and 
capacities to better assess and improve not only the current ACGC activities better but also other student learning activities.

\section{Build a Shared Organizational Vision, Mission, and Goals}

Looking at the development of Vietnamese education, as well as its reforms over the past half-century, it can be seen that the Vietnamese education system is struggling with shifting its focus from transferring knowledge to helping students explore and develop their individual abilities and interests due to strong influences from the Chinese, French, and Russian education systems (Nguyen \& Nguyen, 2008). In order to facilitate the development of ACGC activities and other learning activities for students, Vietnamese school leaders and school personnel may need to build a shared school vision, mission, and goals that support the academic and career development of individual, students including ACGC activities. Findings from this study suggest that in order to create a shared organizational vision, mission, and goals, school principals will need to create opportunities where school leaders and school members including all teachers, staff, and students are able to discuss topics related to ACGC activities. The purpose is to help faculty and staff members develop a deeper understanding of such activities and their roles toward the academic and career development of students. Through these opportunities, school principals will likely be able to inspire and encourage their teachers to support their schools' goals including the design and implementation of ACGC activities as the BC principals in this study did. In order words, school leaders and their school members may need to start with changes at their own individual level in order to develop better attitudes and understandings of these ACGC activities and their significance. 
If the opportunities for school leaders and school members to discuss the given schools' goals by the superiors show these goals were not designed to help students explore and develop as individuals nor did they take into account school and community contexts, school leaders will need to spend time working with school members to set new organizational visions, missions, and goals for their own schools. Importantly, this suggestion provides a solution for many Vietnamese school leaders who accept goalsetting from the superiors as "meaningful and appropriate" (Hallinger, 1998, p.502) and who tell staff what should be completed with "relative little two-way communication" (Hallinger, 2010, p.23). As mentioned earlier in the discussion of key findings, to facilitate individual school principals in building a shared organizational vision, mission, and goals related to ACGC activities, MOET and its lower departments also need to explicitly the need and value of the design and implementation of ACGC activities.

\section{Create School Improvement Plans}

After creating a shared vision, mission, and goals to support ACGC activities, school principals and their school members may create school improvement plans to define their school's targeted work to increase the capability of schools to effectively design and implement ACGC activities. Particularly, in the context of Vietnam, school principals will need to make sure that their own school improvement plans will focus on improving the two areas, human and financial resources. With an ability to improve the success of the utilization of these two resources, school principals will likely help the school achieve a high level of performance in ACGC activities (Botha, 2010).

Human Resources. One of the most valuable resources a school has are people who can get involved in school activities (e.g., school leaders, teachers, and students, and 
individuals like parents, experts, and organizations like universities, business, other schools) (Botha, 2010). As mentioned earlier in the discussion of this chapter, school principals will need to reflect on their commitment to looking for collaborative opportunities with all of these people in order to improve school capacity to create learning opportunities for students. In addition to providing professional development ACGC activities for teachers and staff at school, like the BC principals in this study had done, school principals will need to create a broader learning community where school principals play important roles in bringing teachers, staff, community leaders, parents, experts, and organizational leaders together. This is consistent with the implications and discussion by Graza (2007), Hallinger (1998), Nguyen (2011), and Wilson and Douglas (2013) emphasized as a good strategy to get staskholders involved in assisting the design and implementation of learning opportunities for students. Some recommendations may include bringing diverse stakeholders together in monthly workshops or morning cafe meetings. These workshops and meetings would serve to provide principals and individuals with opportunities to 1) express what support their school needs from the community, 2) learn from reports on the local or national annual unemployment rates, the development of local companies, population growth, school enrollments at the K-12 level and higher educational level, job opportunities, job requirements and so on, and 3) learn about internship and job opportunities from local organizations. Such workshops can help school principals and other school leaders foster the development of school-to-school networks, where school leaders can learn, discuss experiences in the design and implementation of ACGC activities at their school or learned from best practices-from Vietnamese schools which have effectively designed and implemented ACGC activities 
like those of the $\mathrm{BC}$ principals in this study. At these workshops, school principals can discuss collaborative opportunities to create learning opportunities for students as well as strategies to overcome difficulties to make those collaborative opportunities possible. Additionally, such workshop will be opportunities to educate stakeholders about ACGC. In the context of Vietnamese schools where there is a lack of best practices for ACGC and lack of professional guidance staff (Bui, 2014; Do, 2009; Nguyen, 2011), the success of utilizing the broader learning communities is meaningful, because school leaders may start creating the shared vision and build up a strong human resources for designing and implementing ACGC activities at their schools.

Financial Autonomy. In Vietnam, unlike private schools where school funding comes from family contributions, public school funding comes primarily from state funding $(90 \%)$ and a small part from family contributions (10\%) (Tran, 2014). However, public school funding from the state budget and family contributions is not enough to help public schools provide quality educational services for their students (Tran, 2014). In this study, although the key findings did not emphasize having a strong financial resource as a reason for the success of ACGC activities at the BC principals' schools, the findings indicated these school principals' capacity for building a sufficient financial resource seemed to be one of the useful elements to help the $\mathrm{BC}$ principals more effectively implement ACGC activities. Most of the BC principals in this study who worked at private schools were able to recruit guidance and counseling staff partly due to their financial autonomy (See Appendix E). Unlike the BC principals, most of the non-BC school principals, however, found it difficult to recruit staff at their public school, because the funding they had from the government was limited. As the result of better 
financial resources, the $\mathrm{BC}$ principals seemed to be able to offer more useful ACGC activities than the non-BC principals had.

Having sufficient financial resource was useful for the BC principals as ACGC activities required additional costly fees which students' families and the school could not afford. For example, Fon, at the special educational school model, wanted to apply many useful test-based career advising activities (e.g., Dermatoglyphics and discovering the relationship between types of blood and career orientation); however, he gave up because these activities were costly and he instead focused on others (e.g., seminars or interventions led by guidance staff or teachers) which seemed feasible, because he could utilize his school's available human resources. As a result, if both private and public schools have good financial resources, school principals may find it easier to implement additional ACGC activities.

The finding's implication regarding the significance of sufficient financial resource at schools above is consistent with some findings in the literature which finds there is a consistent relationship between school resources and student's outcome (Greenwald, et al.,1996) and school funding and activity creation (Kano, 2008), and with one of the implications in the study of Nguyen (2011) regarding the significance of the increase in school financial resources to support ACGC activities. However, it seems that Vietnamese public school leaders did not have good awareness of the significance of school resources toward schools' activities and also did not have particular plans to raise funds for their school activities. Therefore, to better facilitate new ACGC activities for students, school principals at either public or private schools will likely need to learn how to raise additional funds and meet their fundraising targets. A specific example is if a 
school principal needs to recruit professional guidance and counseling staff to assist the school principal in the design and implementation of ACGC activities, he/she will have to use additional funds to make the decision.

In short, findings from this study suggest Vietnamese school principals will need to make efforts to 1) ensure self-studying in ACGC, 2) create a foundation of core values, vision, and mission where every school member gets a deep understanding of ACGC activities, then challenge their behaviors and attitudes and 3) create strong human and financial resources to support ACGC activities (See Appendix E for the virtualization of related recommendation). With a positive school climate and strong resources, Vietnamese school leaders will likely have the capacity to navigate their own particular steps to effectively design and implement ACGC activities and other learning opportunities.

\section{Implications for Future Research}

\section{Design}

This study is akin to a policy enactment study. Thus, similar future research can contribute to additional understanding of the significance of the design and implementations of ACGC activities at Vietnamese schools, how these activities are implemented in Vietnamese schools, and roles of school principals who are able to crosses policy borders. Future research may consider other areas such as big cities in Vietnam as the research context. The aim of choosing a research context in big cities is, because like Hanoi, the centers of educations are located in big cities where innovation and changes most likely happen more quickly than non-city areas. Cities may offer more opportunities for principals, other educators, and the community to be engaged in border 
crossing, as well as because of more potential resources school principals likely have or create to design, implement, and sustain ACGC activities. Similar research in a different context can help us gain a deeper understanding of the perceptions of high school principals on ACGC activities, and then allow us to understand how those perceptions influence their experience in ACGC activities.

Additionally, similar research may consider making some changes in the data collection stages which was used in this study to get more authentic data. Particularly, future research can deliver the intervention, where some useful ACGC activities are introduced, right after interview 1 at stage 1 instead of the beginning of stage 2 . The reason is that after the first interview and the intervention, principal participants may need time to think about or actually design and implement new ACGC activities they were introduced to in the intervention or based on their own ideas. Then, in interview 2 , principals may be able to provide more useful feedback on the difficulties and strategies they have to use to overcome those difficulties. Additionally, because the time these principals will need to turn those possible ideas or making plans of ACGC activities possible may take one year; I recommend the time between the two stages will be longer than that of this study, for example six months to one year apart. Moreover, after stage 1 or 2 of the data collection, future research may need to make two to three in-depth observations on ACGC activities at two to three of participants' schools. The reason for making just two or three in-depth observations on ACGC activities is to focus on understanding how border crossing activities look like at their schools as well as better understand their efforts to overcome struggles and obstacles to become active border crossers. Moreover, as part of the purpose of data triangulation, making observations, 
along with memos and field notes, after stage 1 and 2 of the data collections serves as a way to examine my participants' answers in their interviews.

Additional future research may also include views of other stakeholders such as organizational leaders, including domestic and foreign employers and universities, experts who are brought in, teachers, parents, and students. These participants are those who work closely with students during and after their high school graduation and may be influenced by what and how school leaders think and do for ACGC activities. Therefore, these participants may have certain expectations and experiences about students' skills and knowledge and what school principals can do to facilitate the development of ACGC activities . As a result, future research may explore their views on getting schools to improve existing ACGC activities or adopt new ACGC ones. MOET might also be included in future study to seeks to understand what they think about how principals are doing with ACGC and also learn about implementation of ACGC activities. Including such multiple participants in future research will help us see broadly about school principals' attitudes toward ACGC, how it is being implemented and what are roadblocks or sustaining strategies. Such future research may help MOET in their decision making process related to professional training for school principals to help them effectively design and implement ACGC activities. These future research also will help expose what the borders are; so that, educators, policymakers, and MOET may work together to figure out useful strategies to overcome those borders to facilitate school leaders in the design, implementation, and sustainability of ACGC activities. 


\section{Theoretical Framework}

Utilizing Border Crossing theory as the main theoretical framework in this study was suitable to explore Vietnamese high school principals' perceptions of ACGC activities and their efforts to push above and beyond the managerial leadership style to create useful ACGC activities for students. This study indicates the application of the border crossing theory should not be limited to only understanding critical educators' efforts to cross borders to support learning opportunities for immigrant youth in the U.S context (Wilson \& Douglas, 2013), but also may need to expand in order to understand critical educators' efforts in offering quality learning opportunities in other contexts, including Vietnam. I did not use the transformational leadership or instructional leadership as the main theoretical framework of this study because in the context of Vietnamese schools, it seems that going from an expected managerial style to becoming a transformational/instructional leadership style needs and/or entails border crossing. When I reflect on the concept of borderlands in this study, it makes more sense because it appears that non-BC principals will need to leave their managerial leadership and take a step forward to move to the in-between space, the site of exploration, where the $\mathrm{BC}$ princials were currenly. While the $\mathrm{BC}$ principals will need to leave the site of exploration in order to move to the site of transformation where these principals are able to use their transformation leadership to create and facilitate better learning opportunities for their students. However, future studies may want to use the transformational or instructional leadership to better understanding of the perspectives of school principals toward their roles as an transformational or instructional leaders in facilitate students' academic achievement in schools, but also their future academic and career preparation. 
Additionally, future research may consider using implementation theory and focusing on Lipsky's (1980) street-level bureaucracy or whose who implement policy on the ground. Using implementation theory may better help researchers examine organizational issues with particular policy directives (Yudof, 1980) and examine whether the implementers have capacity, resources, or training to implement these given policies.

\section{Conclusion}

The ways school principals think about students' learning opportunities and how school principals make their efforts to create resources in order to offer these opportunities not only makes a difference in the success or failure of these learning opportunities, but also greatly impacts the development and achievement of students. Thus, in addition to gaining a strong awareness of learning opportunities for students, as school leaders, they also need to sustain their capacity for self-studying and to become social and educational change agents in order to influence the personal and professional growth of other educators and get individuals and organizations in the community involved in school activities. The findings, discussions, and recommendations of this study points to help Vietnamese school leaders reflect on their current roles and responsibilities. Then, Vietnamese school leaders can change their traditional ways of thinking, working and living, and make necessary changes to improve their school capacity to effectively design and implement ACGC activities and other activities for the academic and career development of all students. 


\section{APPENDIX A: STAGE I-INTERVIEW I}

Thank you so much for taking your time to participate in my interview 1 . I am hoping to learn more about what it's like to be a principal and to work in the school. The following are the interview questions I will likely ask you during the interview.

\section{Participants' Background (administrative experience, school}

\section{descriptions)}

a. Tell me a little bit about your path into education?

b. How did you become an educator?

c. What was your path into administration?

d. Could you tell me something about your administrative experience? What positions were you? How long were them? Where did you get the positions?

e. Describe your school and students? (e.g., students' characteristics, background, and school's description: private, public, ...?)

\section{Overall sense of what they think about preparing students for future} careers or more education

a. Can you tell me, what is needed to help students prepare for a future career?

b. What information do they need to know about their career options or planning to pursue higher education?

c. What activities or courses do you offer at this school that is meant to help prepare students for their future? 
d. Can you tell me about each of these activities in detail? How many students participate in them and how often? Are some more helpful to students than others?

e. Do you think students benefit or not from these activities? Tell me, what makes you think this or gives you this impression?

f. Can you describe for me what ACGC activities look like, sharing specific examples?

g. How do you talk to other educators in the school about these activities?

h. How do you describe these activities and their importance (or not) to teachers, etc. ?

i. How effective are the programs to students based on your perspective?

j. What is your opinion of these activities? Why do you think this?

k. How do you seek out information about career preparation activities? 


\section{APPENDIX B: STAGE 2-SCENARIOS AND INTERVIEW 2}

I will conduct a maximum-30-minutes scenarios where I will actively introduce two to four activities with ACGC to each of my high school principal participants. I modified these activities from some of the existing activities or best practices of ACGC activities from the United States in order to fit Vietnamese school context. As mentioned earlier, choosing to the range of two to four ACGC activities depends on the principals' perceptions of such activities at stage 1 and their interest in exploring these new ACGC activities. According to my own experience, these activities are feasible for their school context because designing and implementing the activities will require minimal school's funding or changes in the curriculum and will not require any specific school personnel with ACGC training. In these activities, principals will make use of human resources and others from the community and encourage the community's involvements and contributions to the development of students' academic and career development.

Indeed, there are four activities, titled: Mentorship, Career Fairs, Field Trips, and Monthly Talk in my scenarios. In each activity, I will provide briefly what it is, how it looks like, and possible considerations for and against applying or adapting it to their schools. Based on my participants' interest, their school context, and their availability, I will make my decision on how many activities and how long I will spend introducing these activities and making the second interviews with my participants. In particular, the activities in my scenarios will include the following information:

\section{Mentorship}

Mentorship is an activity where a mentor focuses on helping a student as a mentee define his/her interests, needs, life goals and barriers to moving on. In the activity, the 
student is the center of the process and advisors are the ones who give assistance or advice when needed. Meeting time between the student and the adviser are flexible based on the students' needs and the advisor's availability. Basically, at the end of a semester, a student and his/her career advisor need to sit together to give a formal or informal assessment of what skills and knowledge the student gained during the semester.

At most of the schools in Vietnam, there are no positions as school counselors and many teachers and school leaders do not have enough skills and are not trained at a basic level about career counseling in order to help students clearly understand their interests and their abilities to make career choices. Thus, it is necessary to build a group of mentors, including individuals in the community from the local government, academia, social services, the faith community, career centers, vocational college, university and businesses, who are willing to offer possible mentorship to students in need while the school's responsibility is to help the students connect with the mentors. Some of the things, a school leader will need to do may be building a strong mentor network and providing necessary assistance in order to develop and retain this activity's effectiveness. However, if a student does not build a strong relationship with his/her mentor and does not have a strong engagement and commitment with the activity, it is likely that the activities cannot be implemented effectively.

\section{School-based Career Fairs}

School-based career fairs are school-community events hosted by a high school where the school and organizations from the community such as vocational institutions, universities, and companies collaborate in order to provide opportunities for students as well as their parents to explore and learn about career and academic options after 
graduation. In the event, there may be so many activities as well as interactions among students and organizational representatives. For example, students have opportunities to ask questions or even look for opportunities for internships and mentorship while vocational institutions and universities introduce their programs, their admissions requirements, scholarships and other related information.

In Vietnam, although such vocational events have been organized annually by some vocational colleges or universities, they are organized outside of school, which is not convenient for students and not advertised to students well. Therefore, school-based career fairs will be a good idea to attract more students' participation and interests. However, the school and organization participants will need to work in order to make their career fairs effective.

\section{Field Trips}

With cooperation and collaborations between the school and agencies in the community, the school offers field trips to their students in order to help them get real experiences and motivations to pursue careers of their interests. In particular, in each semester, students will have some opportunities to have college campus or organization visits in the city to help them get a feel for and learn about these places, and then be able to decide if the colleges or companies are right for them. In a field trip, students can learn about job requirements and ask for an internship or volunteer opportunities, which is likely to benefit the students more than only learn careers in the society through existing career-related activities at school. However, in order to make flied trip possible and effective, the school will need to overcome a variety of difficulties such as looking for volunteers (tour guides, teachers, parents), funding for transportations, finding 
appropriate way to students' internships work well with the student's schedule at class

etc., while the vocation institutes will need to think about how to organize good activities for students.

\section{Monthly Talk}

Monthy talk is a-thirty-to-an-hour session hosted every month by a high school where a guest speaker from the community comes and share a particular career-related topic with a group of students in order to provide the students their experience they have while working in their field. The guest speaker may be a representative from vocational institutes, universities, domestic or international business, retired teachers/leaders, or parents who are willing to support students' academic and career development. The topic these guest speak of a talk depends on either the expert or the school as well as students' needs. Some topic examples may be how to prepare a resume, job applications, how a job interview look, how to write a letter of acceptance, what students should have an international post-secondary application. In this activity, students have opportunities to interact directly with "expert" in many different fields and gain knowledge and skills which they did not have from career fairs or existing career-related activities at class. Although the time for an activity is not long and require many collaborations and preparation between the school and the guest speakers, they will need to think about how to attract as many students as they could because students' participation in the activity is voluntary. 


\section{INTERVIEW 2}

\section{Perceptions of ACGC activities}

a. Are you familiar with any ACGC activities I just mentioned above? Is your school providing any type of school counseling services for students like I just mentioned?

b. If yes, how did you learn about them?

c. Why you choose to implement ACGC activities while you do not have to do it?

\section{Challenges in implementing ACGC activities and how you can overcome} those challenges

d. In what ways you find the activities difficult to implement in your school? (teachers' support?, parents' approval?, local department, funding? policy?, experience?, human resources? community's support? ...)

e. What barriers and obstacles you face in seeking out resources for the activities?

f. What are the main obstacles preventing your efforts to implement ACGC activities at your schools?

g. Do you find any support in order to design and implementing such activities?

(the local department? Local organizations? Parents? Students? Teachers?) 
h. Whom do you often look for when you need advice/help in order to design and implement some new activities for students?

a. Is there any teacher/ staff or parents have good knowledge and skills regarding ACGC activities?

b. Have you got any pressure from the local department or parents to implement such activities?

\section{Strategies to implement ACGC activities}

a. Tell me what kinds of resources from your school/community you can make use of in order to implement ACGC activities at your school? (teachers' support? parents' approval? funding? experience? human resources? community's support? ...)

b. In what ways you find the activities easy to implement in your school? (policy?)

c. What strategies you use to sustain your ability to develop ACGC activities at your schools?

d. How can you overcome all of the barriers you met?

e. Who from your school/ community is willing to offer advice/help/experience when they know you want to design and implement a good activity for students?

f. Is there any teacher/ staff or parents have good knowledge and skills regarding ACGC activities?

g. What did you do to help parents and teachers supports the implementation of ACGC activities at your schools? 
h. How do border crossing principals sustain their ability to implement ACGC activities?

\section{Perceptions of their role in providing students with post-graduation}

\section{options?}

(I think that the answers for this questions come from many other questions I made above. However, I added a few there to clearly explicit my purpose to see how my participant's response to it.)

a. What do you think about your role/ what you can do in order to provide students more post-graduation options?

b. If not you? Who should be the right person?

c. When will you be able to start designing and implementing the activities? (if they are potential border crossers)

d. Do you have any specific plan to make ACGC activities at your schools more effective? Or any plan to add more ACGC activities at your schools.

e. What suggestions do you have to have a good ACGC activities or other new activities? 


\section{APPENDIX C: THE LIST OF THE ACGC ACTIVITIES BC PRINCIPALS AND NON-BC PRINCIPALS HAD OFFERED AND BEEN AWARE OF}

\begin{tabular}{|c|c|c|c|c|}
\hline Principals & $\begin{array}{l}\text { School } \\
\text { Type }\end{array}$ & Area & $\begin{array}{c}\text { ACGC Activities } \\
\text { (offered and were aware of) }\end{array}$ & $\begin{array}{l}\text { \# ACG } \\
\text { Activitive } \\
\text { (Offered, }\end{array}$ \\
\hline $\begin{array}{l}\text { Non BC } \\
\text { group }\end{array}$ & & & & \\
\hline Principal Na & Private & Urban & $\begin{array}{c}\text { School-based college fair* } \\
\text { College Campus visit* } \\
\text { Workshop (life skills, leadership skills)* } \\
\text { Sport clubs (Basketball, Soccer)* } \\
\text { Volunteer work* }\end{array}$ & 3 \\
\hline $\begin{array}{c}\text { Principal } \\
\text { Bach }\end{array}$ & Public & $\begin{array}{c}\text { Suburba } \\
n\end{array}$ & $\begin{array}{l}\text { Monthly Academic and Career-Related } \\
\text { Discussion Sessions } \\
\text { College application advising for } 12^{\text {th }} \\
\text { graders } \\
\text { Advising students for studying abroad in } \\
\text { Japan* }\end{array}$ & 3 \\
\hline $\begin{array}{c}\text { Principal } \\
\text { Long }\end{array}$ & Public & $\begin{array}{c}\text { Suburba } \\
\mathrm{n}\end{array}$ & $\begin{array}{c}\text { Monthly Academic and Career-Related } \\
\text { Discussion Sessions } \\
\text { College fair* } \\
\text { Art clubs (guitar, dance)* } \\
\text { Tutoring sessions* } \\
\text { Sport clubs (Basketball, soccer, and } \\
\text { badminton)* }\end{array}$ & 3 \\
\hline $\begin{array}{c}\text { Principal } \\
\text { Han }\end{array}$ & Public & Urban & $\begin{array}{c}\text { Monthly Academic and Career-Related } \\
\text { Discussion Sessions } \\
\text { Sport clubs (soccer) }\end{array}$ & 2 \\
\hline Principal Fin & $\begin{array}{l}\text { Special } \\
\text { educati } \\
\text { on } \\
\text { Public }\end{array}$ & Urban & $\begin{array}{l}\text { Monthly Academic and Career-Related } \\
\text { Discussion Sessions } \\
\text { Career fairs* } \\
\text { College application advising sessions* } \\
\text { Field trip* }\end{array}$ & 1 \\
\hline $\begin{array}{c}\text { Principal } \\
\text { Mon }\end{array}$ & Public & Urban & $\begin{array}{c}\text { Monthly Academic and Career-Related } \\
\text { Discussion Sessions } \\
\text { English advanced classes* }\end{array}$ & 2 \\
\hline
\end{tabular}


Field trips (College Campus visit) *

College fair*

$\begin{array}{ccc}\text { Principal } & \text { Private } & \text { Suburba } \\ \text { Ben } & & \mathrm{n}\end{array}$

Monthly Academic and Career-Related

Discussion Sessions

College application advising*

Career fair

Traditional culture day*

English-focused events*

Creative experience activities

Field trips*

\section{BC principal \\ group}

Principal

Private

Urban

Fon

Principal Private Urban
Phan

Monthly Academic and Career-Related

$>5$

Discussion Sessions

Career-related course

Dermatoglyphics-based career orientation*

Blood type- based career orientation

Horoscope*

Seminars led by counseling professionals

and experts*

Interventions designed by professional

guidance and counseling staff*

School-based college fair*

Field trips*

Living values education, life skills and sexuality education activities*

Seminars led by success persons such as $\quad>7$ celebrities, business men, alumni at many different areas*

Sport clubs (Swimming, soccer, basket ball, volleyball )*

College application advising*

Life skill, living values education activities*

Field trip/Creative experience activities*

School-based college fair*

Interventions organized by professional

guidance and counseling staff*

Art clubs (piano, guitar, violin, traditional

music instruments)*

English advanced activities* 


\begin{tabular}{|c|c|c|c|}
\hline & $\begin{array}{c}\text { Public } \\
\text { for } \\
\text { Gifted } \\
\text { Studen } \\
\text { ts }\end{array}$ & Urban & $\begin{array}{c}\text { Monthly Academic and Career-Related } \\
\text { Discussion Sessions } \\
\text { Language clubs* } \\
\text { Sport clubs* } \\
\text { Art clubs* } \\
\text { Hand-on experience activities* } \\
\text { Seminars on seven habits of highly } \\
\text { effective people* } \\
\text { Students-led activities (Mentorship, school } \\
\text { website, astronomy-based activities and } \\
\text { others)* } \\
\text { Academic-based events (Math Open day, } \\
\text { Most Wanted Class, Science workshop, } \\
\text { Debate competition, Robotics } \\
\text { Competition)* } \\
\text { Career/college fairs* } \\
\text { College advising sessions* } \\
\text { Extra-curriculum activities (sexuality } \\
\text { education, School's Got Talent, Sport Day, } \\
\text { Volunteer day)* }\end{array}$ \\
\hline $\begin{array}{c}\text { Principal } \\
\text { Hen }\end{array}$ & $\begin{array}{c}\text { Interna } \\
\text { tional } \\
\text { school/ } \\
\text { private }\end{array}$ & Urban & $\begin{array}{c}\text { Career fair } \\
\text { Field trips (Organizations, business, } \\
\text { museum, etc)* } \\
\text { Seminars led by experts, parents and } \\
\text { alumina* } \\
\text { Interventions designed by professional } \\
\text { guidance and counseling staff* } \\
\text { College application advising sessions* } \\
\text { Academic-based events (Debate contest, } \\
\text { Science day)* } \\
\text { Extra-curriculum activities (Volunteer } \\
\text { Day; Life Skills Education)* }\end{array}$ \\
\hline
\end{tabular}

Note: *: No outlined or required by MOET 
APPENDIX E: TYPES OF ACGC ACTIVITIES, IMPLEMENTATION STRATEGIES,

\section{\& IMPLICATIONS FOR PRACTICE}

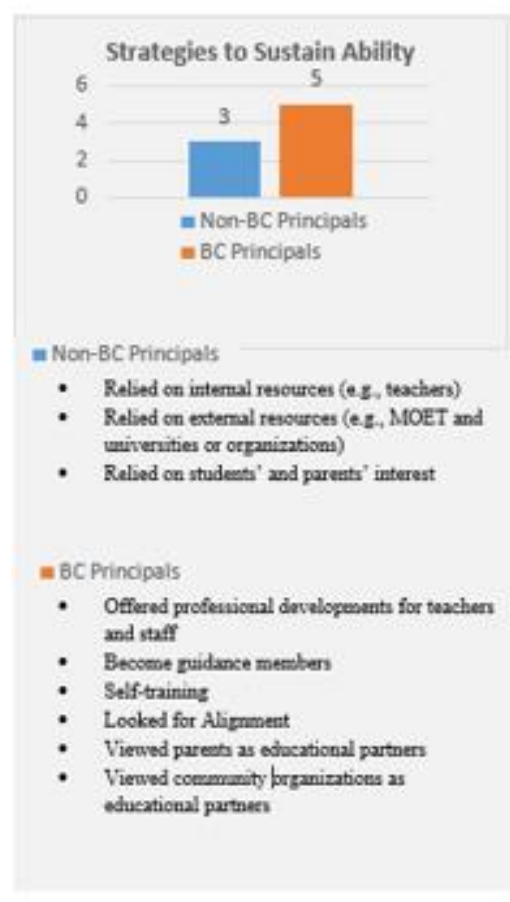

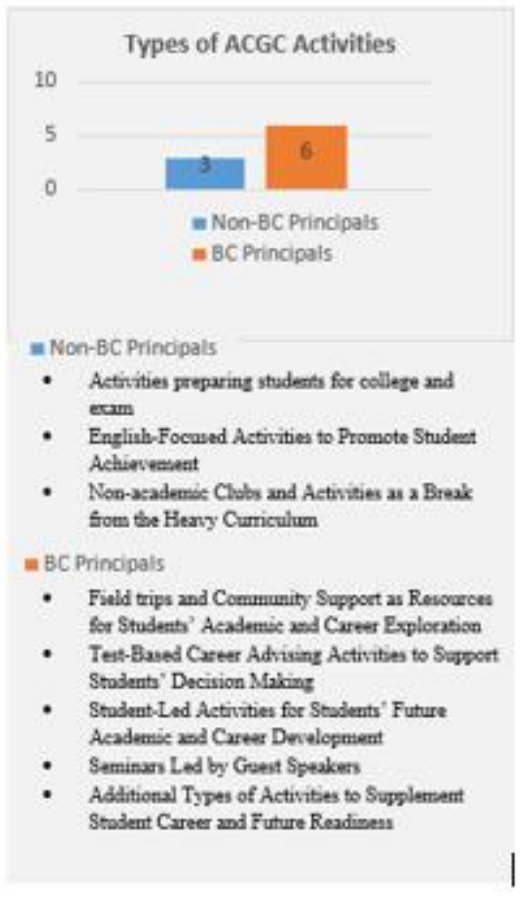

BC Principals' School Types

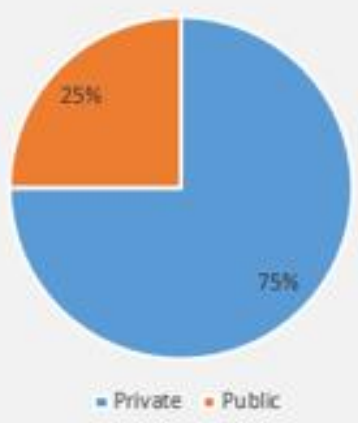

\section{Implications for Practice}

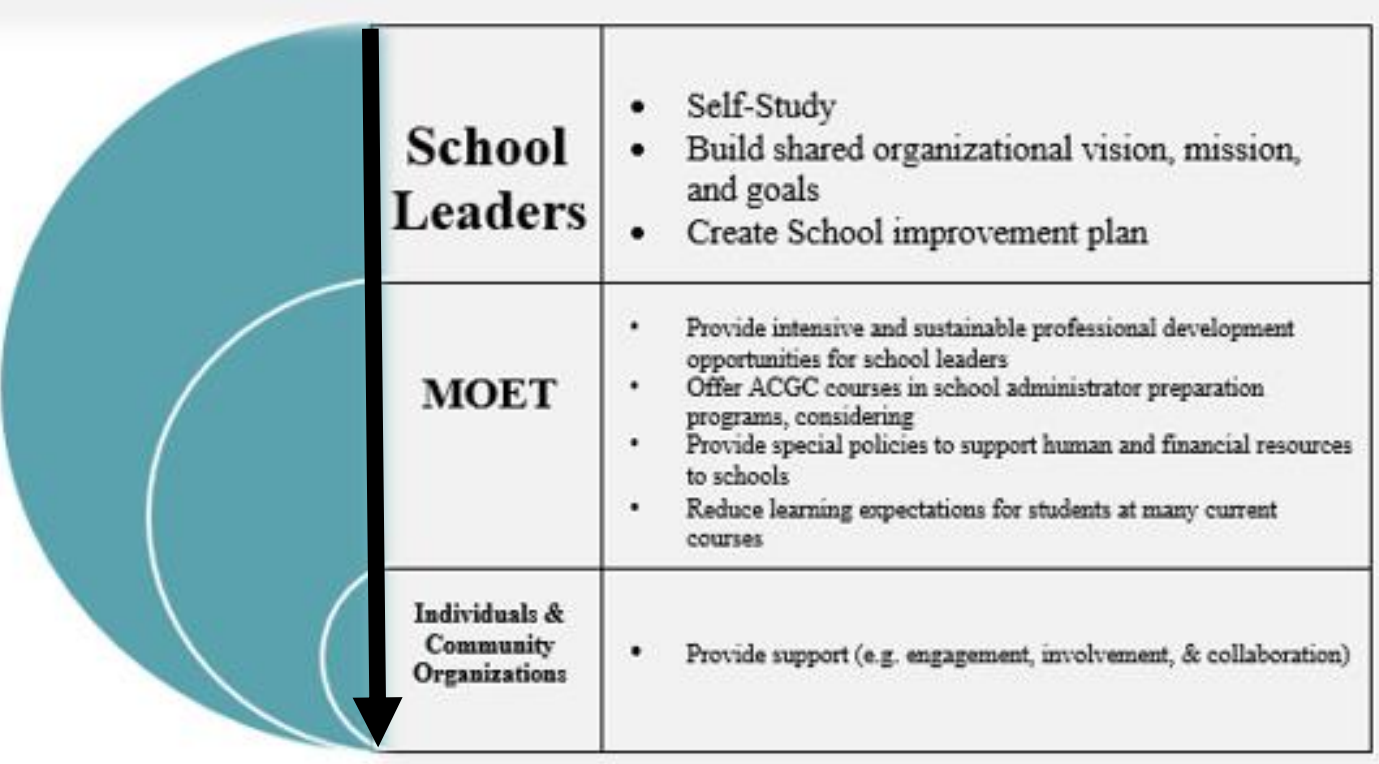




\section{APPENDIX F: CONSENT FORM}

Van Nguyen

PhD Candidate

Department of Educational Leadership and Policy Analysis

University of Missouri, Columbia

Email: vknrk6@mail.missouri.edu

Phone: (will provide a local number)

RESEARCH STUDY PARTICIPANT INVITATION LETTER

Research title: Educational Leaders as Border Crossers: Vietnam and Academic and Career Guidance and Counseling Activities

Dear

I would like to invite you to participate in a research study. The purpose of this research is to explore Vietnamese high school principals' administrative experiences, particularly in organizing and implementing existing career-related activities. The study also seeks to understand challenges and opportunities in implementing other related activities in order to provide students with necessary knowledge and skills for their academic and career development.

Your participation in this study consists two semi-structured interviews and a thirtyminute scenarios. Each interview will take between sixty minutes to an hour and a half at your school and will be recorded and transcribed for the purpose of data analysis. Your participation in this research study is voluntary. You may choose not to participate and you may withdraw your consent to participate at any time. You will not be penalized in any way should you decide not to participate or to withdraw from this study. 
Participation in this study may provide a deeper insight into the significance of activities which provide students with necessary knowledge and skills in order to make better career and academic preparation for their transition from high school to post-secondary levels or other routes. Moreover, the study's implications will be useful once your school are interested in start designing and implementing more activities for students' academic and career development.

There are minimal risks associated with this research. I will do everything to protect your privacy. All personal information, including names, educational background, and school names, and career guidance related documents issued by your schools will be kept pseudonyms and confidential as well as will not be revealed in any publication or presentations.

If you have any questions or concerns about this study or if any problems arise, please contact:

Van Nguyen, the researcher

$\mathrm{PhD}$ Candidate

Department of Educational Leadership and Policy Analysis University of Missouri, Columbia

vknrk6@mail.missouri.edu

(provided a local number)

or

Emily Crawford-Rossi, $\mathrm{PhD}$, the researcher's advisor

303 Hill Hall

Department of Educational Leadership and Policy Analysis 
University of Missouri, Columbia

(573) 884-9554

crawforder@missouri.edu

I have read this consent form and have been given the opportunity to ask questions. I give my consent to participate in this study.

A copy of this consent form should be given to you. 


\section{REFERENCES}

American School Counselor Association. (2003). The ASCA national model: A framework for school counseling programs. Alexandria, VA: Author.

American School Counselor Association. (2004). Ethical standards for school counselors. Alexandria, VA: Author. Retrieved from http://www.school counselor.org/

American School Counselor Association. (2016)). The role of the school counselor. Retrieved from http://www.schoolcounselor.org/asca/media/asca/home/rolestatement.pdf

Anzaldúa, G. (2007). Borderlands la frontera: The new mestiza (3rd ed.). San Francisco, CA: Aunt Lute Books.

Bain., C. (2015). Educational System of Vietnam. Retrieved from http://www.nafsa.org/Professional_Resources/Browse_by_Interest/International_ Students_and_Scholars/Network_Resources/International_Enrollment_Managem ent/Educational_System_of_Vietnam/

Baker, S. B. (2001). Reflections on forty years in the school counseling profession: Is the glass half full or half empty. Professional School Counseling, 5, 75-83.

Blase, J., \& Blase, J. (2000). Effective instructional leadership: Teachers' perspectives on how principals promote teaching and learning in schools. Journal of Educational Administration, 38(2), 130-141.

Bodewig, C., Badiani-Magnusson, R., Macdonald, K., Newhouse, D., Rutkowski. (2014). Skilling up Vietnam: preparing the workforce for a modern market economy. Directions in development; human development. Washington, DC; World Bank Group. Retrieved from: 
http://documents.worldbank.org/curated/en/283651468321297015/Skilling-upVietnam-preparing-the-workforce-for-a-modern-market-economy Borders, L. D., \& Drury, S. M. (1992). Comprehensive school counseling. Counseling \& Development, 70, 487-498.

Botha, R. J. (2004). Excellence in leadership: demands on the professional school principal. South African Journal of Education, 24(3), 239-243.

Charmaz, K. (1990). 'Discovering'chronic illness: Using grounded theory.Social science \& medicine, 30(11), 1161-1172.

Cobia, D. C., \& Henderson, D. A. (2003). Handbook of school counseling. Prentice Hall.

Cooper, C. W. (2009). Performing cultural work in demographically changing schools: Implications for expanding transformative leadership frameworks. Educational Administration Quarterly, 45(5), 694-724.

Cooper, C. W., Riehl, C. J., \& Hasan, L. (2010). Leading and learning with diverse families in schools: Critical epistemology amid communities of practice. Journal of School Leadership, 20(6), 760-790.

Corbin, J., \& Strauss, A. (1990). Basics of qualitative research: Grounded theory procedures and techniques. Basics of qualitative research: Grounded Theory procedures and techniques, 41 .

Creswell, J. W. (2013). Qualitative inquiry and research design: Choosing among five approaches. Sage.

Darling-Hammond, L., Wei, R., Andree, A., Richardson, N., \& Orphanos, S. (2009). Professional learning in the learning profession: A status report on teacher 
development in the United States and abroad. Dallas, TX: National Staff Development Council.

De la Luz Reyes, M., \& Garza, E. (2005). Teachers on the border: In their own words. Journal of Latinos and Education, 4(3), 153-170.

Delors J. et al. (1996). Learning: The Treasure Within, Report to UNESCO of the International Commission on Education for the Twenty-First Century. Paris: UNESCO Publishing.

Do, T. L. H. (2009). The status of Career Orientation consultation in Vietnam. The magazine of Psychology, No.5 (122), 5. Retrieved from http://lrc.tnu.edu.vn/upload/collection/brief/28439_21520121428295817209691p b.pdf

Doan, D. H. (2005) Moral education or political education in the Vietnamese educational system, Journal (3), 451-463.

Douglas, T. M. O. (2013). Confessions of a border crossing brotha-scholar: Teaching race with all of me. In D. J. Davis \& P. Boyer (Eds.), Social justice and racism in the college classroom: Perspectives from different voices (pp. 55-67). Bingley: Emerald Publishing Group Ltd.

Douglas, T. M. O., \& Peck, C. M. (2013). Education by any means necessary: An historical exploration of community-based pedagogical spaces for peoples of African descent. Educational Studies, 49(1), 67-91.

Douglas, T.M.O. (2013). Confessions of a border crossing brotha-scholar: Teaching race with all of me. In Davis, D. J., \& Boyer, P. G. (Eds.), Social Justice Issues and 
Racism in the College Classroom: Perspectives from Different Voices (pp.57-72). Bingley, U.K.: Emerald Group Publishing.

Dykeman, C., Wood, C., Ingram, M., Gitelman, A., Mandsager, N., Chen, M., \& Herr, E. (2003). Career development interventions and academic self-efficacy and motivation: A pilot study. Columbus, $\mathrm{OH}$ : National Dissemination for Career and Technical Education.

Fink, E., \& Resnick, L. B. (2001). Developing principals as instructional leaders. Phi Delta Kappan, 82(8), 598-610.

Frome, P. (2001, April). High Schools That Work: Findings from the 1996 and 1998 Assessments. Research Triangle Park, NC: Research Triangle Institute.

Gallant, D. J., \& Zhao, J. (2011). High School Students' Perceptions of School Counseling Services Awareness, Use, and Satisfaction. Counseling Outcome Research and Evaluation, 2(1), 87-100.

Garza, E. (2007). Becoming a border pedagogy educator: Rooting practice in paradox. Multicultural Education, 15(1), 2-7.

Giroux, H. A. (2005). Border crossings (2nd ed.). New York, NY: Routledge Taylor \& Francis Group.

Goldstein, T. (2016). Border Crossing in the Classroom through Performed Ethnography. Penn GSE Perspectives on Urban Education, 13(1), 4-19.

Greenwald, R., Hedges, L. V., \& Laine, R. D. (1996). The effect of school resources on student achievement. Review of Educational Research, 66(3), 361-396. 
GSO (2011). Area, population, and population density in 2011 by locality. Retrieved in August, 20, 2017 from

http://www.gso.gov.vn/default.aspx?tabid=387\&idmid=3\&ItemID=12875

Gurr, D., Drysdale, L., \& Mulford, B. (2006). Models of successful principal leadership. School leadership and management, 26(4), 371-395.

Hallinger, P. (2010). Making education reform happen: is there an 'Asian'way?. School Leadership and Management, 30(5), 401-418.

Hallinger, P. (2011). Leadership for learning: Lessons from 40 years of empirical research. Journal of educational administration, 49(2), 125-142.

Hallinger, P., \& Heck, R. H. (1998). Exploring the principal's contribution to school effectiveness: 1980-1995. School Effectiveness and School Improvement, 9(2), $157-191$

Hallinger, P., \& Heck, R. (2002). What do you call people with visions? The role of vision, mission, and goals in school leadership and improvement. In K. Leithwood \& P. Hallinger (Eds.), Second international handbook of educational leadership and administration (pp. 9-40). Dordrecht, NL: Kluwer.

Hallinger, P., \& Truong, D. T. (2014). Exploring the contours of context and leadership effectiveness in Vietnam. Leading and Managing, 20(2), 43.

Hallinger, P., Hallinger, P., Walker, A., Walker, A., Nguyen, D. T. H., Nguyen, D. T. H., ... \& Nguyen, T. T. (2017). Perspectives on principal instructional leadership in Vietnam: a preliminary model. Journal of Educational Administration, 55(2), 222-239. 
Hanoi People's Committee. (2013). Decision No.20/2013/QĐ-UBND. Retrieved from: https://thuvienphapluat.vn/van-ban/Giao-duc/Quyet-dinh-20-2013-QD-UBNDco-so-vat-chat-giao-vien-chuong-trinh-mam-non-Ha-Noi-204730.aspx

Heck, R. H. (1992). Principals' instructional leadership and school performance: Implications for policy development. Educational evaluation and policy analysis, 14(1), 21-34.

Ho, M. P. T., \& Berg, D. (2010). Educational leadership challenges: Vietnam's system of higher education. Asia Leadership Roundtable 2010.

HoChiMinh, Department of Education and Traning (2014). Guidance for implementing career orientation activities, career education and extra-activities in the general secondary school in 2014-2015. Retrieved from: http://hcm.edu.vn/huong-nghiepday-nghe-pt/van-ban-chi-dao-ve-giao-duc-huong-nghiep-c41395-53472.aspx

Hoover-Dempsey, K. V., Bassler, O. C., \& Brissie, J. S. (1992). Explorations in parentschool relations. The Journal of Educational Research, 85(5), 287-294.

Houtenville, A. J., \& Conway, K. S. (2008). Parental effort, school resources, and student achievement. Journal of Human Resources, 43(2), 437-453.

Hughes, K. L., \& Karp, M. M. (2004). School-based career development: A synthesis of the literature. New York, NY: Columbia University-Institute on Education and the Economy Teachers College.

Izzo, C. V., Weissberg, R. P., Kasprow, W. J., \& Fendrich, M. (1999). A longitudinal assessment of teacher perceptions of parent involvement in children's education and school performance. American Journal of Community Psychology, 27(6), 817-839. 
Kano, M., \& Bourque, L. B. (2008). Correlates of school disaster preparedness: main effects of funding and coordinator role. Natural Hazards Review, 9(1), 49-59.

Kaufman, P., Bradby, D., \& Teitelbaum, P. (2000). High schools that work and whole school reform: Raising academic achievement of vocational completers through the reform of school practice. National Center for Research in Vocational Education, Graduate School of Education, University of California at Berkeley.

Kaufman, P., Bradby, D., \& Teitelbaum, P. (2000, February). High schools that work and whole school reform: Raising academic achievement of vocational completers through the reform of school practice. Berkeley, CA: National Center for Research in Vocational Education.

Lapan, R. T., Gysbers, N. C., \& Sun, Y. (1997). The impact of more fully implemented guidance programs on the school experiences of high school students: A statewide evaluation study. Journal of Counseling \& Development, 75(4), 292-302.

Lapan, R.T., Gysbers, N.C., Hughey, K., \& Arni, T.J. (1993). Evaluating a guidance and language arts unit for high school juniors. Journal of Counseling \& Development, 71(4).

Le., V. (2017). Những con số "biết nói" về giáo dục đại học Việt Nam. Retrieved August 11, 2017 from http://vietnamnet.vn/vn/giao-duc/tuyen-sinh/nhung-con-so-bietnoi-ve-giao-duc-dai-hoc-viet-nam-389870.html

Lehman, C. M., Clark, H. B., Bullis, M., Rinkin, J., \& Castellanos, L. A. (2002). Transition from school to adult life: Empowering youth through community ownership and accountability. Journal of Child and Family Studies, 11(1), 127141. 
Leuwerke, W., Walker, J., \& Shi, Q. (2009). Informing principals: The impact of different types of information on principals' perceptions of professional school counselors. Professional School Counseling, 12(4), 263-271.

Levesque et al., (2008). Statistical Analysis Report. U. S Department of Education. National Center for Education Statistics

Lockhart, T. (2006). Writing the self: Gloria Anzaldúa, textual form, and feminist epistemology. Michigan Feminist Studies, 20, 19-36

Merriam, S. B. (2009). Qualitative research: A guide to design and implementation. San Francisco, CA: Jossey-Bass.

MOET. (1981). Circular No. 31-TT on career orientation guidance for high schools. Retrieved from https://thuvienphapluat.vn/van-ban/Giao-duc/Thong-tu-31-TTcong-tac-huong-nghiep-trong-nha-truong-pho-thong-su-dung-hop-ly-hoc-sinhpho-thong-tot-nghiep-huong-dan-Quyet-dinh-Hoi-dong-Chinh-phu-43891.aspx

MOET. (2003). Directive No. 33 on Career Orientation education for secondary students. Retrieved on July 23th 2003 from https://thuvienphapluat.vn/van-ban/Giaoduc/Chi-thi-33-2003-CT-BGDDT-tang-cuong-giao-duc-huong-nghiep-hoc-sinhpho-thong-54587.aspx

MOET. (2006). Decision No. 12 on Admissions Regulation in the Secondary Education Level. Retrieved from https://thuvienphapluat.vn/van-ban/Giao-duc/Quyetdinh12-2006-QD-BGDDT-quy-che-tuyen-sinh-trung-hoc-co-so-pho-thong11026.aspx

MOET. (2007). Directive No. 8608 on career guidance for $11^{\text {th }}$ graders in 2007-08. Retrieved from https://thuvienphapluat.vn/cong-van/Giao-duc/Cong-van-8608- 
BGDDT-GDTrH-thuc-hien-hoat-dong-giao-duc-Nghe-pho-thong-lop-11-

143875.aspx

MOET (2011a). Vietnam Education Statistic from the school year 1999-2000 to 2010-

2011. Retrieved August 9, 2017, from

http://pbc.moet.gov.vn/?page=11.11\&view=3544

MOET (2011b). Circular 12/2011/TT-BGDDT. Retrieved from

http://vanban.chinhphu.vn/portal/page/portal/chinhphu/hethongvanban?class_id=

1\&_page=1\&mode=detail\&document_id=99977

MOET (2014). No. 3119. Guidance on career orientation education for secondary

students. Retrieved from https://luatvietnam.vn/giao-duc/cong-van-3119-bgddt-

gdcn-bo-giao-duc-va-dao-tao-87552-d6.html\#noidung

MOET (2018a). Press Conference on the New Curriculum for the General Education.

Retrieved from: hHttps://moet.gov.vn/tintuc/Pages/tin-tong-

hop.aspx?ItemID=5756

MOET (2018b). Circular No.32/2018/TT-BGDDT. Retrieved from

https://data.moet.gov.vn/index.php/s/xvD7X3JpdxSF855\#pdfviewer

National Center for Education Statistics (NCES) (2001). The Condition of Education

2001. Washington, DC: U.S. Department of Education.

Nguyen, C. (2010) The role of principal as school leader and manager, Journal of Education Science, 58, pp. 6-8.

Nguyen, T.H. \& Wu, B. (2012) Much ado about many things: Principle function analysis and evaluation of principals' instructional leadership in Vietnam, International Journal of Innovative Management, Information and Production, 3(2), pp. 61-73 
Nguyen, T., T., H. (2011). Status of vocational consultancy for students in some secondary high schools in Ho Chi Minh City. The science Magazine, Ho Chi Minh City Pedagogy University, Vietnam. Retrieved from: http://www.vjol.info/index.php/sphcm/article/viewFile/14790/13287

Noguera, P. A., \& Wing, J. Y. (2006). Unfinished Business: Closing the Racial Achievement Gap in Our Schools. Education Review//Reseñas Educativas.

OCTAE (2017). College and Career Guidance and Counseling. Retrieved on August 10, 2017 from https://www2.ed.gov/about/offices/list/ovae/pi/cte/guidcoun2.html

O'Hara, M. (2000). The effects of a two-semester career exploration intervention class on the career development inventory scores of high school seniors. Retrieved from: http://icdl.uncg.edu/ft/080101-02.html

Oliver, L.W. \& Spokane, A.R. (1988). Career intervention outcomes: What contributes to client gain? Journal of Counseling Psychology, 35(4).

Paisley, P. O., \& Borders, L. D. (1995). School counseling: An evolving specialty. Journal of Counseling and Development: JCD, 74(2), 150.

Parsad, B., Alexander, D. , Farris, E., \& Hudson, L. (2003). High school guidance counseling. (NCES 2003-015). Washington, D.C.: U.S. Department of Education, National Center for Education Statistics.

People's Committee of Ho Chi Minh City (2014). Decision No. 3036/QD-UBND on Criteria for Good Performing Schools. Retrieved from https://thuvienphapluat.vn/van-ban/Giao-duc/Quyet-dinh-3036-QD-UBND-2014tieu-chi-Truong-tien-tien-xu-the-hoi-nhap-khu-vuc-quoc-te-Ho-Chi-Minh238213.aspx 
Perry, C. (1998). Processes of a case study methodology for postgraduate research in marketing. European Journal of Marketing, 32(9/10), 785-802.

Philip Hallinger, (1998) "Educational change in Southeast Asia: The challenge of creating learning systems", Journal of Educational Administration, 36 (5), 492-509,

Pope, M. (2000). A Brief History of Career Counseling in the United States. The Career Development Quarterly, 48(3), 194-211.

Reardon, R. C., \& Lenz, J. G. (1999). Holland's theory and career assessment. Journal of Vocational Behavior, 55(1), 102-113.

Ruiz-Quintanilla, A. (1990). Major work meaning patterns toward a wholistic picture. In Work motivation. Lawrence Erlbaum Associates, Incorporated. Kieinbeck, H. Quast, H. Thiery, a H. Hacker (Eds.), Work motivation (pp. 257-272).

Schenck, A. D. (2015). Improving Education in Confucian Countries through Analysis of Organizational Challenges, Leadership, and Responsibilities. Journal of International Education and Leadership, 5(1), n1.

Sebastian, J., \& Allensworth, E. (2012). The influence of principal leadership on classroom instruction and student learning: A study of mediated pathways to learning. Educational Administration Quarterly, 48(4), 626-663.

Sink, C. A., \& Stroh, H. R. (2003). Raising achievement test scores of early elementary school students through comprehensive school counseling programs. Professional School Counseling, 6(5), 350-364.

Stake, R. E. (1995). The art of case study research. Thousand Oaks, CA: Sage.

Supovitz, J. A., \& Turner, H. M. (2000). The effects of professional development on science teaching practices and classroom culture. Journal of Research in Science 
Teaching: The Official Journal of the National Association for Research in Science Teaching, 37(9), 963-980.

The Central Committee and the Politburo (1981). No. 126 Decision on career orientation in the high school level. Retrieved from https://thuvienphapluat.vn/van-ban/Laodong-Tien-luong/Quyet-dinh-126-CP-cong-tac-huong-nghiep-trong-truong-phothong-su-dung-hoc-sinh-pho-thong-co-so-pho-thong-trung-hoc-tot-nghiep43052.aspx

The Ministry of Labour, Invalids and Social Affairs (MOLISA). (2017). Chuyển Giao quản lý giáo dục nghề nghiệp từ Bộ GD-ĐT sang Bộ LĐ-TBXH. Retrieved August 10, 2017 from http://www.molisa.gov.vn/vi/Pages/chitiettin.aspx?IDNews=26075

Tran, T. P. H. (2009). Franco-Vietnamese schools and the transition from Confucian to a new kind of intellectuals in the colonial context of Tonkin. Harvard Yen-Ching Institute Working Paper.

Tran, T. T. H. (2014). Education financing in Vietnam. Revue internationale d'éducation de Sèvres. Retrieved from https://journals.openedition.org/ries/3895

Truong, D. T. (2013). Confucian values and school leadership in Vietnam. Ph.D thesis, Victoria University of Wellington. Retrieved from http://researcharchive.vuw.ac.nz/xmlui/bitstream/ ...

Tuoi tre (2016). College dropouts due to academic mismatch. Retrieved from $4^{\text {th }}$ May 2016 from http://tuoitre.vn/tin/giao-duc/20160504/sinh-vien-bo-hoc-do-chon-sainganh/1094884.html 
Van Roekel, N. P. D. (2008). Parent, family, community involvement in education. Policy Brief. Washington, DC: National education Association.

Vescio, V., Ross, D., \& Adams, A. (2008). A review of research on the impact of professional learning communities on teaching practice and student learning. Teaching and Teacher Education, 24(1), 80-91.

Vietnam National University. (2015). Decision No.4245 /QĐ-ÐHQGHN. Retrieved from https://education.vnu.edu.vn/index.php/WebControl/viewpage/129

Vietnam National University. (2018). Decision No.155 /QD-DHQGHN. Retrieved from https://education.vnu.edu.vn/index.php/WebControl/viewpage/142

Waintrup, M. G., \& Unruh, D. K. (2008). Career development programming strategies for transitioning incarcerated adolescents to the world of work. Journal of Correctional Education, 127-144.

Whiston, S.C., Sexton, T.L., \& Lasoff, D.L. (1998). Career-intervention outcome: A replication and extension of Oliver and Spokane (1988). Journal of Counseling Psychology, 45(2).

Whitaker, B. (1997). Instructional leadership and principal visibility. The Clearing House: A Journal of Educational Strategies, Issues and Ideas, 70(3), 155-156.

Wilson, C. M., Ek, L. D., \& Douglas, T. R. M. (2014). Recasting border crossing politics and pedagogies to combat educational inequity: Experiences, identities, and perceptions of Latino/a immigrant youth. The Urban Review, 46(1), 1-24.

Wilson, C. M., Ek, L. D., \& Douglas, T. R. M. (2014). Recasting border crossing politics and pedagogies to combat educational inequity: Experiences, identities, and perceptions of Latino/a immigrant youth. The Urban Review, 46(1), 1-24. 
World Bank (2017). Unemployment, youth total. Retrieved from http://data.worldbank.org/indicator/SL.UEM.1524.ZS?end=2016\&locations=VN $\&$ start $=1991$

Yin, R. K. (2013). Case study research: Designs and methods. Thousand Oaks, CA: Sage.

Yudof, M. G. (1980). Implementation theories and desegregation realities. Ala. L. Rev., 32, 441.

Zalaquett, C. P. (2005). Principals' perceptions of elementary school counselors' role and functions. Professional School Counseling, 451-457. 


\section{VITA}

Van Nguyen was born and grew up in Hanoi, Vietnam, on April 11, 1986 in an extended family which has a strong tradition of working in the educational field. After she earned a B.A. degree in Teaching English as Second Language from Vietnam National University in 2008, Van taught English to young children and freelanced as a career and academic advisor for high school students in Vietnam.

In 2011, Van moved to the U.S for her M.A. program in Learning and Instruction at the Department of Educational Leadership and Policy Analysis, College of Education, at the University of Missouri. The program provided her opportunities to gain the basic foundations of knowledge of Pre-K-12 administration and to begin to recognize certain issues within the Vietnamese education system and their causes. In order to have an opportunity to further her research and study of education, Van pursued a Ph.D. in Pre-K-12 administration and policy at the same institution beginning in 2013. Her dissertation focused on Vietnamese school principles' perceptions and actions as they pertain to preparing students for their future academic and career paths.

During her Ph.D. journey, she worked in different positions as a graduate assistant, project director, and project coordinator for some projects at the University of Missouri. Additionally, Van is interested in making a contribution to the increase in the reading culture for Vietnamese children. Thus, in 2017, Van launched a non-profit book project, named Grand Dad's Bookshelf, in order to provide Vietnamese children with opportunities to read invaluable books they have no or limited access to by sending thousands of donated books from her U.S friends to Ha Noi, Vietnam for an open-access library that she hopes to open in the near future. Moreover, as the founder and developer 
of this project and as the first female in her extended family to receive a Ph.D. degree, Van wants to send a message to encourage people who are suffering from poverty and women and children are suffering from discrimination and violence both in her home country and in the U.S to explore and pursue their dreams and lifelong learning. 